\title{
The behaviour of Bolders Bank glacial till under undrained cyclic loading
}

Accepted for publication in Geotechnique 7/5/2020

E. Ushev

Arup, formerly Department of Civil and Environmental Engineering, Imperial College London, SW7 2BU

R. J. Jardine

Department of Civil and Environmental Engineering, Imperial College London, SW7 2BU

\section{Abstract}

Analysis of foundation behaviour under repeated loading can be important to the design of offshore facilities, towers, bridges, wind-turbines and other structures. While detailed guidance is available on how some geomaterials behave under cycling, few such studies have been reported on the glacial formations that are widespread across parts of northern Europe and under the North and Baltic Seas. This paper presents a cyclic laboratory investigation involving block samples of Bolders bank till, which is one of the most extensive North Sea glacial formations. Static and cyclic triaxial tests are reported on nominally identical, low plasticity, high OCR, specimens from Cowden, near Hull in the UK. Twentythree cyclic tests are reported on specimens that were re-consolidated to $\mathrm{K}_{0}$ stresses before experiencing up to 3500 undrained cycles involving a range of mean and cyclic shear stress combinations. The impacts of cycling on effective stress paths and strain development, cyclic stiffness and damping ratios are reported and interpreted with respect to parallel index, oedometer and monotonic triaxial compression and extension tests. Stable, metastable and unstable patterns of behaviour are identified, along with different cyclic failure modes. The styles of cyclic response are related to the till's static yielding behaviour. While the till can only manifest quasi-elastic behaviour within a very small $\left(Y_{1}\right)$ Kinematic Yield Surface $(K Y S)$, a larger second $\left(Y_{2}\right) K Y S$ is identified within which repeated loading leads to a non-linear yet stable response, with negligible mean effective stress drifts or stiffness degradation with low and stabilising strain accumulation rates. Cyclic paths that engage and relocate the $Y_{2}$ surface lead to greater permanent strains, mean effective stress drifts and stiffness decays that become progressively more marked as the magnitudes of the cyclic stress perturbation and the number of cycles increase. While cycling under stable or metastable conditions increased the ultimate undrained strength of specimens that did not develop excessive strains, most cyclic paths that exceeded and climbed the till's Hvorslev surface were unstable and eventually failed. The experiments identified the key factors that affect the till's response to repeated loading and provide a basis for developing, testing and calibrating cyclic constitutive models and establishing simplified design procedures for comparable tills.

Key words: Glacial-till; cyclic loading; stress-path laboratory tests. 


\section{Introduction}

Assessing how foundations respond to cyclic loading can be important in foundation design, especially with offshore structures; see for example Andersen (2009) or Jardine et al. (2012). Stress-path laboratory tests on site-specific, or regionally typical, soil types offer an element-level approach for studying how regular cycling influences soil behaviour. The soil response is tracked as cycling progresses in terms of permanent strain development, cyclic stiffness and damping ratio changes and, if undrained, mean effective stress or pore pressure drifts; the number of cycles at which any cyclic failure develops is also a key outcome. Multiple testing programmes involving wide ranges of cyclic conditions have been reported for sands (see for example Wichtmann et al. (2005)) and low-tomedium OCR clay sediments; see for example Andersen (2015).

Offshore Gravity Based Structure (GBS) designers routinely employ such testing to assess directly how severe storms may affect safety and performance. While the designers of offshore piled foundations often neglect the effects of axial load cycling, Aghakouchak et al. (2015), Aghakouchak (2015) and Jardine (2020) applied cyclic triaxial and hollow cylinder apparatus (HCA) tests directly to assess its impact on piles driven in sands, matching successfully the cyclic field tests described by Jardine and Standing (2012) and model tests reported by Tsuha et al. (2012). Jardine (2020) also reports several offshore projects where design has been guided by site-specific cyclic simple shear testing and cyclic tests on piles driven at representative sites.

Load cycling often has its most critical impact under undrained conditions and interpretive constitutive frameworks of varying complexity have been developed to simulate the responses observed in undrained cyclic laboratory tests. Simple non-linear cyclic models can capture shear modulus degradation and hysteresis by defining a backbone curve to determine the monotonic stress-strain response, combined with sets of unloading and reloading rules, see: Ramberg \& Osgood (1943), Pyke (1979), Puzrin and Shiran (2000) or Taborda and Zdravkovic (2012). These models' predictive capabilities are limited by the implicit decoupling of the stress-strain response from the generation of excess pore water pressures, or changes in mean effective stress. More advanced effective stressbased elastic-plastic constitutive laws can simulate more completely the cyclic responses of clays. One class of models, originating from Dafalias (1986), considers anisotropic extensions of the Modified Cam Clay model. Dafalias et al's (2006) SANICLAY framework accounts for the softening responses seen in soft clays and the de-structuration under loading of natural sensitive clays. Seidalinov and Taiebat (2014) proposed a versatile modification of the framework that accounts for de-structuration due to cyclic loading in low OCR clays. Kinematic hardening constitutive models that apply bounding surface plasticity frameworks through extensions of Modified Cam Clay include those proposed by 
Rouania and Muir Wood (2000), Kavvadas and Amorosi (2000), Baudet and Stallebrass (2004) and Grammatikopoulou et al (2006).

While the above experimental and theoretical developments focus principally on characterising and modelling the generally contractive cyclic responses seen in experiments on low-to-medium OCR, potentially sensitive or structured, clays, far less emphasis has been given to investigating and modelling stiff, insensitive, high OCR clays. This paper presents an experimental investigation into the undrained cyclic behaviour of low plasticity, high OCR, Bolders bank glacial till. The formation is widespread under the North Sea; Davies et al. (2011) and similar deposits are encountered frequently in engineering projects located across northern Europe, as well offshore in the North and Baltic Seas. The experiments provide a new benchmark for the development and calibration of cyclic design frameworks and constitutive models for application in such strata.

The samples were taken from Cowden, on the Holderness peninsula near Hull in NE England where static and cyclic piling research has been conducted since the 1970s; see Ove Arup \& Partners Ltd (1986), Lehane and Jardine (1994), and Karlsrud et al. (2014). Cowden was also one of the two test sites selected for the recent PISA monopile wind-turbine research project described by Byrne et al. (2017), which included cyclic lateral loading tests on tubular steel piles with outside diameters up to two metres.

\section{Site conditions and till response to monotonic loading}

Powell and Butcher (2003) and Zdravkovic et al. (2020) outline the key geotechnical aspects of the $40 \mathrm{~m}$ thick, stiff and lean, Bolders Bank clay till present at Cowden, which overlies chalk and include isolated sand layers. The till's deposition is likely to have involved both drained and undrained cyclic pre-shearing stages which may have contributed to its relatively high in-situ undisturbed undrained shear strengths and low liquidity indices. More detailed descriptions of the till's properties are given by Ushev (2018) and Liu (2018), who emphasise the important impact of its coarse sand, gravel and cobble fractions and also characterised the till's anisotropic monotonic stiffness and shear strength characteristics. Ushev's tests on Geobor-S rotary samples taken to $12 \mathrm{~m}$ depth led to the profiles given in Figure 1 of natural water contents, liquid and plastic limits while his anisotropically consolidated undrained (CAU) triaxial tests gave the undisturbed undrained shear strengths from stress-path tests, which were run from in-situ $K_{0}$ stresses at an axial strain rate of $5 \% /$ day.

The cyclic study presented in this paper tested specimens trimmed from high-quality cubical (350 $\mathrm{x}$ $350 \times 350 \mathrm{~mm}$ ) block samples taken at $3.00-3.50 \mathrm{~m}$ depth in a closely supported excavation near to the Geobor-S boreholes. At this depth the till consists of approximately $30 \%$ clay, $40 \%$ silt, $20 \%$ sand and 
$10 \%$ gravel. A high pressure oedometer experiment on reconstituted till and monotonic undrained triaxial tests on $\mathrm{K}_{0}$ reconsolidated natural specimens from the same depth range led to the key outcomes in Figure 2a), which identifies parallel $\mathrm{K}_{0}$ Normal Compression and Critical State lines for the till at this depth. A typical unload-reload trace is also reported. Ushev's (2018) analysis of the oedometer and triaxial shear strength data identified Yield Stress Ratio (YSR), or apparent OCR, range of 10 to 14 within the cyclic test samples' depth range.

Considering the mean cyclic test specimen depth of $3.40 \mathrm{~m}$, the in-situ stresses were estimated as $\sigma_{\checkmark}^{\prime}$ $=50 \mathrm{kPa}, \sigma_{h}^{\prime}=75 \mathrm{kPa}$, with $\mathrm{K}_{0}=1.5$. Figure $2 \mathrm{~b}$ ) shows the undrained effective stress paths, where $q=$ $\left(\sigma_{v}^{\prime}-\sigma_{h}^{\prime}\right)$ and $p^{\prime}=\left[\sigma_{v}^{\prime}+2 \sigma_{h}^{\prime}\right] / 3$, manifested in triaxial compression and the extension tests conducted from in-situ conditions on samples from 2.5 to $4.0 \mathrm{~m}$ depth. Under constant volume, undrained, conditions the radial strains $\varepsilon_{\mathrm{r}}=-\varepsilon_{\mathrm{a}} / 2$ and $\varepsilon_{\mathrm{a}}=\varepsilon_{\mathrm{s}}$, the shear strain invariant. The deviator stress (q) against absolute axial strain $|\varepsilon|$ curves are shown in Figure $3 a$ ) while the small-strain initial response is presented at enlarged scale as $|\Delta q|$ againtst $|\varepsilon|$ in Figure $3 b)$. Compression tests on Cowden till reach stable plateaux after experiencing large axial strains, with the specimens failing by bulging and no shear bands forming; their final stress points are interpreted as stable critical states with ultimate $M=q / p^{\prime}=1.0$, as shown in Figure 2. Specimens tested in extension develop localised necking failures after around $6 \%$ strain which lead to apparent peak shear strengths and post-peak softening. However, the global post-peak stress-strain response is not considered representative of the local behaviour applying within the necking region and the lower extension $S_{u}$ values is not representative of the till's true anisotropy, which was investigated separately in HCA tests; see Liu (2018).

The triaxial specimens were equipped with local axial and radial strain sensors, based on the systems proposed by Cuccovillo and Coop (1997) and Ackerley et al (2016), whose very high-resolution allowed the linear stress-strain behaviour manifested in Figure $3 \mathrm{~b}$ ) to be defined accurately in extension and compression along with the limits to the linear $Y_{1}$ Kinematic Yield Surface (KYS) as defined by Jardine (1992). These features cannot be resolved without employing such local strain instruments. At this depth the linear regions extended vertically in q-p' space by around $\pm 2.5 \mathrm{kPa}$ (after $\varepsilon_{\text {axial }}=\varepsilon_{s}$ increments of around $1.10^{-5}$ ) and the mean initial elastic stiffnesses amounted to $202 \pm 36 \mathrm{MPa}$, as established by linear regression analysis of the initial linear test portion. While similar stiffnesses should apply in extension and compression, differences are seen that reflect the test specimens' slightly different sampling depths $(3.40 \mathrm{~m}$ and $3.45 \mathrm{~m})$ and a slight tendency for samples to creep very slowly in extension following the application of $\mathrm{K}_{0}>1$. Small-strain cyclic probing tests reported by Ushev (2018) and Liu (2018) confirm that plastic straining commences once the $Y_{1}$ KYS is reached and that, once engaged, the $Y_{1} K Y S$ is dragged with the current effective stress point. Multiple tests on samples at other depths show that the stiffnesses grow in proportion to in-situ $\left[\mathrm{p}^{\prime}\right]^{0.5}$ and that the KYS vertical 
extent in q-p' stress space grows in proportion to $p^{\prime}$. Figure 3c) shows how the till's secant and tangent stiffness curves vary with strain after engaging the till's $Y_{1}$ KYS in plots where the undrained vertical stiffnesses is normalised by $\left[p^{\prime}\right]^{0.5}$; which brings the respective stiffness curves into narrow bands over the full depth profile; Ushev (2018). Note that the stress strain curves can show changes in slope on reaching $Y_{1}$, which lead to discontinuities in the tangent stiffness curves. Other static and dynamic probing tests by Ushev (2018) and Liu (2018) following the Kuwano and Jardine (2002) procedures demonstrated that the till's stiffness is anisotropic over the full strain range and that behaviour within the $Y_{1}$ KYS under can be expressed for this depth and in-situ stress conditions by the transversely isotropic stiffness and Poisson ratios listed in Table 1. The till has remarkably high elastic bulk stiffness $\left(K^{\prime}\right)$, which far exceeds any elastic parameters that might be interpreted from the swelling portion of the oedometer curve shown in Figure 2a).

Ushev (2018) interreted large-scale ' $Y_{3}$ yield points' (as defined by Jardine 1992) from his compression tests as the points (at $q \approx 100 \mathrm{kPa}$ ) where the effective stress paths rotated from and the initial negative $\mathrm{dp}^{\prime} / \mathrm{dq}$ ratios (that reflect the till's elastic stiffness anisotropy) to follow paths with positive, dilative, $\mathrm{dp}^{\prime} / \mathrm{dq}$ directions. He also interpreted the notional Hvorslev surface shown on Figure $2 \mathrm{~b}$ ) that ran from the final critical state point back to the no-tension cut-off and encompassed the large strain undrained effective stress paths. Uncertainty regarding the ultimate conditions applying locally within the necked regions of the extension tests led to assuming similar critical states and Hvorslev surfaces to those established in compression. The monotonic framework summarised in Figures 2 and 3 is central to interpreting the cyclic tests.

\section{Cyclic testing programme}

The cyclic study presented comprised 23 triaxial experiments on a mix of $38 \mathrm{~mm}$ and $100 \mathrm{~mm}$ diameter specimens, as listed in Table 2. Ushev's (2018) cyclic triaxial tests were performed, under stresscontrol, in Bishop and Wesley (1975) type hydraulic stress path cells. Lubricated top and base sample ends were employed comprising double latex membranes incorporating radial cuts and a thin layer of silicone grease. In addition to high resolution local strain gauges, mid-height pore-pressure probes Hight (1982) were deployed. The specimens were cut from the blocks by a hand-saw, trimmed to cylinders in a soil lathe and saturated after setup by increasing the isotropic cell pressure until $B>$ 0.95. Full surface drainage was employed through filter paper strips placed on the specimen exteriors. Reconsolidation was performed to the in-situ stresses estimated for $3.4 \mathrm{~m}$ depth. The necessary effective stress changes were applied no faster than $1 \mathrm{kPa} / \mathrm{h}$ and the specimens were held under drained conditions at $q=-25 \mathrm{kPa}$ and $p^{\prime}=67 \mathrm{kPa}$ until the axial strain creep rate fell below $0.005 \% /$ day. 
Multiple specimens were cycled directly from these conditions. However, larger numbers were cycled from higher mean q values and these were loaded, undrained, at axial stress rates to achieve the desired (pre-cycling) $\mathrm{q}_{\mathrm{m}}$ values. In most cases $2 \mathrm{kPa} / \mathrm{h}$ rates of axial stress change were employed to impose $q_{m}$, although $5 \mathrm{kPa} / \mathrm{h}$ rate was employed for specimens that were cycled from $q_{m}=200 \mathrm{kPa}$. All the specimens tested with $\mathrm{q}_{\mathrm{m}}>-25 \mathrm{kPa}$ were held under undrained conditions until their axial creep rates became negligible $(<0.005 \% /$ day $)$.

Regular undrained sinusoidal cyclic deviatoric stress cycles were then applied with periods (in most cases) of $5 \mathrm{~min}(0.0033 \mathrm{~Hz})$ per cycle. As described in Appendix $A$, this relatively slow rate was chosen after multiple trials as giving the best compromise with the systems available between: (i) good cyclic load control, (ii) accurate and full logging of each cycle and (iii) accurate cyclic pore-pressure measurement over each individual cycle. Cyclic failure was defined as occurring when either: i) the axial strains, of either sign, exceeded $10 \%$ or ii) the strain rates became too high for the actuators to maintain the required stress paths. Ushev (2018) explored the impact of varying loading rates under monotonic conditions and confirmed that the till's response varied with strain rate. A 10-fold increase in strain rate could result in a $6 \%$ increase in undrained shear strengths and $10-14 \%$ gain in non-linear stiffnesses. Conversely, increasing the period of applied cycling can led to larger permanent deformations developing and fewer cycles being required to reach failure.

The interactive influences of the mean $q_{m}$ and cyclic $q_{c y c}$ deviatoric stresses were explored through the combinations outlined in Figure 4, which offers parallel schemes for normalising the loading parameters. The first employs the conventional total stress $q_{c y c} / 2 S_{u}$ and $q_{m} / 2 S_{u}$ measures. The till's mean $\mathrm{S}_{\mathrm{u}}$ value at this depth (averaging $\approx 130 \mathrm{kPa}$ in triaxial compression and $\approx 120 \mathrm{kPa}$ in extension monotonic tests) was $125 \mathrm{kPa}$ and the resulting $\mathrm{S}_{\mathrm{u}} / \sigma^{\prime}{ }_{\mathrm{v}}$ ratio of 2.5 is indicative of an apparent OCR (or Yield Stress Ratio, YSR) $\approx 12$, which varies markedly with depth; Ushev (2018). Figure 4 also shows alternative 'effective-stress' normalised axes with $q_{c y c} / p^{\prime}$ insitu and $q_{m} / p^{\prime}$ insitu and distinguishes between those tests where the maximum and/or minimum $q / p^{\prime}$ inclinations exceeded the $M$ ratio indicated by the monotonic tests. Specimens sheared monotonically to higher ratios tended to dilate as they progressed to their ultimate shear failures; see Figure $2 b$ ).

The sub-plots given in Figure 5a) to c) define the extents of the maximum and minimum deviatoric stresses $q_{\max }$ and $q_{\min }$ applied in each cyclic series (comprising of up to six $q_{c y c}$ cases) conducted at fixed $q_{m}$ values $=-25 \mathrm{kPa}$ (the in-situ case), $50 \mathrm{kPa}, 125 \mathrm{kPa}$ or $200 \mathrm{kPa}$. Also shown are the interpreted monotonic critical state points and Hvorslev surfaces. Five of the higher amplitude cyclic tests failed according to the adopted criteria after the indicated number $\left(\mathrm{N}_{\mathrm{f}}\right)$ of cycles. All other specimens remained un-failed when the loading halted after 1500 to 3500 cycles. Those with accumulated axial strains $\varepsilon_{a}<4 \%$ were sheared (after allowing $24 \mathrm{~h}$ periods for any undrained creep to stabilise) 
monotonically to compressive failure at axial strain rates of $5 \% /$ day to provide information on postcyclic shearing behaviour.

\section{Numbers of cycles to failure}

Interpreted contours are shown in Figure 4 of the cyclic stress combinations under which the tests indicated failure after $\mathrm{N}=10,100$ or 1000 cycles. The contours were established by semi-logarithmic interpolation between the experimental results, modified from Andersen's (2015) linear procedure for lower OCR clays. The failed tests' $N_{f}$ values are also annotated; points marked with a '>' sign represent cases that remained un-failed at the specified total number of cycles. The nominal $N_{f}=1$ contours extend from $\mathrm{q}_{\mathrm{cyc}} / 2 \mathrm{~S}_{\mathrm{u}}=0, \mathrm{q}_{\mathrm{m}} / 2 \mathrm{~S}_{\mathrm{u}}=-1$ to $\mathrm{q}_{\mathrm{cyc}} / 2 \mathrm{~S}_{\mathrm{u}}=1, \mathrm{q}_{\mathrm{m}} / 2 \mathrm{~S}_{\mathrm{u}}=+1$ and neglect any strain rate dependency of $S_{u}$ over the ranges considered. Contours on the less populated extension side of the interactive diagram are shown as straight, dashed lines interpreted from the monotonic extension tests.

The interaction diagram may be separated into an un-failed zone and regions where failures occurred by either (i) a combination of large cyclic and average strains, as defined in Figure 6, that led to "abrupt failure" or (ii) cases where large mean strains developed without correspondingly large cyclic strains and samples tended to a "creeping failure". The abrupt failure mode is typical for specimens cycled symmetrically from in-situ stresses $\left(q_{m}=-25 \mathrm{kPa}\right)$ with high $q_{c y c}$ values, while the creeping failure mode applied in tests with higher initial deviatoric offsets $\left(q_{m} \geq 50 \mathrm{kPa}\right)$.

Most of the 13 samples that did not fail under cyclic conditions developed apparently stable critical states when sheared monotonically to large compressive strains. The post-cyclic undrained shear strengths of the un-failed specimens revealed $\mathrm{S}_{u}{ }^{\text {post-cyclic }} / \mathrm{S}_{u}{ }^{\text {TXC }}$ ratios exceeding unity (one exception is the test at $q_{m}=200 \mathrm{kPa}$ which had a ratio of 0.93 ) with an average of 1.19 . Stable or metastable cyclic loading appears to lead to slightly higher undrained shear strengths at constant void ratio. As noted below, stable cyclic loading had little impact on the samples' mean effective stresses. Given also the till's very high bulk stiffness the gains in undrained shear strength exhibited by un-failed samples could not be explained by positive plastic volumetric straining. Instead, it appears to be related to the effects of the many low-level, shear strain cycles that led to a stable non-linear and principally reversible response being established after the first few load cycles.

Effective stress paths under cyclic loading

A special feature of the cyclic tests was their ability to track effective stress paths accurately throughout cycling and identify trends that varied systematically with the loading parameters, $\mathrm{q}_{\mathrm{m}} / 2 \mathrm{~S}_{\mathrm{u}}$, 
$\mathrm{q}_{\mathrm{cyc}} / 2 \mathrm{~S}_{\mathrm{u}}$ or $\mathrm{q}_{\mathrm{cyc}} / \mathrm{p}^{\prime}$ insitu and $\mathrm{q}_{\mathrm{m}} / \mathrm{p}^{\prime}$ insitu and $\mathrm{N}$. Figures 7 to 12 present, in multiple sub-plots, the paths, grouped into sets that employed the same $\mathrm{q}_{\mathrm{cyc}}$ amplitudes. Also shown in each sub-plot are the notension lines, the Hvorslev surfaces and failure $M$ lines identified from the static tests.

The cyclic tests all exceeded their short $( \pm 2.5 \mathrm{kPa})$ quasi-elastic ranges, and so manifested non-linear stiffness and minor plastic straining. Nevertheless, the Figure 7 sub-plots reveal that all the $\mathrm{q}_{\mathrm{cyc}}=10 \mathrm{kPa}$ tests presented relatively tight, steady and stable effective stress path loops, including tests where $q_{m} / p^{\prime}>M$ and in the $q_{m}=200 \mathrm{kPa}$ case, approached the outer Hvorslev surface established from slow monotonic tests. The paths were oriented nearly vertically in the 'in-situ' $\mathrm{q}_{m}=-25 \mathrm{kPa}$ test but rotated clockwise to give positive $d q / d p^{\prime}$ slopes in the higher $q_{m}$ experiments. Slight gains in $p^{\prime}$ were observed over the first 1000 cycles, followed by either stasis or slightly falling values as cycling continued. The $\left|\Delta p^{\prime}\right|$ changes amounted to less than $0.05 p^{\prime}$ over the 1 to 2 weeks required to apply 2000 to $3500,5-$ minute period, cycles. Figure 8 shows that the experiments involving the next largest $\mathrm{q}_{\mathrm{c} y \mathrm{c}}=25 \mathrm{kPa}$ $\left(\mathrm{q}_{\mathrm{cyc}} / 2 \mathrm{Su}=0.1\right)$ amplitude also exhibited broadly stable responses. Shifts can be seen again from an initially "dilative" drift trend to one indicating slightly "contractive" behaviour, but after lower numbers of cycles than in the equivalent lowest amplitude $\left(q_{c y c}=10 \mathrm{kPa}\right)$ cases. The tests' overall $\left|\Delta p^{\prime} / p^{\prime}{ }_{0}\right|$ changes were smaller than $5 \%$ over the 1697 to 2013 cycles applied in the $q_{m}=-25$ cases, while the $q_{m}=125 \mathrm{kPa}$ test, which also approached the Hvorslev surface showed a $6 \%$ drift.

Overall, the $q_{\mathrm{cyc}}=10$ and $25 \mathrm{kPa}$ experiments followed broadly stable effective stress paths over thousands of cycles. Working from tests involving far fewer cycles on other soils, Jardine (1992), (2013) and Kuwano and Jardine (2007) identified a ' $Y_{2}$ ' Kinematic Yielding Surface (KYS) which marked a threshold beyond which soil behaviour changed distinctly under cyclic or (drained) static loading. In the analysis that follows, we define the $Y_{2}$ threshold as corresponding to the limit to the undrained cyclic stress paths within which $\left|\Delta p^{\prime} / p^{\prime}{ }_{0}\right|$ remains $<5 \%$ over 2000 cycles and, as discussed later, no significant loss of cyclic stiffness occurs. The $q_{c y c}=25 \mathrm{kPa}, q_{m}=125 \mathrm{kPa}$ test, which showed $\left|\Delta \mathrm{p}^{\prime} / \mathrm{p}_{0}{ }_{0}\right|=$ $6 \%$, exceeds this criterion marginally. Tests with the same $q_{c y c}=25 \mathrm{kPa}$, but lower $\mathrm{q}_{\mathrm{m}}$, remained within their $Y_{2}$ surfaces. Pre-shearing to $q_{m}=125 \mathrm{kPa}$ evidently diminished the absolute size of the current KYS, even though the undrained pre-loading path led to 'dilative' increases in $\mathrm{p}^{\text {'. }}$

The $\mathrm{q}_{\mathrm{cyc}}=50 \mathrm{kPa}\left(\mathrm{q}_{\mathrm{cyc}} / 2 \mathrm{~S}_{\mathrm{u}}=0.2\right)$ tests conducted at $\mathrm{q}_{\mathrm{m}}=-25$ and $50 \mathrm{kPa}$ developed the more extensive and broader effective stress paths shown in parts a) and b) of Figure 9 . Their initially dilative trends and movements to the right were followed by more contractive shifts between $\mathrm{N}=100$ and 1000 , that subsequently slowed and led to overall $\left|\Delta p^{\prime} / p^{\prime}{ }_{0}\right|$ drifts $\approx 10.0 \%$. The paths clearly engaged and modified the till's $Y_{2}$ surface (as defined above) but remained well within the Hvorslev surface. No failure occurred, indicating metastable outcomes. Increasing the cyclic amplitude to $\mathrm{q}_{\mathrm{cyc}}=75 \mathrm{kPa}$ 
$\left(\mathrm{q}_{\mathrm{cyc}} / 2 \mathrm{~S}_{\mathrm{u}}=0.3\right)$ in tests from $\mathrm{q}_{\mathrm{m}}=-25$ and $50 \mathrm{kPa}$ led to the still more marked $\mathrm{p}^{\prime}$ drifts seen in Figure 10, parts a) and b). In the first case, the imposed minima in q approached the Hvorslev surface interpreted from slow monotonic extension tests. However, both specimens survived the 2000 or more cycles imposed, so their behaviour was also metastable. The effective stress paths observed under cycling with $\mathrm{q}_{\mathrm{cyc}}=75 \mathrm{kPa}$ amplitudes and $5 \mathrm{~min}$ periods from $\mathrm{q}_{\mathrm{m}}=125 \mathrm{kPa}$ appeared to cross (and so violate) the 'slow shearing' Hvorslev surface in compression (see Figures 10 part c)) provoking "dilative" behaviour over the first 100 cycles $\left(\left|\Delta p^{\prime} / p^{\prime}{ }_{0}\right|>25.0 \%\right)$ followed by a rightward drift, away from the $Y_{3}$ yield surface. The cyclic strain rate was around 40 times that applied in the monotonic test and the observed 'over-shooting' is interpreted as being due to shear strain rate effects.

The resulting $q-p^{\prime}$ loops remained relatively symmetrical and of limited width. No failure occurred. Even though significant permanent strain accumulation took place over the 2000 cycles, as detailed later, these tests also classify as being metastable.

However, the higher amplitude $\mathrm{q}_{\mathrm{cyc}}=100$ and $150 \mathrm{kPa}\left(\mathrm{q}_{\mathrm{cyc}} / 2 \mathrm{~S}_{\mathrm{u}}=0.4\right.$ and 0.6$)$ experiments conducted from $q_{m}=-25,50$ and $125 \mathrm{kPa}$ all first violated the 'slow shearing' Hvorslev surface and subsequently progressed to fail within 1000 cycles; see Figures 11 and 12. Their final stages involved cyclic axial strain rates of 10 to more than $1000 \% / \mathrm{h}$, which were up to 200 times higher than in the reference monotonic experiments, which may explain again why they were able to occupy regions of effective stress space that were inadmissible in the slower tests. Their initial cyclic effective stress paths showed markedly dilative behaviour, which the till could not sustain for many cycles. The specimens' $p^{\prime}$ values started to fall more significantly on unloading than they rose during loading, leading to a contractive overall trend with the paths heading leftward towards the origin, developing irregular loops and broad "butterfly" shapes. As summarised in Figure 6, large permanent strains accumulated, and cyclic failures developed with maximum deviatoric stresses $q_{\max }$ as low as half the $2 \mathrm{~S}_{\mathrm{u}}$ limit applying to the monotonic tests, despite the cyclic tests higher axial strain rates.

The experiments demonstrate that the high YSR Cowden till's cyclic response is controlled by how the effective stress paths invoked by any given level of cycling map onto the till's kinematic 'small-strain' and outer yielding surfaces. Behaviour remains linear-elastic provided the cycles remain within the $Y_{1}$ surface whose size, although very small, increases with in-situ p'. Stable non-linear responses are seen under cycles whose $q_{c y c} / p^{\prime}$ amplitudes allow them to remain within the second $Y_{2}$ surface size. Failure develops when the loading paths' peaks or troughs attempt to exceed or climb significant distances up and along the Hvorslev surface.

Although strain-rate dependent aspects of behaviour may allow cyclic paths to exceed the 'static slow shearing' Hvorslev surface, as noted above, this is only possible when the cyclic strains are large. Any 
foundation built in or on the till that experiences such cycles can be expected to exceed its serviceability criteria.

As shown in Figures $2 \mathrm{a})$ and $\mathrm{b}$ ) the ratio of $\mathrm{p}_{\text {critical state }}^{\prime} / \mathrm{p}^{\prime}$ in-situ is high $(\approx 4.0)$ for the Cowden till samples taken at 3 to $3.5 \mathrm{~m}$, reflecting its high YSR $(\approx 12)$ at the depth considered. This is the key feature that leads to cyclic failures at $\left[q_{c y c} / S_{u}+q_{m} / S_{u}\right]$ ratios as low as 0.5 . However, YSR often varies strongly with depth at glacial sites (as is true at Cowden) and as a result, the $q_{c y c} / S_{u}, q_{m} / S_{u}$ combinations at which failure occurs under given numbers of cycles are likely to also vary significantly. Relating the loading limits to the till's stable Hvorslev surface provides a more direct link to the effective-stress mechanism that controls cyclic failure. In the same way, normalising the loading parameters by $p^{\prime}$ (as $q_{c y c} / p^{\prime}$ and $\mathrm{q}_{\mathrm{m}} / \mathrm{p}^{\prime}$ ) should lead to criteria that are less sensitive to variations with depth in soil state or YSR.

\section{Overall trends for mean effective stress drifting under cycling}

It is important in cyclic foundation analysis to consider further details of how the soil responds to cycling. An example of the mean effective stress drifts recorded in each test during the $100^{\text {th }}$ cycle is shown as functions of $\mathrm{q}_{\mathrm{cyc}}$ and $\mathrm{q}_{\mathrm{m}}$ in Figure 13. The data are presented as $\Delta \mathrm{p}^{\prime} / \mathrm{p}_{0}$ percentages. As Cowden till exhibits generally "dilatant" initial behaviour, followed by "contraction" under medium and high cyclic stress amplitudes the overall p' contours rise and fall. To help identify the points at which these changes occur, contours are shown of the "incremental" $d p^{\prime} / p^{\prime}{ }_{0}$ per cycle rates of change (as averaged over intervals of 20 cycles) in Figure 14, parts a) to c). The zero value contours, shown with thicker lines, represent the locus of the points where dilative behaviour gives way to contractive. The loci move progressively downwards in the $q_{c y c}, q_{m}$ plots as the number of cycles increases.

\section{Evolution of strains}

\section{Axial strain contours}

The corresponding patterns of change in axial strains, which is equivalent here to shear strain invariant $\varepsilon_{s}$, are presented as contours of accumulated average and cyclic axial strains for the $N=10,100$ and 1000 cases in Figure 15, parts a) to c). The contours, which are spaced on nearly logarithmic intervals, were obtained by linear interpolation. Their intersection with the horizontal axis is defined by the axial strains accumulated during the companion monotonic compression tests. The testing programme left uncertainties on the extension side, where the contour patterns are presented as dashed lines extending to $\mathrm{q}_{\mathrm{cyc}} / 2 \mathrm{~S}_{\mathrm{u}}=0.2\left(\mathrm{q}_{\mathrm{cyc}}=50 \mathrm{kPa}\right)$. The contours naturally become more densely packed in the lower portions of the plots as $\mathrm{N}$ increases. They also change in shape and inclination as $\mathrm{N}$ rises, showing a greater dependence on both $\mathrm{q}_{\mathrm{m}}$ and $\mathrm{q}_{\mathrm{cyc}}$ as cycling progresses. 


\section{Axial strain accumulation trends}

The accumulation of average axial strains $\varepsilon_{\text {mean }}$ with number of cycles $(N)$ is examined in Figure 16 with sub-plots (part a) to c)) employing logarithmic axes and grouping the sets of tests conducted at $\mathrm{q}_{\mathrm{m}}=$ 25 to $125 \mathrm{kPa}$. All the experiments developed some permanent straining, although three of the four tests that sustained the lowest ( $10 \mathrm{kPa})$ cyclic amplitudes tended to stabilise after 100 to 1000 cycles and had rates that were often comparable to the slow residual creep rates $(<0.005 \% /$ day $)$ applying before cyclic started. The broad trends seen over the full durations of all tests that manifested stable or metastable effective stress paths, and those from the initial stages of unstable tests, appear to follow approximately power law relationships with $\mathrm{N}$ :

$$
\varepsilon=A(N)^{l}
$$

The trend lines indicate an average exponent / that does not appear to vary systematically with the cyclic loading variables but falls around 0.35 ; most tests showed exponents within \pm 0.15 of this mean. However, the parameter $A$ varies with both $q_{c y c}$ and $q_{m}$ and Ushev (2018) showed that the empirical relationships given by Eq. (2) to Eq. (4) allow the experimental $\varepsilon_{\text {mean }}$ trends to be fitted with coefficients of determination $>80 \%$.

$$
\begin{gathered}
A=a\left(\frac{q_{c y c}}{p_{0}^{\prime}}\right)^{b} \\
a=0.075 e^{2.34\left[\frac{q_{m}}{p_{0}}\right]} \\
b=2.06 e^{0.21\left[\frac{q_{m}}{p_{0}}\right]}
\end{gathered}
$$

\section{Cyclic stiffness}

As illustrated in Figure 17 by the $50^{\text {th }}$ cycle of the high-level $q_{c y c}=150 \mathrm{kPa}, q_{m}=-25 \mathrm{kPa}$ experiment, which failed after 71 cycles, the stress and strain maxima do occur at the exactly the same time under high level cycling; the same is true of the minima. Undrained cyclic secant vertical equivalent Young's Moduli ( $\mathrm{E}_{\text {sec }}^{\mathrm{u}}$ ) may therefore be defined for each cyclic loop by four alternative $\Delta \mathrm{q} / \Delta \varepsilon$ combinations; Ushev (2018) considered the average from the four possible combinations to be the most representative measure.

The trends for the average cyclic secant stiffness are presented in Figure 18, part a) to c) grouped by cases maintaining the same $q_{m}$ values. The tests that manifested stable effective stress loops (and remained within the till's $Y_{2}$ kinematic yield surfaces) showed stiffness either growing slightly with $N$, 
or falling modestly before stabilising. Cycling within the $\mathrm{Y}_{2}$ kinematic yield surface (at constant overall volume and with little change in $p^{\prime}$ ) generates repetitive plastic shear strains that appear to stiffen the soil's response under the applied loading.

However, metastable and unstable tests all show significant stiffness degradation that did not stabilise within the number of applied cycles. Ushev (2018) shows that their stiffness degradation trends could be matched by exponential expressions:

$$
E_{s e c}^{u} / p^{\prime}=B e^{-C q_{c y c} / p_{0}^{\prime}}
$$

The coefficient $B$ appears $\approx 1950( \pm 15 \%)$ independently of the cyclic loading variables. However, coefficient $C$ varies with $\mathrm{N}$ as indicated by Eq. (6) and the coefficients $c$ and $d$ depend on $\mathrm{q}_{\mathrm{m}}$ as indicated by Eq. (7) and Eq. (8).

$$
\begin{array}{cc}
C=c N^{d} & \text { Eq. (6) } \\
c=1.37 e^{0.3 q_{m} / p \prime_{0}} & \text { Eq. (7) } \\
d=0.07 e^{-1.1 q_{m} / p_{0}} & \text { Eq. (8) }
\end{array}
$$

\section{Damping ratios}

The variations of damping ratio $D$ (defined as the ratio of the inscribed area of the stress-strain loop to the maximum elastic energy stored during each cycle) with $\mathrm{N}$ and $\mathrm{q}_{\mathrm{cyc}}$ are presented in Figures 19, parts a) to c) with logarithmic axes and grouped according to the tests' $q_{m}$ value ( $q_{m}=200 \mathrm{kPa}$ single test's $m=0.12$ and is not shown). Stable and metastable tests indicated $D$ ratios that fell as cycling continued, while unstable tests exhibited sharp rises in $D$ as they approached failure. Ushev (2018) suggests that the trends applying before the onset of any cyclic failure can be matched by further functions as given in Eq. (9) to Eq. (11):

$$
D=L(N)^{-m}
$$

Where $L$ appears insensitive to $q_{m}$ and depends principally on cyclic amplitude ratio $q_{c y c} / p^{\prime}{ }_{0}$ as indicated in Eq. (10), while $m$ varies mainly with $q_{m} / p^{\prime}{ }_{0}$ as shown by Eq. (11):

$$
\begin{aligned}
& L=18.1\left(\frac{q_{c y c}}{p_{0}^{\prime}}\right)^{0.31} \\
& m=0.035 e^{0.65\left[\frac{q_{m}}{p_{0}}\right]}
\end{aligned}
$$


Ushev (2018) gives corresponding details of the energy dissipated per cycle in each test, showing that the tests whose stress paths remained within the $Y_{2}$ limits dissipated less than $1 \mathrm{~J} / \mathrm{m}^{3}$ in each cycle. Metastable showed greater rates of energy consumption $\left(10^{-1}\right.$ to $\left.\quad 10^{-2} \mathrm{~kJ} / \mathrm{m}^{3}\right)$, while unstable tests showed very high rates $\left(>1 \mathrm{~kJ} / \mathrm{m}^{3}\right.$ per cycle) as they approached failure.

\section{Tracking the evolution of the cyclic kinematic yield surfaces}

As noted earlier, the cyclic responses observed in stable and metastable tests can be related to two kinematic yield surfaces that, once engaged, move with the current effective stress point. Ushev (2018) showed from monotonic stress probing tests that the first elastic, $Y_{1}$, region is approximately elliptical in shape and has a maximum height of only about $\pm 2.5 \mathrm{kPa}$ in-situ at the 3.0 to $3.5 \mathrm{~m}$ cyclic series' sampling depth. He could not identify any second $Y_{2}$ surface from his monotonic tests, but this KYS has been defined in this paper as the threshold limit to: i) stable effective stress conditions that involve less than $5 \%$ variation in $p^{\prime}$ over $2000 \pm 500$ cycles and (ii) practically constant cyclic stiffness. The experiments showed that tests that satisfy these two criteria also tended to exhibit low damping ratios and energy dissipation per cycle, as well as low and stabilising axial strain rate trends. Figure 20 marks the approximate boundaries of the $Y_{1}$ (red circles) and $Y_{2}$ (black ellipses) kinematic yield surfaces that surround each $q_{m}$ point, along with the points at which large scale $\left(Y_{3}\right)$ yielding developed under cyclic loading, which are shown as squares.

The plotted ellipses are shown with nominal aspect ratios of 2:1: the $Y_{2}$ surfaces were characterised through only undrained cyclic tests that established their vertical limits but gave no information on their width in q-p' space. Fully drained cyclic tests that involve only changes in $p^{\prime}$ with little or no change in q over large number of cycles are required to check the assumed $Y_{2}$ surface shapes, and these have not been attempted. Nevertheless, the $Y_{2}$ surfaces' vertical dimensions were seen to diminish as the pre-loading effective conditions approached the outer Hvorslev boundary, even though $p^{\prime}$ increased as the samples moved along this undrained loading path. While cyclic loading within the initial $Y_{2}$ KYSs does not appear deleterious, paths that engage $Y_{2}$ on each loading and unloading stages dissipate far more energy and provoke marked stiffness degradation and strain accumulation.

\section{Summary}

The experiments on Bolders bank glacial till provide comprehensive information on the cyclic response a highly significant, and yet previously hardly investigated, class of geomaterials. The low plasticity, 
high YSR, dilatant clay responded to cycling in distinctly different ways to the principally contractant low OCR clays on which most previous studies have focussed. The tests offer insights into the phenomena that must be captured in representative constitutive models, as well as a benchmark against which such models may be tested. The key aspects established include the conditions under which cyclic failure can be expected to develop, as well as the impact of cycling on mean effective drifts, cyclic permanent strains, stiffness degradation, damping ratio and monotonic undrained shear strength. This previously unavailable information can also be used to guide directly engineering analyses of the cyclic response of foundations installed in comparable tills, including the PISA programme of cyclic lateral loading tests conducted at Cowden on large monopiles; Byrne et al. (2017).

\section{Conclusions}

1. The cyclic test outcomes can be summarised succinctly in contoured interaction diagrams that express the effects of the cyclic loading parameters on the number of cycles to failure, mean effective stress drifts, accumulated (mean) and cyclic (amplitude) strains. The diagrams can be divided into "safe" and "unsafe" zones. Failure occurred in the latter through either "abrupt" or "creeping" modes.

2. The interaction diagrams can be developed in terms of cyclic and mean shear stresses normalised by total or effective stress parameters, with the latter being more representative for the high YSR, low plasticity, Cowden till.

3. The till's cyclic behaviour can also be interpreted within a critical state framework which recognises the onset of significant changes of behaviour once carefully defined kinematic yield surfaces are engaged. Behaviour is linear elastic within the initial $Y_{1}$ kinematic yield surface, which only applies over a very limited range of q-p' stress space; which was around $\pm 2.5 \mathrm{kPa}$ in vertical extent under in-situ stresses at the $3.4 \mathrm{~m}$ average sampling depth considered.

4. However, cycling loading could lead to completely stable outcomes, with negligible mean effective stress drifts and stiffness degradation, provided the cyclic effective stress paths remained within a more extensive $Y_{2}$ kinematic yield surface. Repeated non-linear, and yet principally recoverable, shear straining under constant volume conditions allowed the till to grow, sustain or recover its secant stiffness and undrained shear strength. Only minor permanent strains and effective stress drifts developed, which could stabilise, while damping ratios and energy dissipation remained low.

5. The $Y_{2}$ kinematic yield surface moves with the effective stress path once it is engaged. Under stable in-situ conditions, the $\mathrm{Y}_{2}$ "bubble" grew in height (in q-p' space) in proportion with $p^{\prime}$ indicating isotropic hardening. However, undrained pre-shearing stages that involved raising 
peak $q / p$ ' above $M$ diminish the KYS 'bubble' heights, even though such paths led to dilative responses that increased the specimens' mean effective stresses: the $Y_{2}$ surface's hardening rules also depend on $\mathrm{q} / \mathrm{p}^{\prime}$.

6. Cyclic loading paths that engaged the $Y_{2}$ yield surface but remained within the outer Hvorslev surface developed more significant $p^{\prime}$ drifts, permanent strains and stiffness losses that varied systematically with the cyclic loading variables and the number of cycles imposed. Such tests could sustain $\mathbf{2 0 0 0}$ or more cycles without manifesting full failure, so their responses were considered metastable.

7. The key trends of all tests could be fitted over their pre-failure ranges by empirical relationships that employed the effective stress variables $q_{c y c} / p^{\prime}{ }_{0}$ and $q_{m} / p_{0}^{\prime}$.

8. Cyclic loading tests that crossed the monotonic tests' outer Hvorslev surface underwent sharp effective stress path direction changes. Cyclic failure ensued in most such tests. However, in some cases positive rate effects allowed the cyclic effective stress paths to travel beyond the Hvorslev surface interpreted from relatively slow monotonic tests.

\section{Acknowledgements}

The Authors' research was partially funded by the PISA JIP project and Orsted. Their financial support is greatly appreciated. They also express their appreciation to their colleagues in PISA laboratory work, particularly Dr Tingfa Liu, and other elements of the programme, which prompted the Cowden cyclic study, and to the project's sponsors. They also acknowledge work of the Socotec staff who carried out the block sampling and the numerous contributions made by the technical staff at Imperial College to enabling the taxing experimental work. 


\section{Nomenclature}
A, B, C, L, a, b, c, d Empirical coefficients
CSL
Critical state line
D
Damping ratio
ESP
Effective stress path
$E^{\mathrm{u}} \sec$
Undrained vertical secant Young's modulus
$E_{\mathrm{v}}{ }^{\prime}, E_{\mathrm{h}}{ }^{\prime}$
Drained vertical and horizontal Young's moduli respectively
$E_{\mathrm{v}}{ }^{\mathrm{u}}, E_{\mathrm{h}}{ }^{\mathrm{u}}$
Undrained vertical and horizontal Young's moduli respectively
GBS
Gravity Based Structures
$G_{\text {hh }}$
Shear modulus in horizontal plane
$G_{h v}, G_{v h}$
Shear moduli in vertical plane
$\mathrm{ICL}$
Intrinsic compression line
JIP
Joint industry project
$K^{\prime}$
Effective bulk modulus
$\mathrm{K}_{0}$
Stress ratio $\sigma_{h}^{\prime} / \sigma_{v}^{\prime}$ for zero lateral strain
KYS
Kinematic Yield Surface
Slope of the $\varepsilon_{\text {mean }}-\mathrm{N}$ curve
$\mathrm{LL}$
Liquid limit
m
Slope of the D-N curve
M
Slope of the failure (Critical state) line
$\mathrm{N}$
Number of cycles
$\mathrm{NCL}$
Normal compression line
$\mathrm{N}_{\mathrm{f}}$
Number of cycles to failure
OCR
Overconsolidation ratio
$p^{\prime}$
Mean effective stress
$\mathrm{p}_{0}^{\prime}$
Initial mean effective stress 
PISA

PL

q

$\mathrm{q}_{\mathrm{cyc}}, \mathrm{q}_{\mathrm{cyclic}}$

$q_{m}, q_{\text {mean }}$

$q_{\min }, q_{\max }$

$\mathrm{S}_{u}$

TXC

TXE

v

$Y_{1}, Y_{2}$

$\mathrm{Y}_{3}$

YSR

$\varepsilon_{\mathrm{a}}$

$\varepsilon_{\text {cyclic }}$

$\varepsilon_{\text {mean }}$

$\varepsilon_{\mathrm{r}}$

$\varepsilon_{\mathrm{s}}$

$\lambda$

$v_{v h}{ }^{\prime}, v_{h v^{\prime}}, v_{h h}{ }^{\prime}$

$v_{v h}{ }^{u}, v_{h v}{ }^{u}, v_{h h}{ }^{u}$

$\sigma_{h}^{\prime}$

$\sigma_{v}^{\prime}$
Pile Soil Analysis project

Plastic Limit

Triaxial deviatoric stress

Cyclic deviatoric stress

Mean deviatoric stress

Minimum and maximum deviatoric stresses

Undrained shear strength

Triaxial compression test

Triaxial extension test

Specific volume

Kinematic yield points

Large scale 'gross' yield point

Yield Stress Ratio defined as $\sigma_{\mathrm{vy}}^{\prime} / \sigma_{\mathrm{v} 0}^{\prime}$

Axial (vertical) strain

Cyclic axial (vertical) strains recorded during cyclic loading

Average axial (vertical) strains recorded during cyclic loading

Radial strain

Shear strain

Slope of the 1-D compression line

Drained Poisson's ratios in the cross-anisotropic elastic model

Undrained Poisson's ratios in the cross-anisotropic elastic model

Horizontal effective stress

Vertical effective stress 


\section{References}

Ackerley, S.K., Standing, J.R. and Kamal, R.H. (2016) A system for measuring local radial strains in triaxial apparatus. Géotechnique. 66 (6), 515-522.

Aghakouchak, A. (2015) Advanced laboratory studies to explore the axial cyclic behaviour of driven piles. PhD Thesis, Imperial College London.

Aghakouchak, A., Sim, W.W. and Jardine, R.J. (2015) Stress-path laboratory tests to characterise the cyclic behaviour of piles driven in sands. Soils and Foundations.

Andersen, K. (2009) Bearing capacity under cyclic loading - offshore, along the coast, and on land. The 21st Bjerrum Lecture. Canadian Geotechnical Journal. 46 (5), 513-535.

Andersen, K. (2015) Cyclic soil parameters for offshore foundation design Meyer (ed.). Frontiers in Offshore Geotechnics III, ISFOG.1 pp.5-82.

Baudet, B.A. and Stallebrass, S.E. (2004) A constitutive model for structured clays. Géotechnique 2004; 54(4):269-78.

Bishop, A.W. and Wesley, L.D. (1975) A hydraulic triaxial apparatus for controlled stress path testing. Géotechnique. 25 (4), 657-670.

Byrne, B.W., McAdam, R.A., Burd, H.J., Houlsby, G.T., Martin, C.M., Beuckelaers, W., Zdravković, L., Taborda, D.M.G., Potts, D.M., Jardine, R.J., Ushev, E.R., Liu, T., Abadias, D., Gavin, K., Igoe, D., Doherty, P., Skov Gretlund, J., Andrade, M P., Muir Wood, A., Schroeder, F C., Turner, S., Plummer, M A L., (2017) PISA: New Design Methods for Offshore Wind Turbine Monopiles. In: Proceedings of the 8th International Conference on Offshore Site Investigation and Geotechnics. 2017 London. pp. 142-161.

Cuccovillo, T. and Coop, M.R. (1997) The measurement of local axial strains in triaxial tests using LVDTs. Géotechnique. 47 (1), 167-171.

Davies, B.J., Roberts, D.H., Bridgalnd, D.R., Cofaigh, C.O. and Riding, J.B. (2011) Provenance and depositional environments of Quaternary sediments from the western North Sea Basin. Journal of Quaternary Science. 26 (1), 59-75.

Dafalias, Y.F. (1986) An anisotropic critical state soil plasticity model. Mechanics Research Communications 1986; 13(6):341-347.

Dafalias, Y.F., Manzari, M.T. and Papadimitriou, A.G. (2006). SANICLAY: simple anisotropic clay 
plasticity model. Int. J. Numer. Anal. Meth. Geomech., 2006; 30:1231-1257.

Gasparre, A., Nishimura, S., Minh, N.A., Coop, M.R. and Jardine, R.J. (2007) The stiffness of natural London Clay. Géotechnique. 57 (1), 33-47.

Grammatikopoulou, A., Zdravkovic, L., and Potts, D.M. (2006). General formulation of two kinematic hardening constitutive models with a smooth elastoplastic transition. International Journal of Geomechanics, Vol.6 (5): 291-302.

Hight, D.W. (1982) A simple piezometer probe for the routine measurement of pore pressure in triaxial tests on saturated soils. Géotechnique. 32 (4), 396-401.

Jardine, R.J. (1992) Some observations on the kinematic nature of soil stiffness. Soils and Foundations. $32(2), 111-124$.

Jardine, R.J., Andersen, K. \& Puech, A. (2012) Keynote Paper. Cyclic loading of offshore piles: potential effects and practical design. Proc $7^{\text {th }}$ Int. Conf. on Offshore Site Investigations and Geotechnics, SUT London, pp 59-100.

Jardine, R.J. \& Standing, J.R. (2012) Field axial cyclic loading experiments on piles driven in sand. Soils and Foundations. 52 (4), 723-736.

Jardine, R.J. (2013) Advanced laboratory testing in research and practice. 2nd Bishop Lecture. In: Proc. Int. Conf. Soil Mech. and Geot. Eng. Paris, Eds Delage et al., Presses des Ponts, Paris, Vol 1, pp. 35-55.

Jardine, R.J. (2020) Geotechnics, Energy and Climate change: the 56th Rankine Lecture. Géotechnique. Géotechnique. 70 (1), pp. 3-59.

https://www.icevirtuallibrary.com/doi/full/10.1680/igeot.18.RL.001

Karlsrud, K., Jensen, T.G., Wensaas Lied, E.K., Nowacki, F. \& Simonsen, A.S. (2014) Significant ageing effects for axially loaded piles in sand and clay verified by new field load tests. In: Proceedings of the Offshore Technology Conference, Houston, TX, USA, paper OTC-25197-MS, https://doi.org/10.4043/25197-MS2014 Houston.

Kavvadas, M. and Amorosi, A. (2000) A constitutive model for structured soils. Géotechnique; 50 (3): $263-73$.

Kuwano, R. and Jardine R.J. (2002) On the applicability of cross anisotropic elasticity to granular materials at very small strains. Géotechnique. 52 (10), 727-750.

Kuwano, R. \& Jardine, R.J. (2007) A triaxial investigation of kinematic yielding in sand. Géotechnique. 
57 (7), 563-579.

Lehane, B.M. \& Jardine, R.J. (1994) Displacement pile behaviour in glacial clay. Canadian Geotechnical Journal. 31 (1), 79-90.

Liu, T. F. (2018) Advanced laboratory testing for offshore pile foundations under monotonic and cyclic loading, PhD thesis, Imperial College London.

Nishimura, S. (2014) Assessment of anisotropic elastic parameters of saturated clay measured in triaxial apparatus: Appraisal of techniques and derivation procedures. Soils and Foundations 54(3):364-376.

Ove Arup \& Partners Ltd (1986) Research on the Behaviour of Piles as Anchors for Buoyant Structures. Stationery Office Books.

Powell, J.J.M. \& Butcher, A.P. (2003) Characterisation of a glacial till at Cowden, Humberside T S Tan, K K Phoon, D W Hight, \& S Cerark (eds.). Proceedings of the International Workshop on Characterisation and Engineering Properties of Natural Soils. Vol 2 Tan et al eds, Pub. Swets \& Zeitlinger, Lisse, Netherlands pp.983-1020.

Puzrin, A.M. and Shiran, A. (2000) Effects of the constitutive relationship on seismic response of soils. Part I. Constitutive modeling of cyclic behavior of soils. Soil Dyn. Earth Eng; 19: 305-18.

Pyke, R.M. (1979) Nonlinear soil models for irregular cyclic loadings. J Geotech Eng Div ASCE, 105 (GT6): 715-26.

Ramberg, W., Osgood, W.R. (1943) Description of stress-strain curves by three parameters. Technical Note No. 902, National advisory committee for aeronautics; Washington, DC.

Rouainia, M. and Muir Wood, D. (2000) A kinematic hardening constitutive model for natural clays with loss of structure. Géotechnique 2000;50(2):153-64.

Seidalinov, G. and Taiebat, M. (2014) Bounding surface SANICLAY plasticity model for cyclic clay behavior. Int J Numer Anal Methods Geomech. ;38:702-24.

Taborda, D. M. G. and Zdravkovic, L. (2012). Application of a Hill-Climbing technique to the formulation of a new cyclic nonlinear elastic constitutive model. Computers and Geotechnics, 43: 80-91.

Tsuha, C.H.C., Foray, P.Y., Jardine, R.J., Yang, Z.X., Silva, M. \& Rimoy, S. (2012) Behaviour of displacement piles in sand under cyclic axial loading. Soils and Foundations. 52 (3), pp 393-410.

Ushev, E. (2018) Laboratory Investigation of the Mechanical Properties of Cowden Till Under Static and Cyclic Conditions. Imperial College London. 
Wichtmann, T., Niemunis, A. \& Triantafyllidis, T. (2005) Strain accumulation in sand due to cyclic loading: drained triaxial tests. Soil Dynamics and Earthquake Engineering. 25 (11), 967-979.

Zdravkovic, L., Jardine, R., Taborda, D.M.G., Abadias, D., Burd, H.J., Byrne, B.W., Gavin, K., Houlsby, G.T., Igoe, D., Liu, T., Martin, C.M., McAdam, R.A., Muir Wood, A., Potts, D.M., Skov Gretlund, J. and Ushev, E.. (2019) Ground characterisation for PISA pile testing and analysis. Geotechnique Ahead of print.

https://www.icevirtuallibrary.com/doi/abs/10.1680/jgeot.18.PISA.001 


\section{Appendix A}

Pore-pressure distribution under cyclic loading

The rough ends of conventional triaxial apparatus' base and top platens act to resist radial soil movement at the boundaries. Total stress and consequently pore pressure non-uniformities ensue under static or cyclic loading, unless the loading is slow enough to allow full pore pressure equilibration to occur. Lubricated ends were employed to overcome such non-uniformities, although this step slowed down the base pore-pressure response.

The pore-water pressure distributions developed during cyclic loading were investigated with three trial tests equipped with lubricated ends and multiple miniature pore pressure probes. All specimens were tested in $100 \mathrm{~mm}$ diameter cells, after reconsolidation to in-situ stresses under the same cyclic amplitude $\mathrm{q}_{\mathrm{cyc}}=50 \mathrm{kPa}$. The tests are distinguished by the extensions added at the end of the test code, pwp1 to pwp3, as listed in Table 2. Test pwp1 was equipped with two pore-pressure probes mounted on the specimens while tests pwp2 and 3 had three. The results revealed:

- Good agreement could be achieved between the pore-pressures measured at the base and probes over each whole cycle with cyclic periods $\mathrm{T}>30 \mathrm{~min}$, however this loading period is both impractical for research and far from representative of offshore storm conditions.

- Full equilibration of otherwise non-uniform pore-pressures through slow testing leads to measurements that are less representative of ideal element behaviour than those made locally under more rapid loading in the middle part of the specimen.

- The differences between individual local pore-pressure probe readings reduce to small values $(<$ $2 \mathrm{kPa}$ ) under cycling with $\mathrm{T}=5 \mathrm{~min}$, showing that relatively uniform distributions apply over the main part of the samples under cycling at this rate.

- While the $T=5 \mathrm{~min}$ tests are still slower than anticipated in the field, this was the fastest rate at which tests could be controlled effectively.

- While peak and trough sample base measurements are not reliable for cycling with $\mathrm{T}<30 \mathrm{~min}$, the average (mid-cycle) base pore pressures recorded in faster cyclic tests were found close to those from the pressure probes.

- The presence of lubricated ends slows down the base response but reduces the non-uniformity induced by rough platens.

- Mid-height pore-pressure probes provide the best measurements of true elemental soil behaviour over individual cycles in cyclic tests with periods less than 30min. 
The effect of cyclic loading frequency on the behaviour

The shearing rate effect on the cyclic behaviour of Cowden till was investigated with additional slower experiments from in-situ stresses $\left(q_{m}=-25 k P a\right)$ with $q_{c y c}=100$ and $150 \mathrm{kPa}\left(q_{c y c} / 2 S_{u}=0.4\right.$ and 0.6$)$ on $100 \mathrm{~mm}$ diameter specimens from the $3.40 \mathrm{~m}$ depth, cycled with periods of $120 \mathrm{~min}(1.4 \times 10-4 \mathrm{~Hz})$ and $\mathrm{T}=360 \mathrm{~min}(4.6 \times 10-5 \mathrm{~Hz})$. The results indicate:

- Reducing the cyclic frequency leads to a further decrease in the average pore water pressure recorded during each cycle with broader individual effective stress cyclic loops.

- Slowing the cyclic loading leads to greater cyclic softening, energy dissipation, stiffness degradation and more marked permanent strain accumulation.

- The number of cycles to failure decreased as the cyclic frequency was reduced. 
Table 1. Summary for the 3.0 to $3.5 \mathrm{~m}$ depth range of Cowden till's anisotropic and bulk elastic stiffness components, normalised by elastic undrained vertical stiffness, and Poisson's ratios. Shown to two significant places.

\begin{tabular}{|c|c|c|c|c|c|c|c|c|c|}
\hline$E_{\mathrm{vvh}} / \mathrm{E}_{\mathrm{vu}}$ & $\mathrm{E}_{\mathrm{v}} / \mathrm{E}_{\mathrm{vu}}$ & $\mathrm{E}_{\mathrm{h}} / \mathrm{E}_{\mathrm{vu}}$ & $\mathrm{G}_{\mathrm{vh}} / \mathrm{E}_{\mathrm{vu}}$ & $\mathrm{G}_{\mathrm{hh}} / \mathrm{E}_{\mathrm{vu}}$ & $\mathrm{K}^{\prime} / \mathrm{E}_{\mathrm{vu}}$ & $\mu_{\mathrm{vh}}{ }^{\prime}$ & $\mu_{\mathrm{hh}}{ }^{\prime}$ & $\mu_{\mathrm{hvu}}$ & $\mu_{\mathrm{hhu}}$ \\
\hline 2.2 & 0.81 & 2.1 & 1.0 & 1.3 & 4.1 & 0.41 & -0.17 & 1.12 & -0.12 \\
\hline
\end{tabular}

Table 2. Programme of cyclic loading tests 


\begin{tabular}{|c|c|c|c|c|c|c|}
\hline No. & Test Code & $\begin{array}{l}q_{\mathrm{m}} \\
\mathrm{kPa}\end{array}$ & $\begin{array}{l}\mathrm{q}_{\mathrm{cyc}} \\
\mathrm{kPa}\end{array}$ & $v, \mathrm{kN} / \mathrm{m}^{3}$ & $\begin{array}{l}\mathrm{p}_{0} \\
\mathrm{kPa}\end{array}$ & $\begin{array}{l}\text { Final } \\
\text { void } \\
\text { ratio }\end{array}$ \\
\hline 1 & CB38KUC3.4_qm25qc10 & -25 & 10 & 21.64 & 68.2 & 0.418 \\
\hline 2 & CB100KUC3.4_qm25qc25 & -25 & 25 & 21.48 & 67.0 & 0.430 \\
\hline 3 & CB100KUC3.4_qm25qc50 & -25 & 50 & 21.65 & 75.9 & 0.431 \\
\hline 4 & CB38KUC3.4_qm25qc75 & -25 & 75 & 22.16 & 67.6 & 0.425 \\
\hline 5 & CB38KUC3.4_qm25qc100 & -25 & 100 & 21.45 & 76.2 & 0.433 \\
\hline 6 & CB38KUC3.4_qm25qc150 & -25 & 150 & 21.82 & 93.1 & 0.411 \\
\hline 7 & CB100KUC3.4_qm50qc10 & 50 & 10 & 21.57 & 65.3 & 0.444 \\
\hline 8 & CB38KUC3.4_qm50qc25 & 50 & 25 & 21.88 & 79.6 & 0.406 \\
\hline 9 & CB100KUC3.4_qm50qc50 & 50 & 50 & 21.76 & 73.7 & 0.407 \\
\hline 10 & CB38KUC3.4_qm50qc75 & 50 & 75 & 21.41 & 74.0 & 0.451 \\
\hline 11 & CB38KUC3.4_qm50qc100 & 50 & 100 & 21.54 & 77.8 & 0.433 \\
\hline 12 & CB38KUC3.4_qm50qc150 & 50 & 150 & 21.78 & 91.5 & 0.420 \\
\hline 13 & CB38KUC3.4_qm125qc10 & 125 & 10 & 21.77 & 96.4 & 0.438 \\
\hline 14 & CB38KUC3.4_qm125qc25 & 125 & 25 & 21.71 & 98.9 & 0.415 \\
\hline 15 & CB100KUC3.4_qm125qc50 & 125 & 50 & 21.81 & 97.8 & 0.430 \\
\hline 16 & CB38KUC3.4_qm125qc75 & 125 & 75 & 21.83 & 93.1 & 0.411 \\
\hline 17 & CB38KUC3.4_qm125qc100 & 125 & 100 & 21.28 & 104.8 & 0.468 \\
\hline 18 & CB100KUC3.4_qm200qc10 & 200 & 10 & 21.77 & 170.6 & 0.427 \\
\hline 19 & CB100KUC3.4_qm-25qc50_pwp1 & -25 & 50 & 21.98 & 71.3 & 0.428 \\
\hline 20 & CB100KUC3.4_qm-25qc50_pwp2 & -25 & 50 & 21.65 & 67.5 & 0.442 \\
\hline 21 & CB100KUC3.4_qm-25qc50_pwp3 & -25 & 50 & 22.07 & 70.3 & 0.418 \\
\hline 22 & CB100KUC3.4_qm-25qc100_T & -25 & 100 & 21.53 & 74.7 & 0.431 \\
\hline 23 & CB100KUC3.4_qm-25qc150_T & -25 & 150 & 21.92 & 64.4 & 0.415 \\
\hline
\end{tabular}


Figures

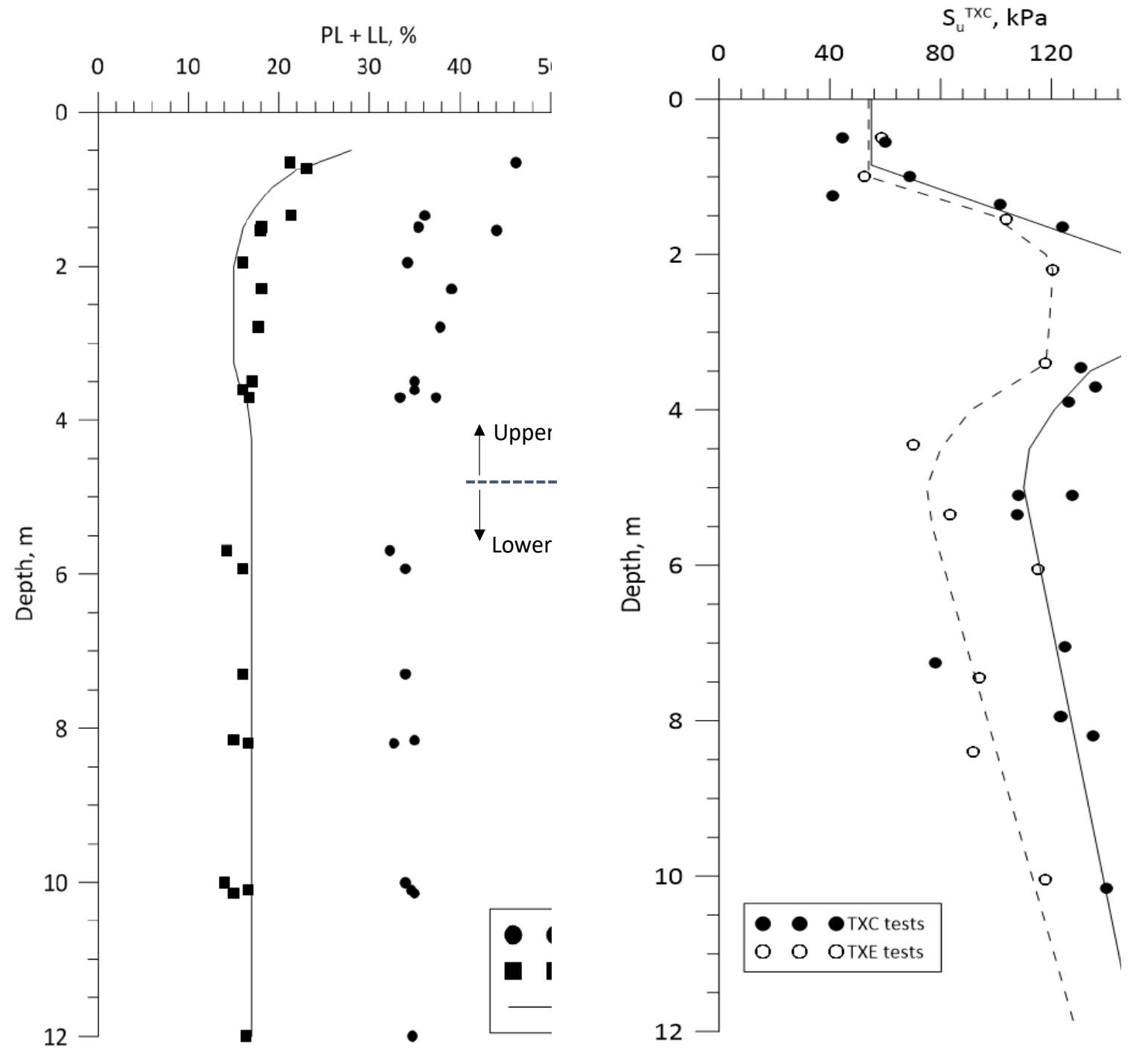

Figure 1 Profiles of natural water content, liquid and plastic limits, undrained triaxial shear strengths in compression (TXC) and extension (TXE) 


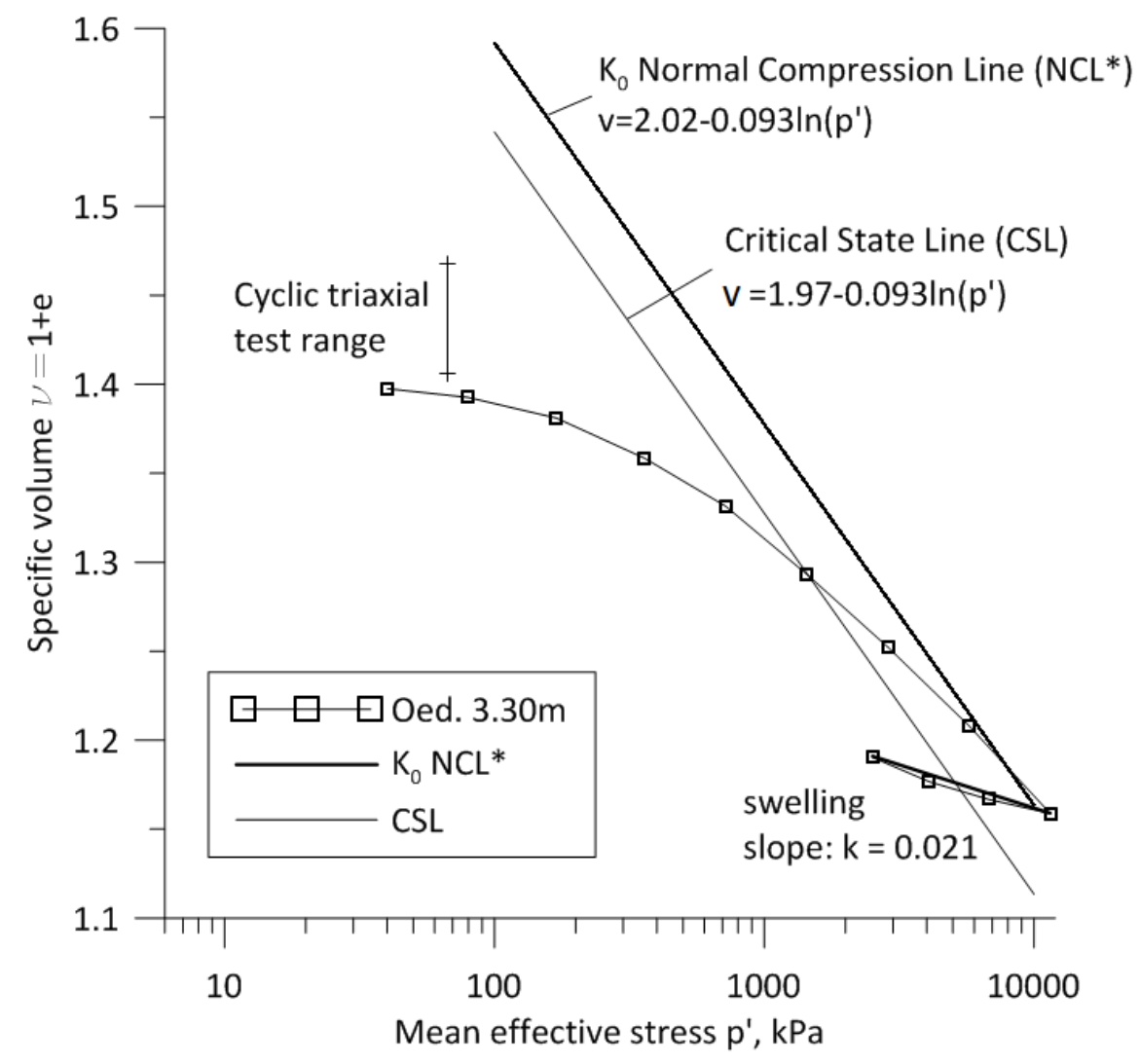

Figure 2a) Typical oedometer compression and triaxial Critical State CS line from tests on samples from 3.0 to $3.5 \mathrm{~m}$ depth.

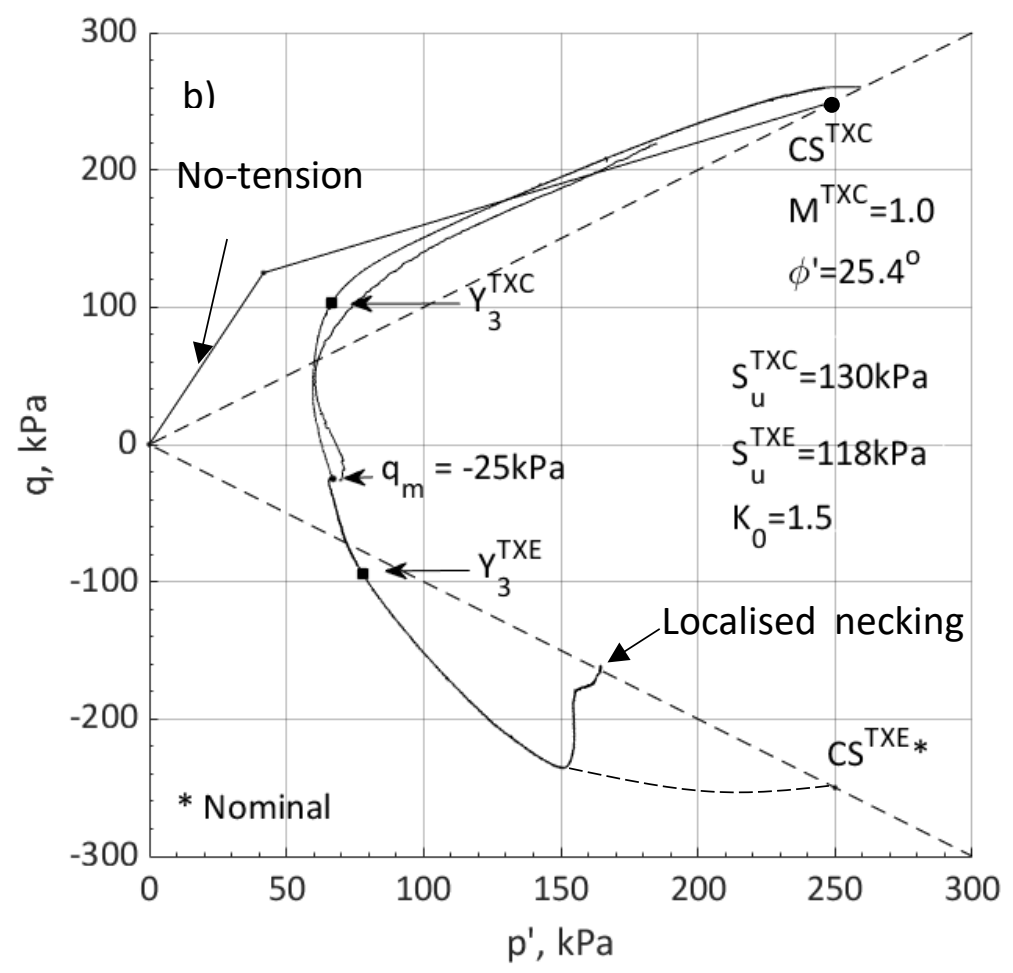

Figure 2b) Effective stress paths developed in monotonic undrained triaxial tests with the interpreted Hvorslev surface in TXC for the 3.0 to $3.5 \mathrm{~m}$ depth range 


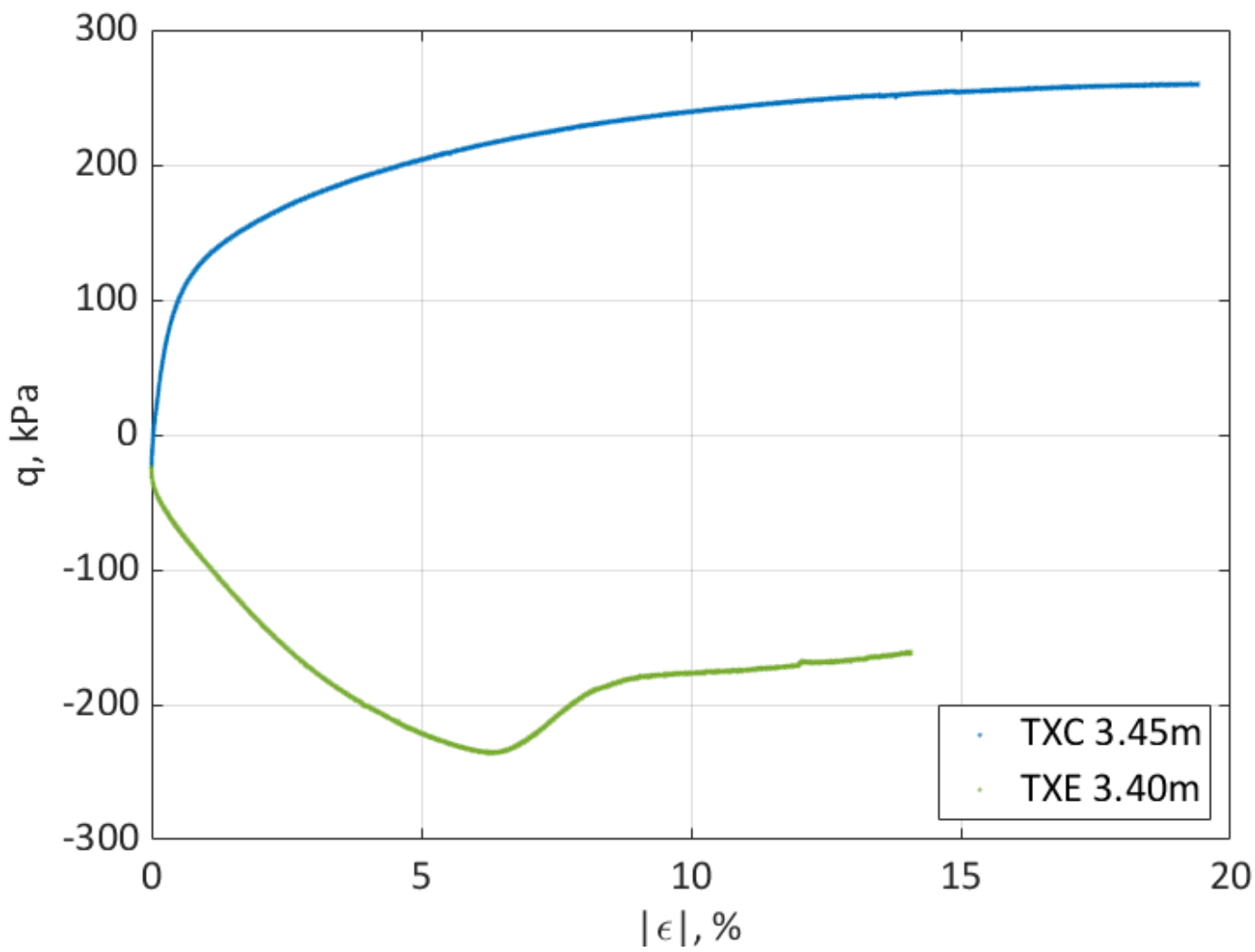

Figure 3a) Stress strain curves from monotonic undrained triaxial compression and extension tests from $\approx 3.4 m$ depth

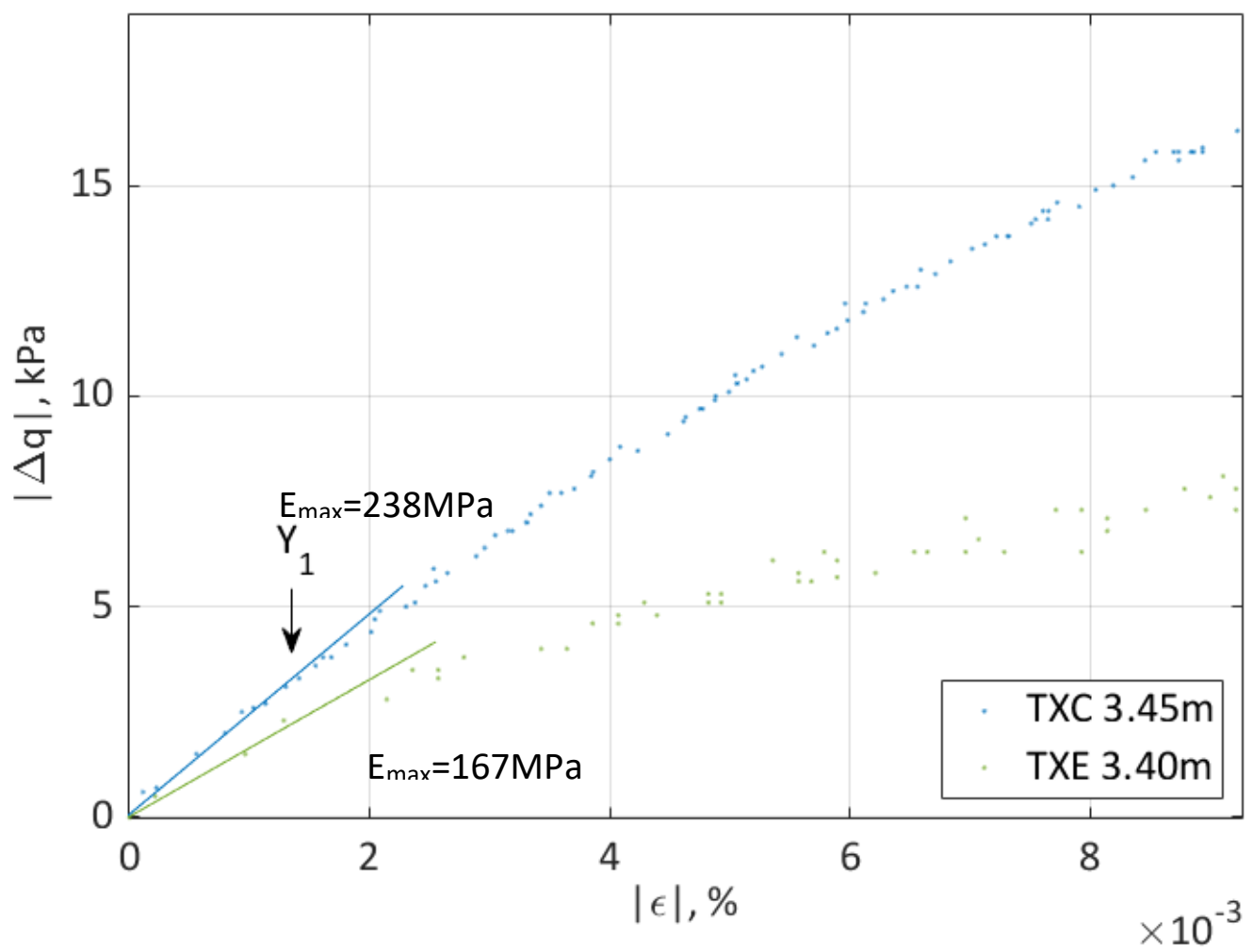

Figure 3b) Stress strain curves at small strains from monotonic undrained triaxial compression and extension tests from $\approx 3.4 \mathrm{~m}$ depth 


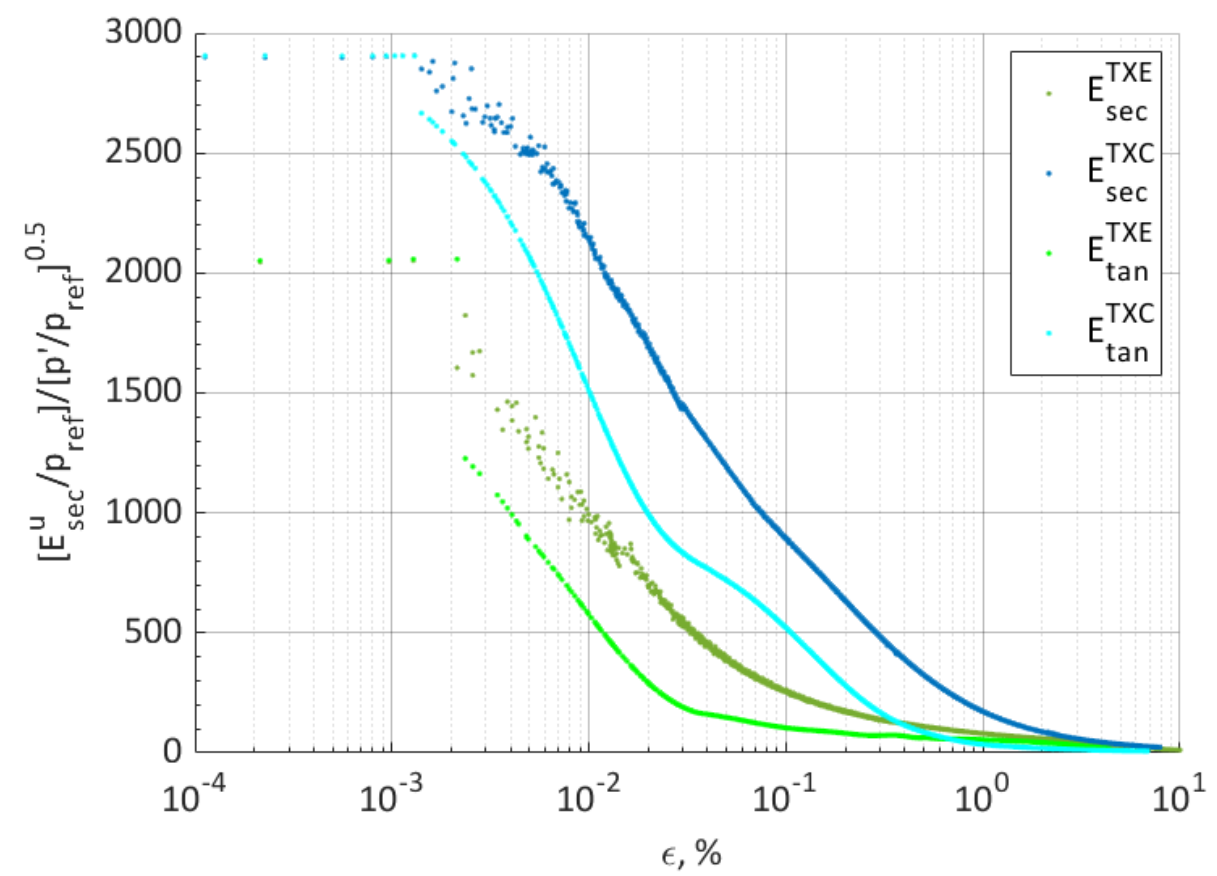

Figure 3c) Tangent and secant stiffness-strain curves from monotonic undrained triaxial compression and extension tests from $\approx 3.4 m$ depth normalised by $\left[p^{\prime}\right]^{0.5}$ 


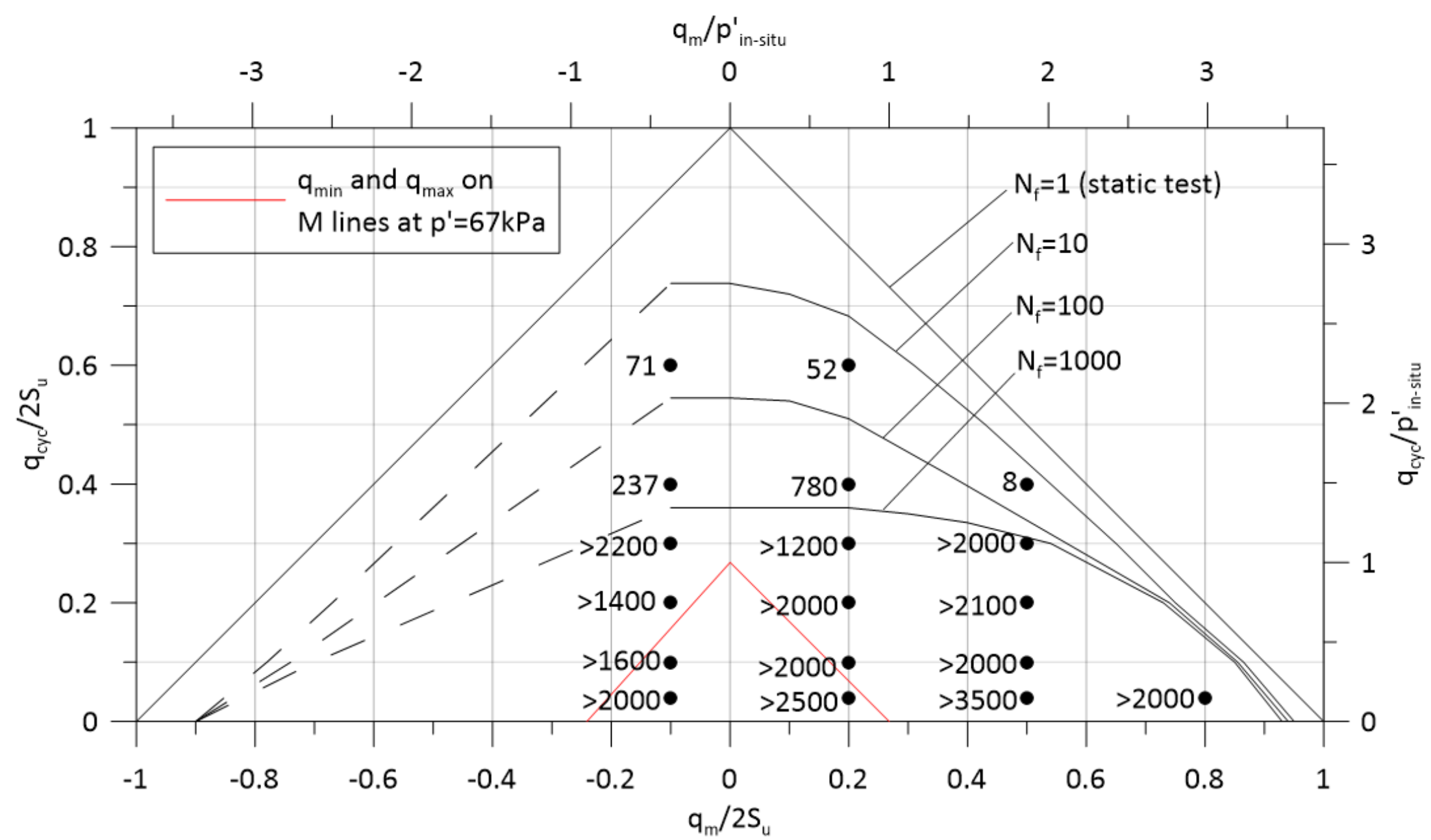

Figure 4 Cyclic stress space with static failure, $M$, surface contours and contours of number of cycles to failure as a function of $q_{c y d} / 2 S_{u}$ and $q_{m} / 2 S_{u}$ as well as $q_{c y d} / p^{\prime}{ }_{\text {in-situ }}$ vs $q_{m} / p_{\text {in-situ }}^{\prime}$ 

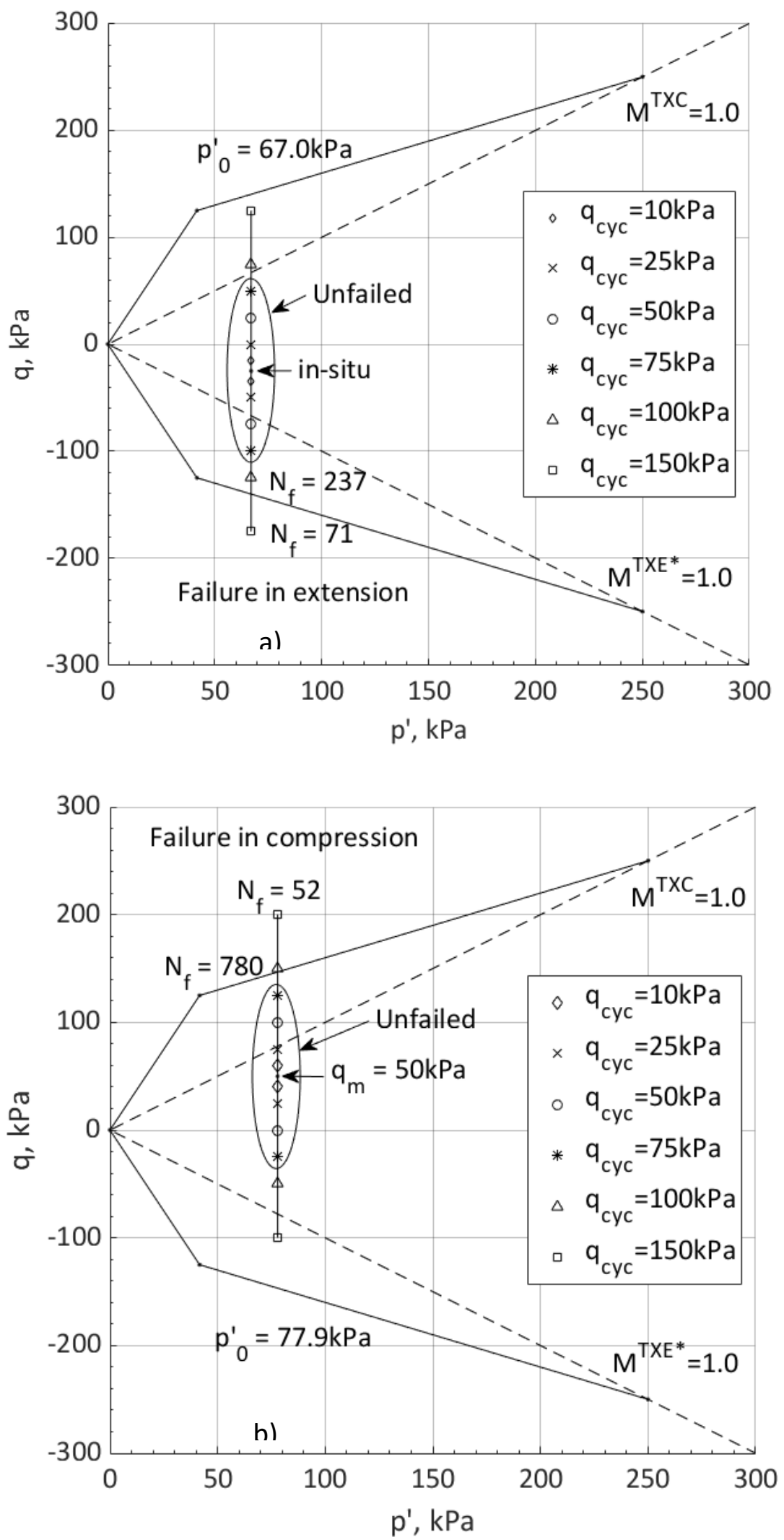

Figure 5 Extent of the cyclic amplitudes in relation to the Hvorslev surfaces established in monotonic triaxial tests; $\left.q_{m}=a\right)-25$ and b) $50 \mathrm{kPa}$ 


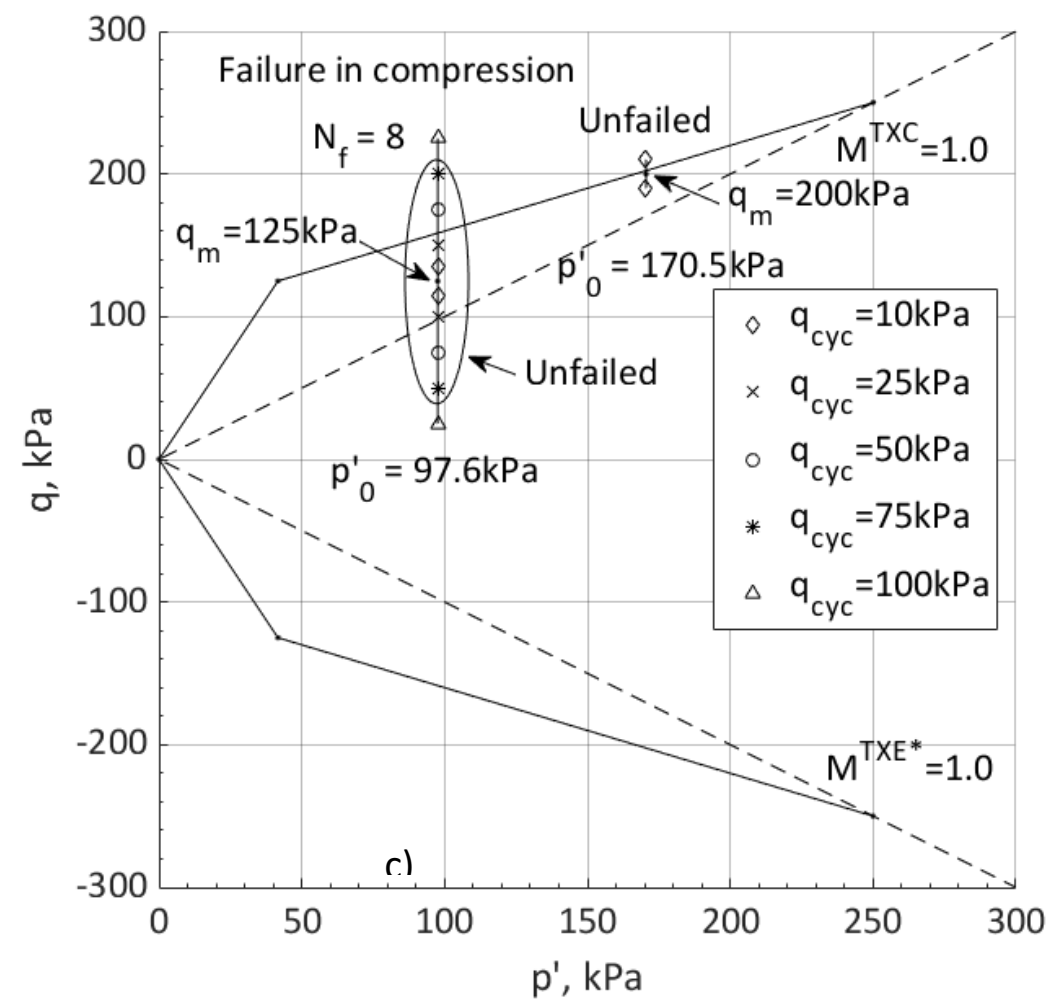

Figure 5 Extent of the cyclic amplitudes in relation to the Hvorslev surfaces established in monotonic triaxial tests; $\left.q_{m}=c\right) 125$ and $200 \mathrm{kPa}$ 


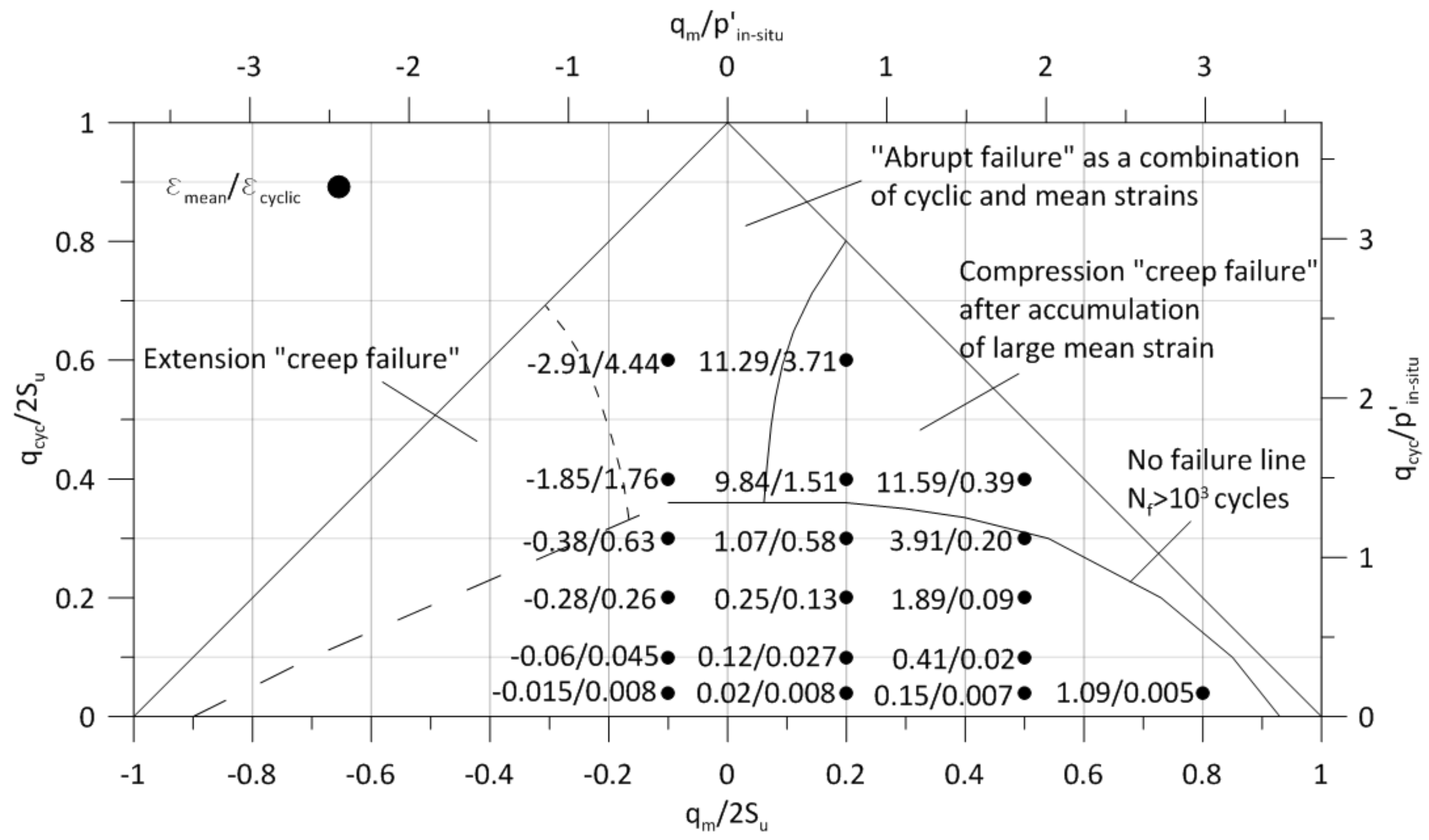

Figure 6 Combination of mean and cyclic axial strains at end of tests. Numbers represent values as $\varepsilon_{\text {mean }} / \varepsilon_{c y c l i c}$ in \% 

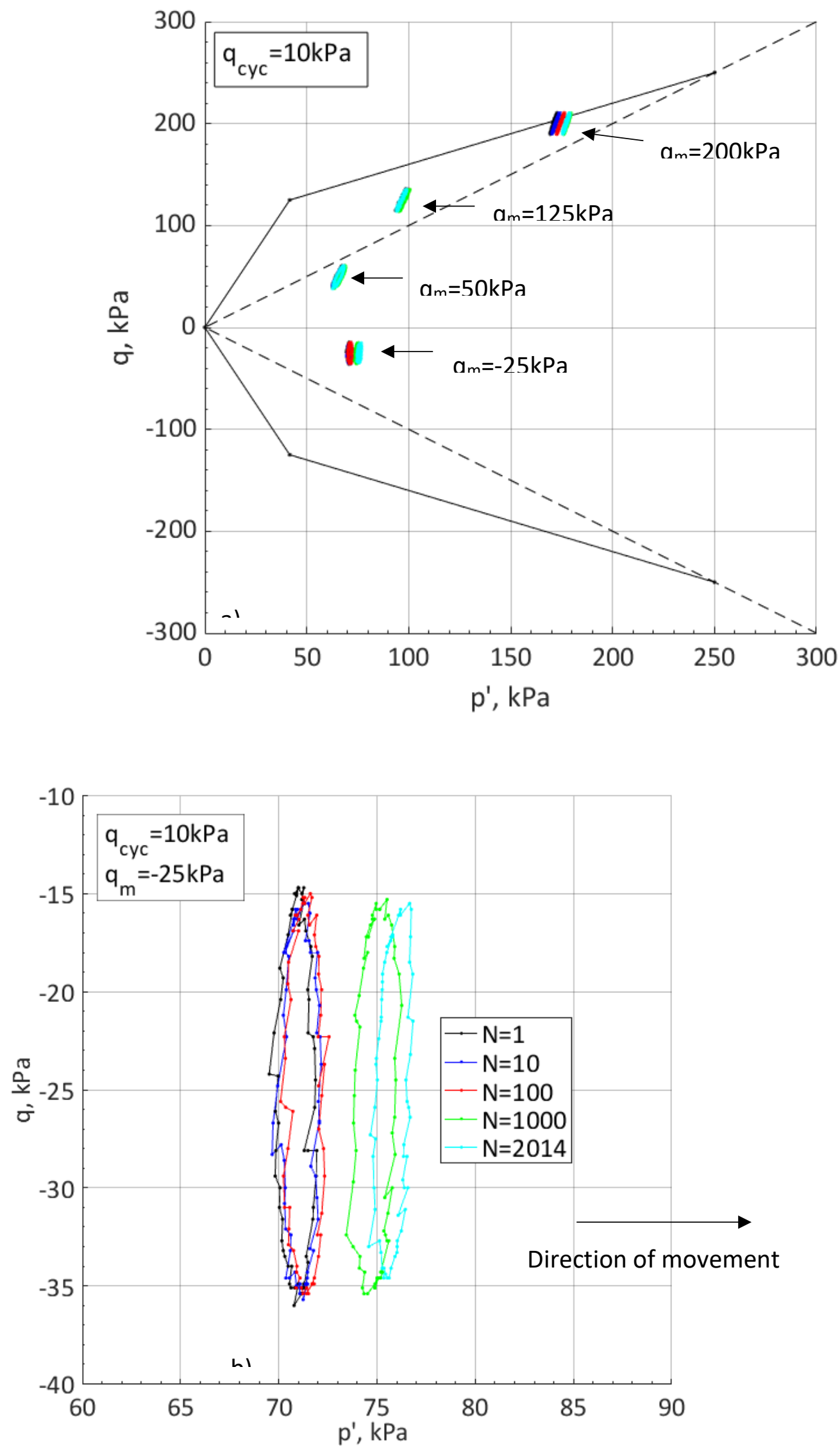

Figure 7 Effective stress paths during cycling with $q_{c y c}=10 \mathrm{kPa}$. Part a) combined plot and b) from $q_{m}=-25 \mathrm{kPa}$ (in-situ) 

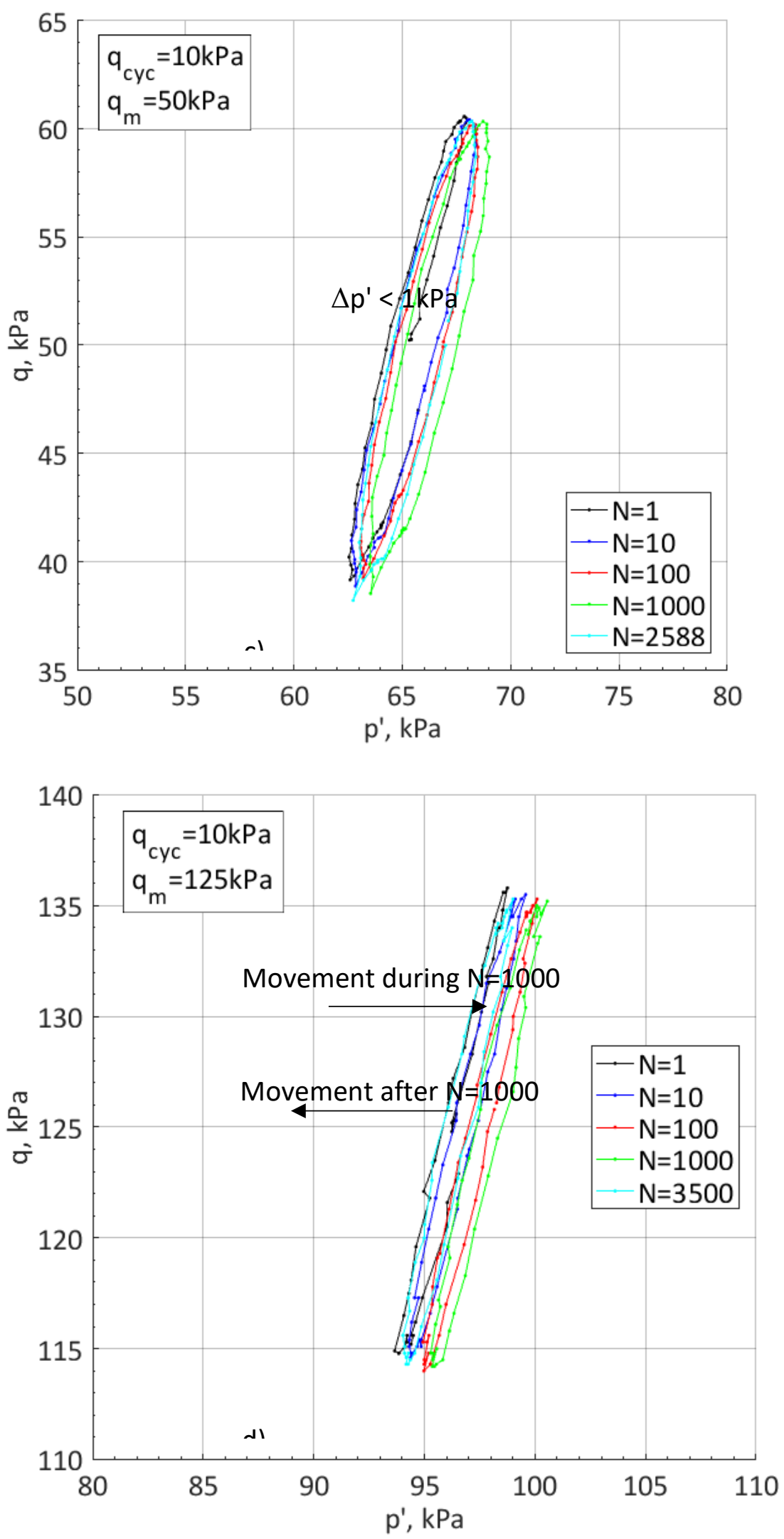

Figure 7 Effective stress paths during cycling with $q_{c y c}=10 \mathrm{kPa}$. Part c) from $q_{m}=50 \mathrm{kPa}$ and d) from $q_{m}=125 \mathrm{kPa}$ 


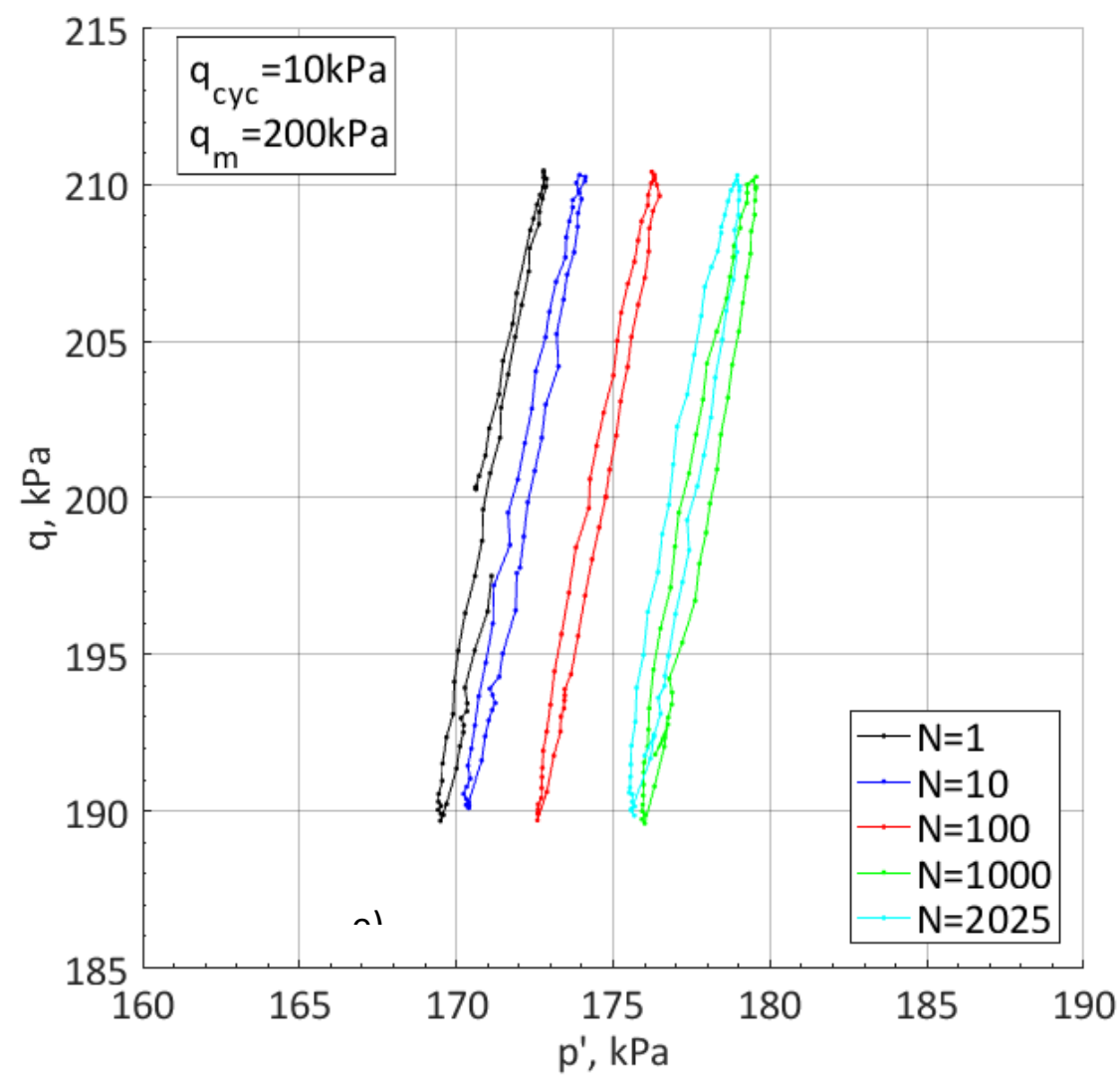

Figure 7 Effective stress paths during cycling with $q_{c y c}=10 \mathrm{kPa}$. Part e) from $q_{m}=200 \mathrm{kPa}$

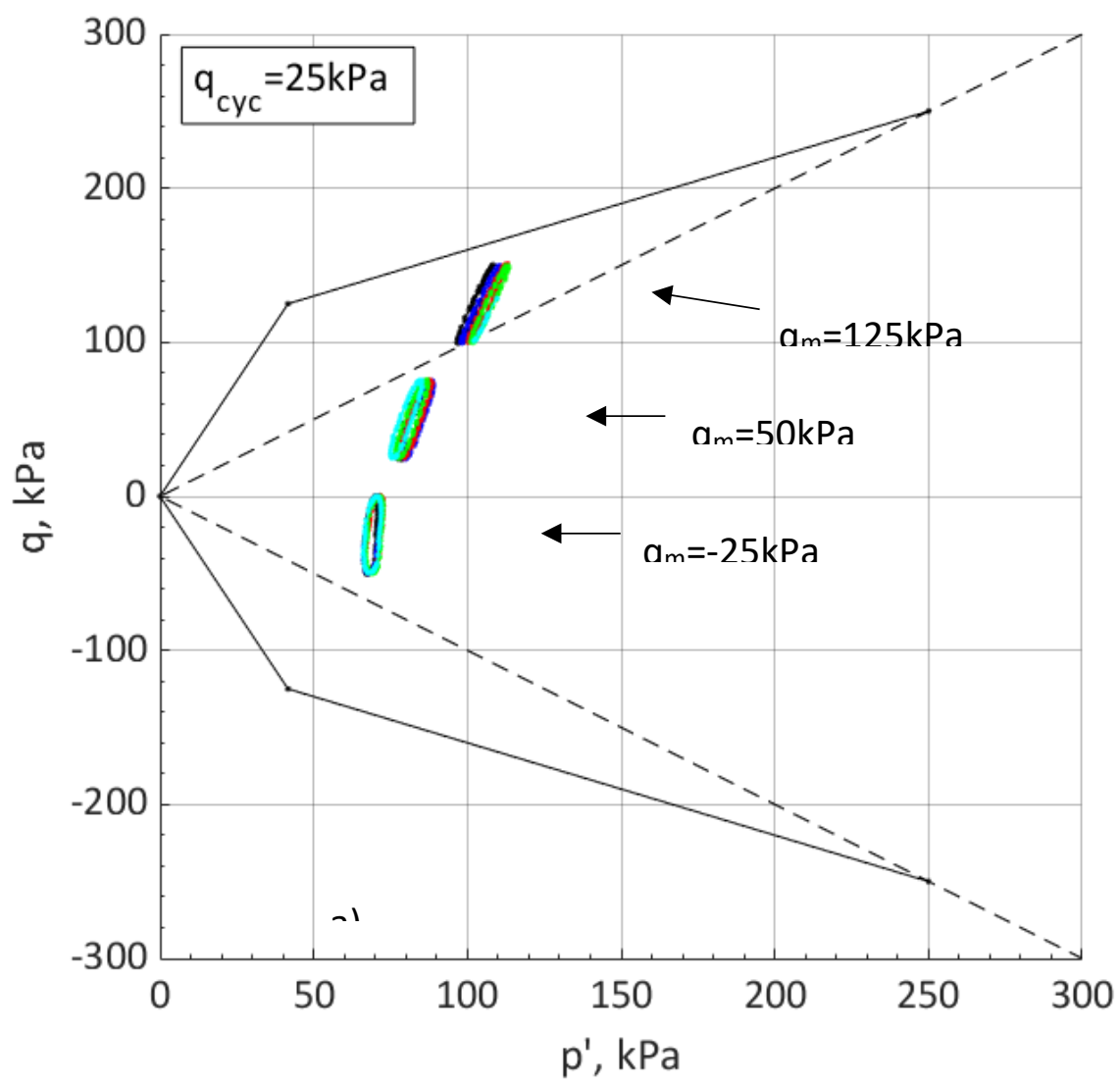




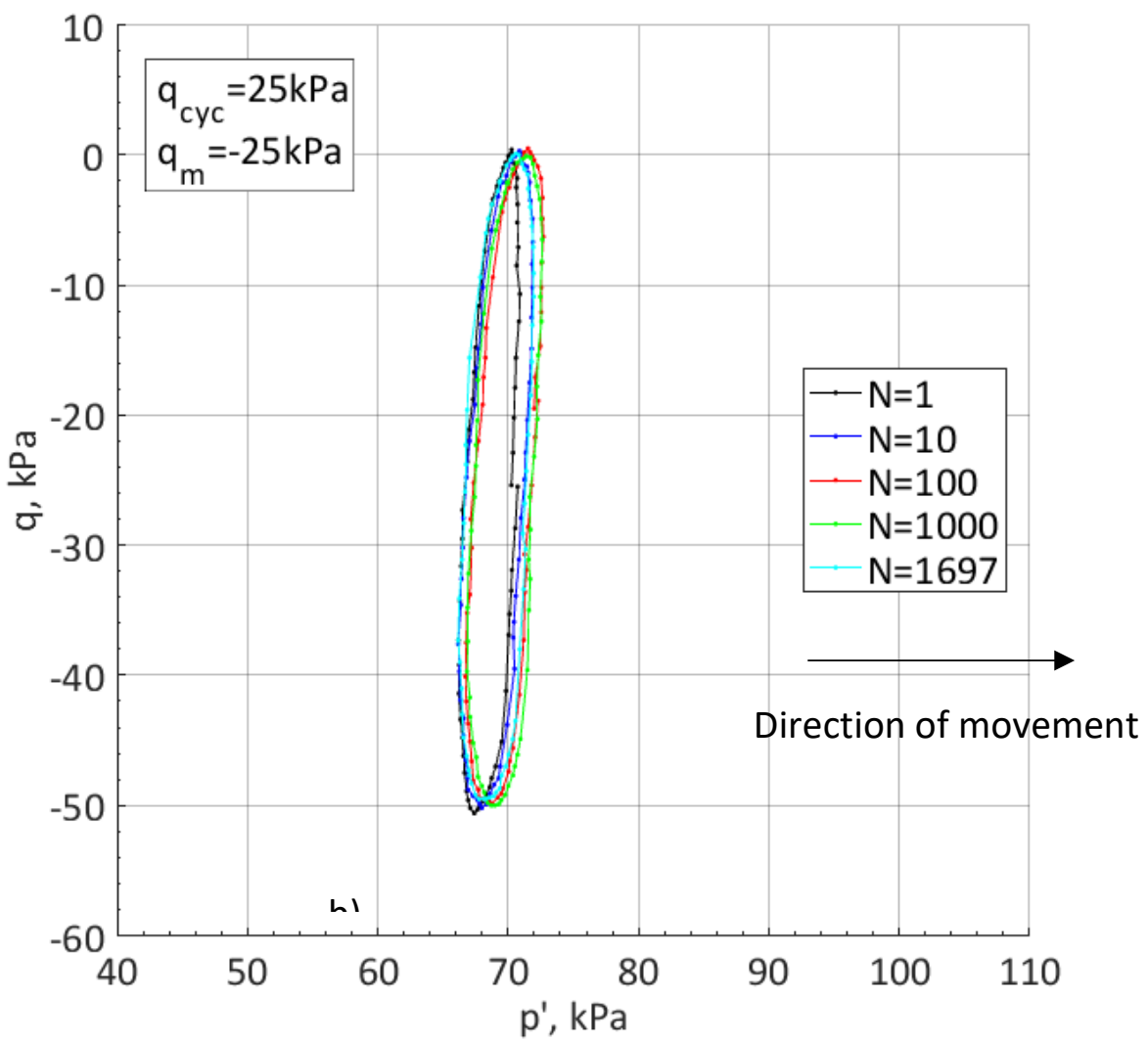

Figure 8 Effective stress paths during cycling with $q_{c y c}=25 \mathrm{kPa}$. Part a) combined plot and b) from $q_{m}=-25 k P a($ in-situ)

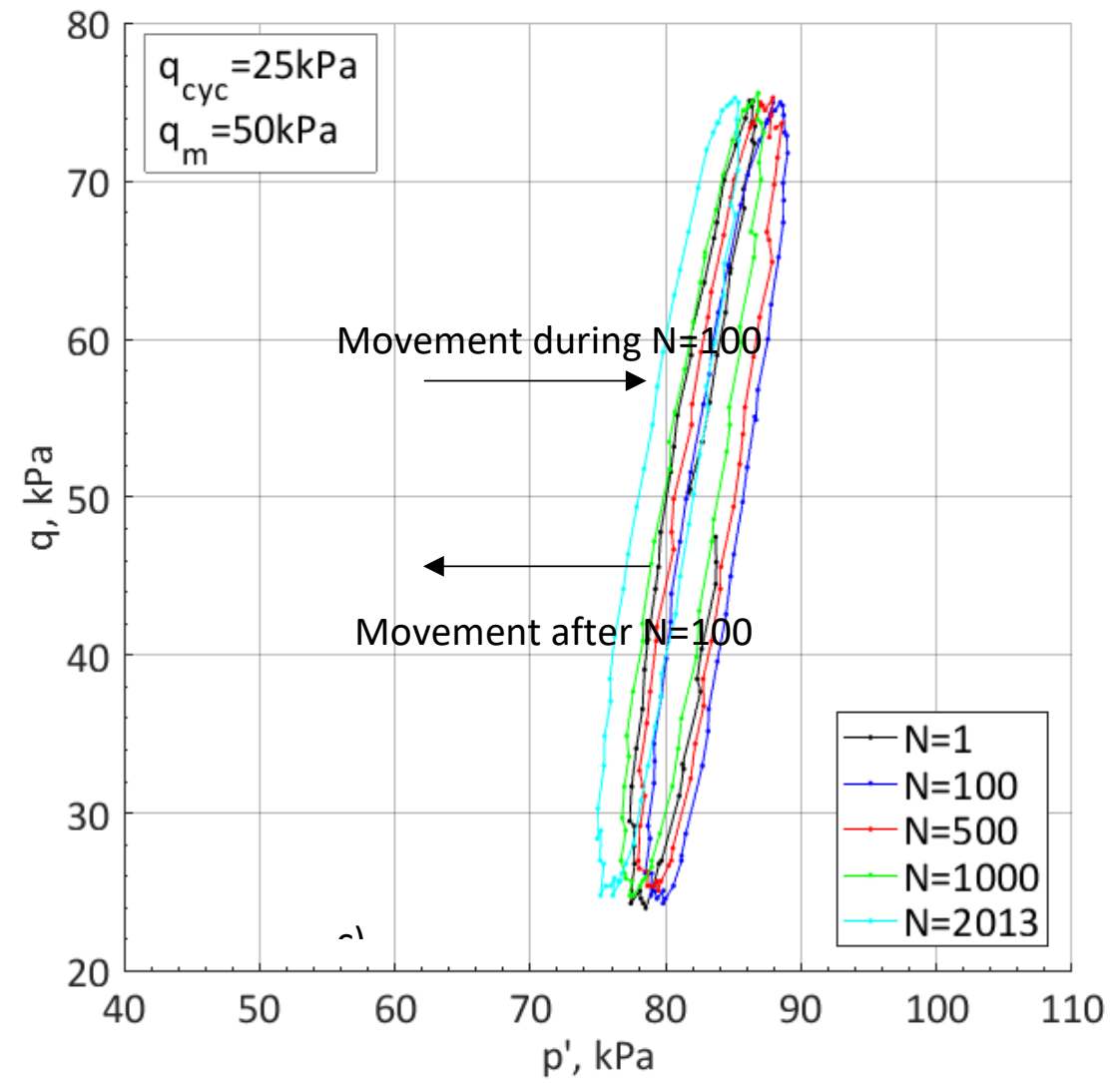




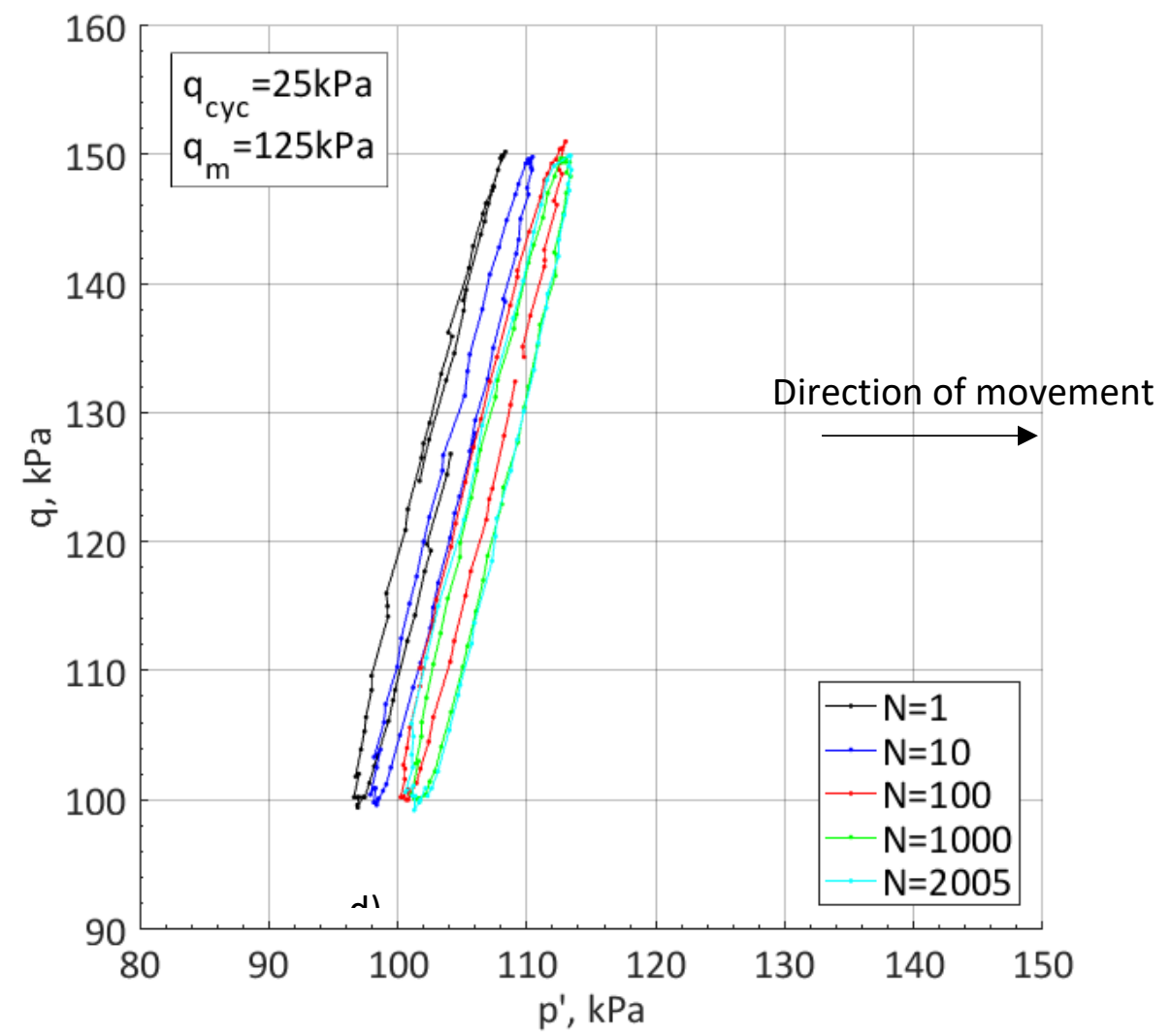

Figure 8 Effective stress paths during cycling with $q_{c y c}=25 \mathrm{kPa}$.Part c) from $q_{m}=50 \mathrm{kPa}$ and d) from $q_{m}=125 \mathrm{kPa}$

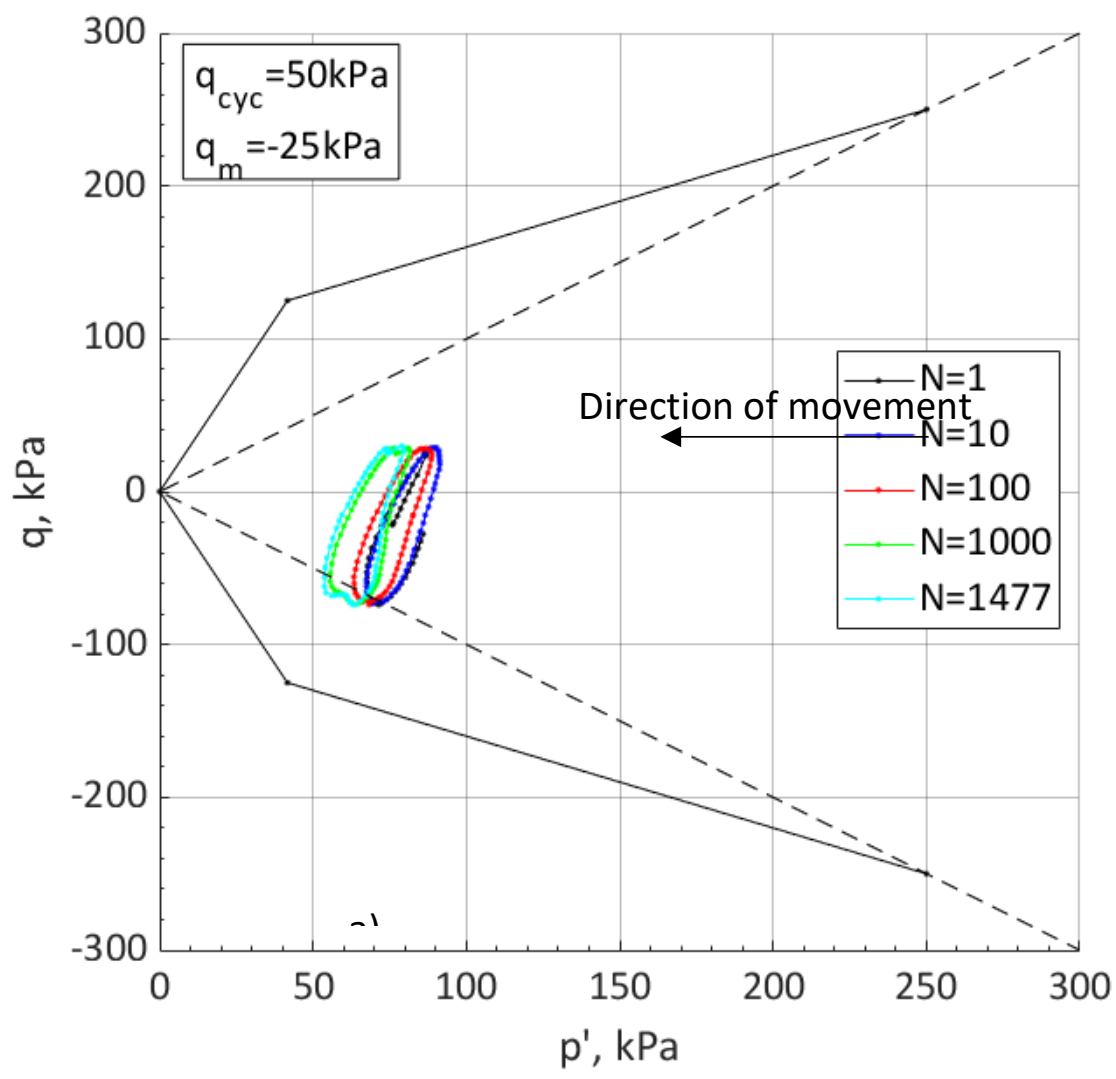




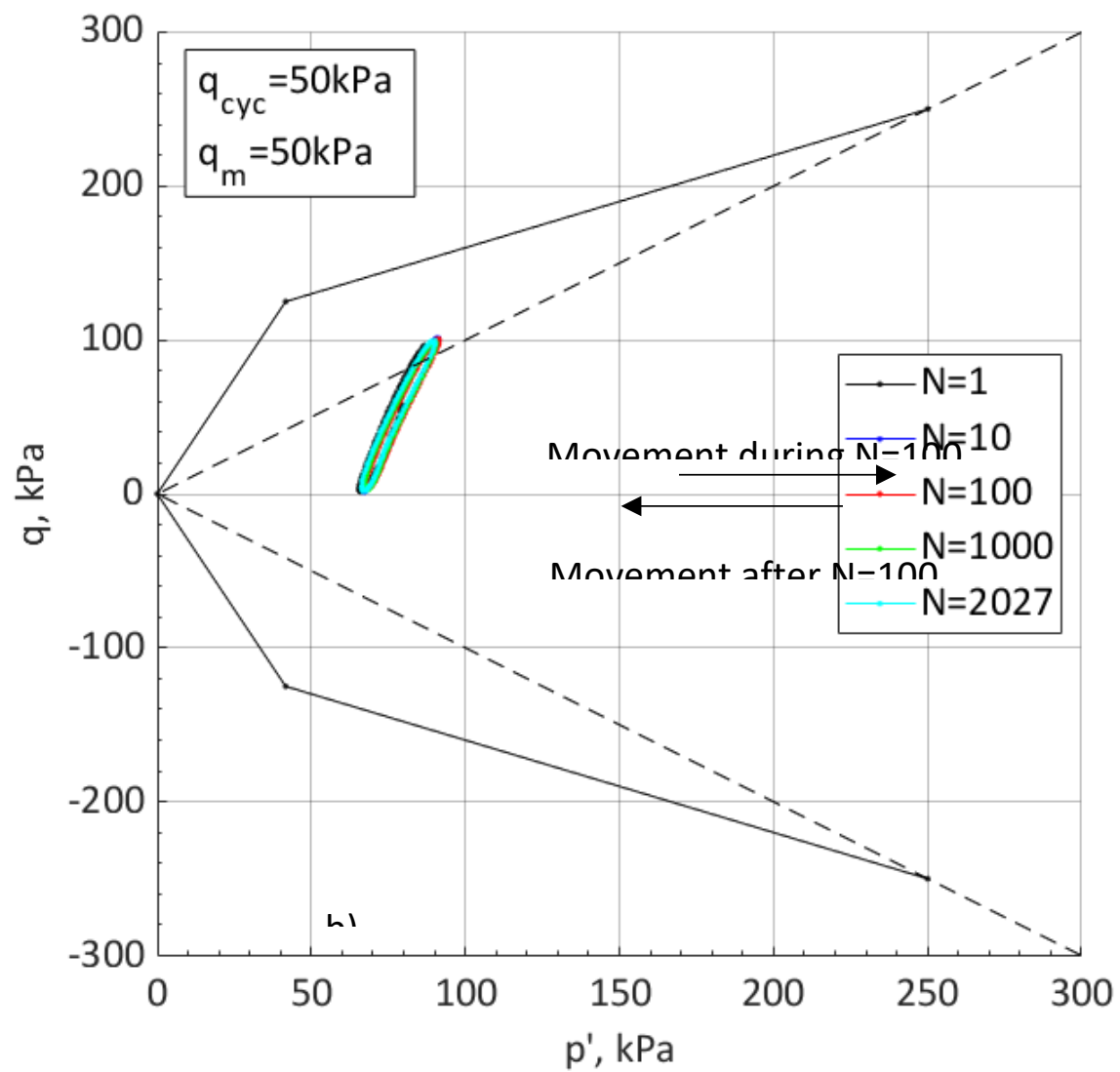

Figure 9 Effective stress paths during cycling with $q_{c y c}=50 \mathrm{kPa}$. Part a) $q_{m}=-25 \mathrm{kPa}$ and b) $q_{m}=$ $50 \mathrm{kPa}$

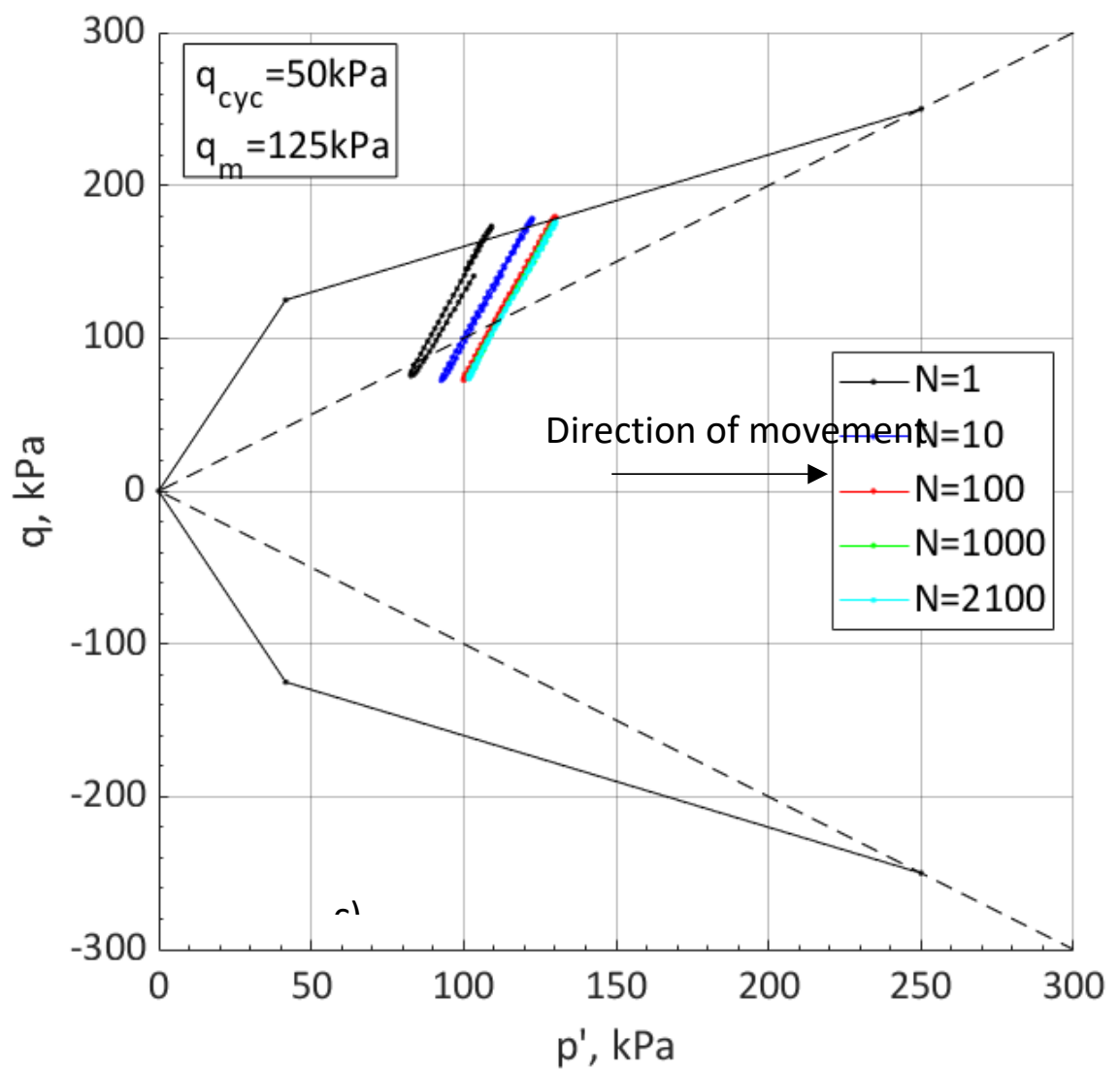

Figure 9 Effective stress paths during cycling with $q_{c y c}=50 \mathrm{kPa}$. Part c) $q_{m}=125 \mathrm{kPa}$ 

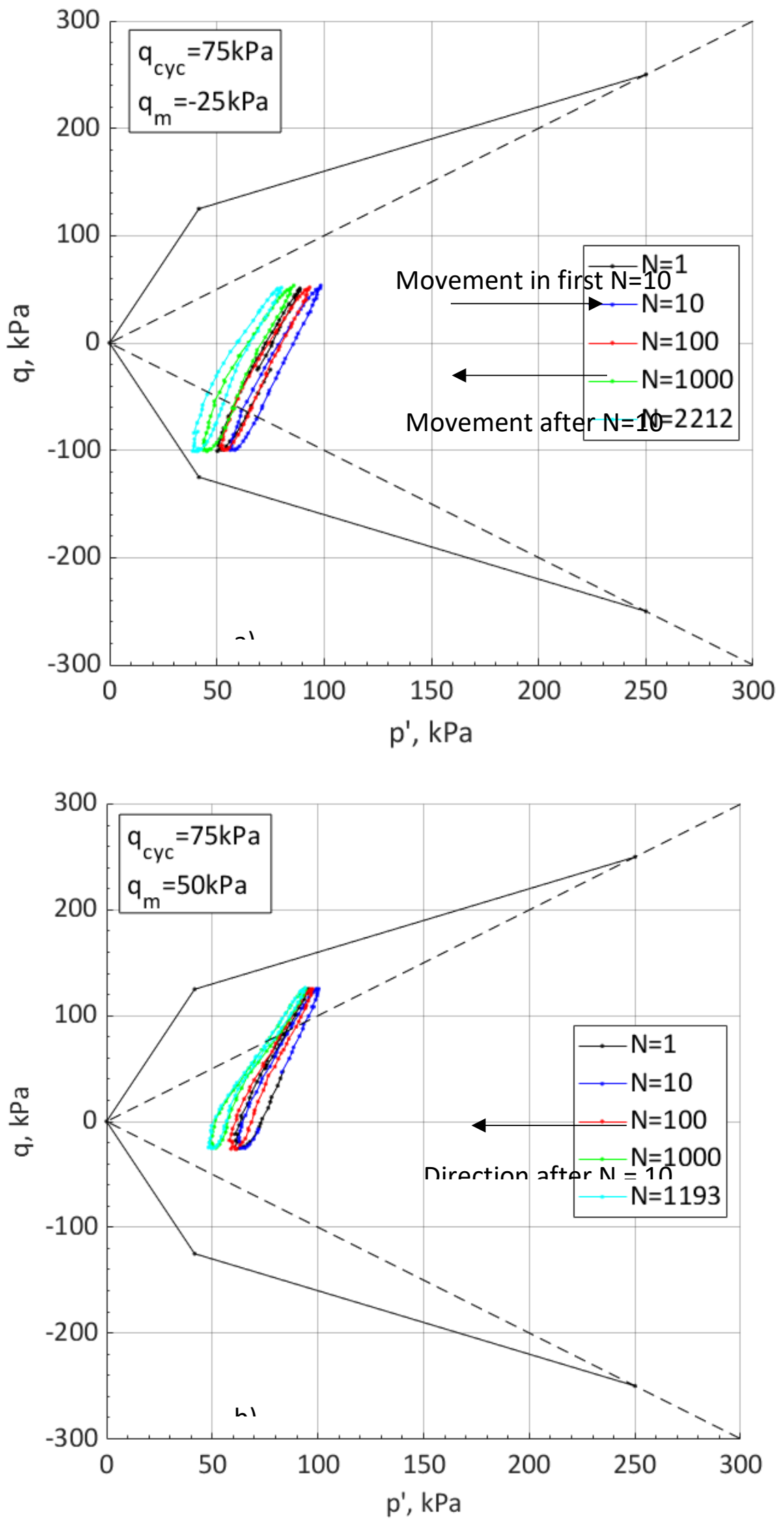

Figure 10 Effective stress paths during cycling with $q_{c y c}=75 \mathrm{kPa}$. Part a) $q_{m}=-25 \mathrm{kPa}$ and b) $q_{m}=$ $50 \mathrm{kPa}$ 


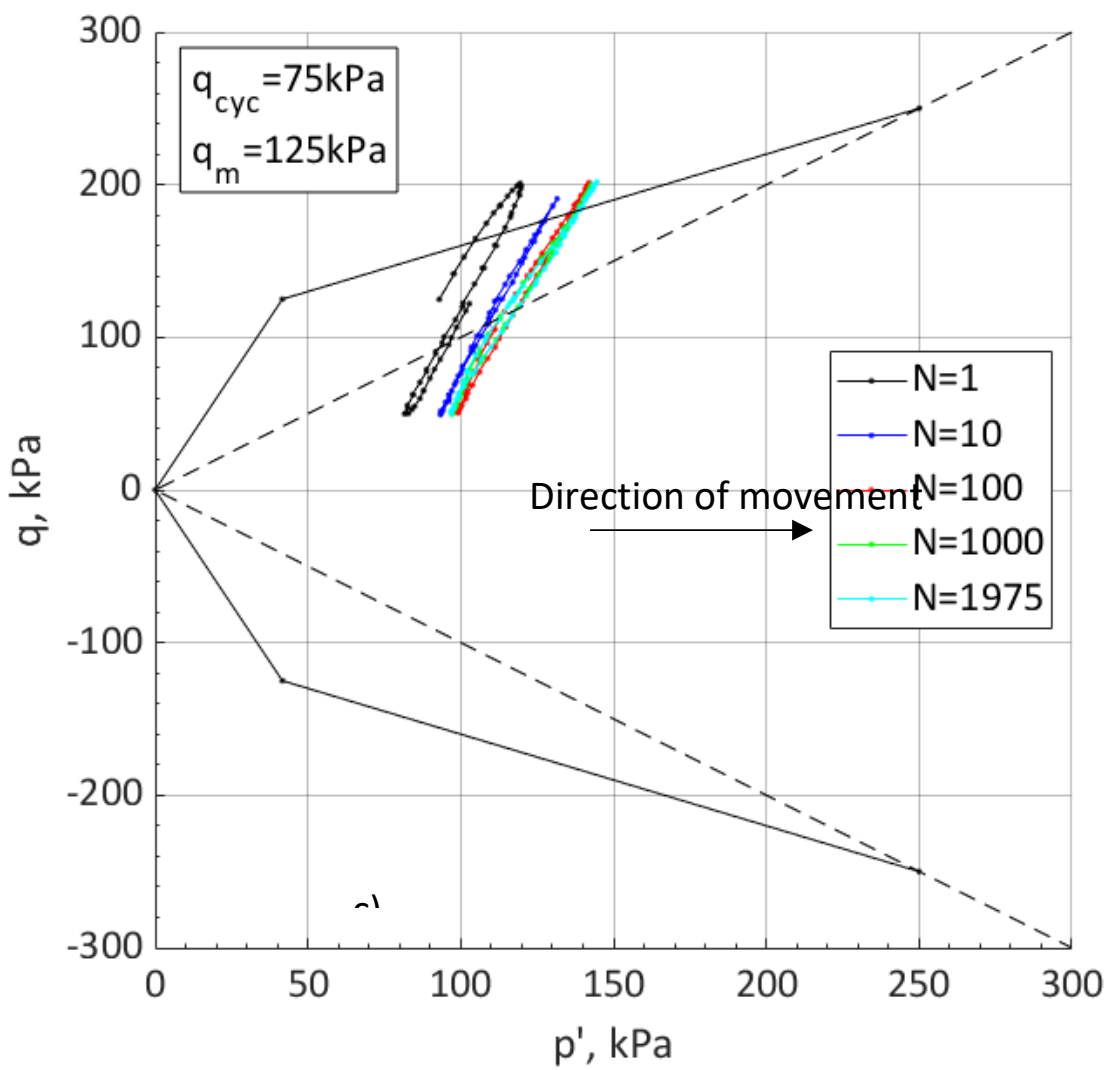

Figure 10 Effective stress paths during cycling with $q_{c y c}=75 \mathrm{kPa}$. Part c) $q_{m}=125 \mathrm{kPa}$

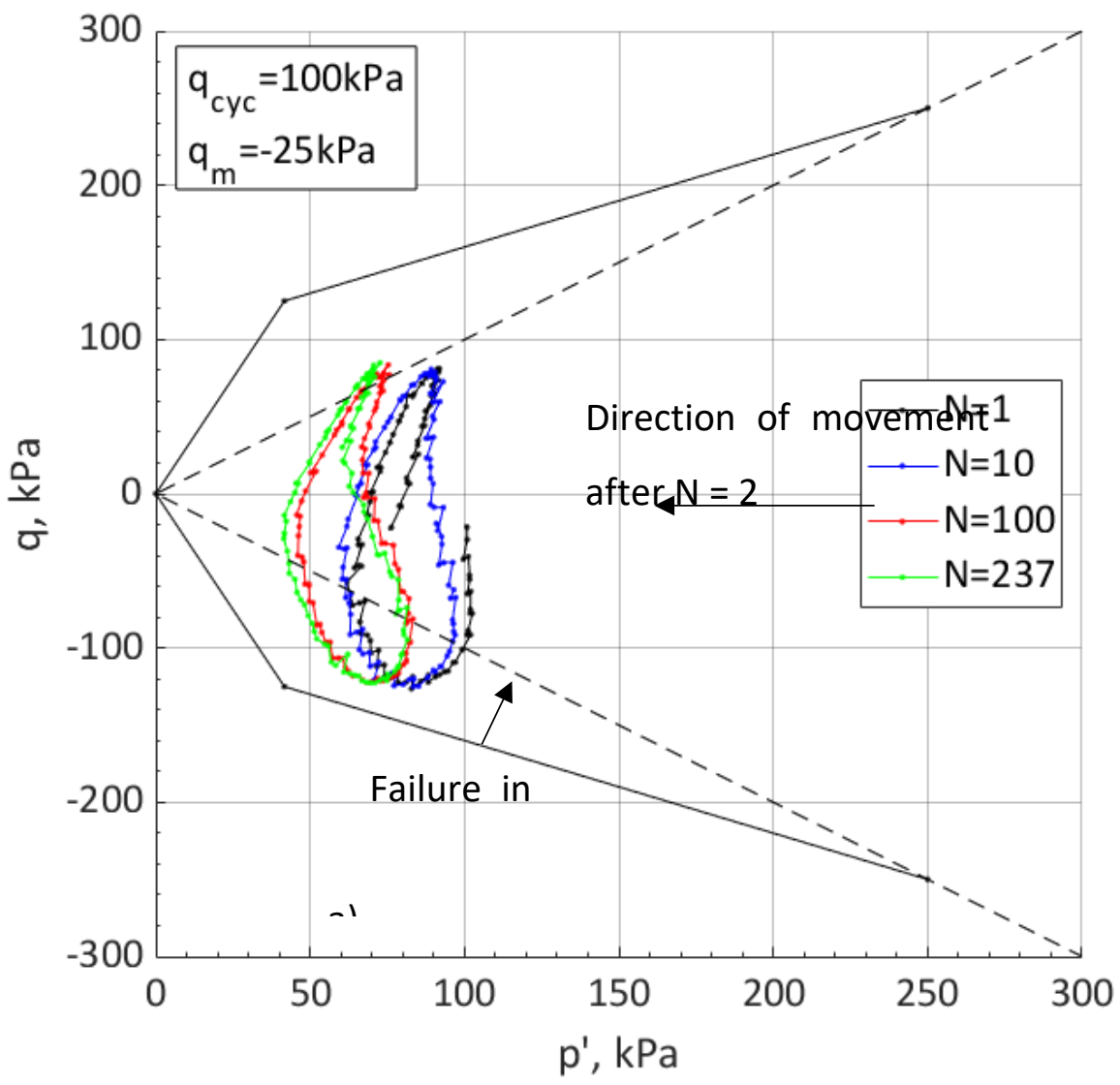




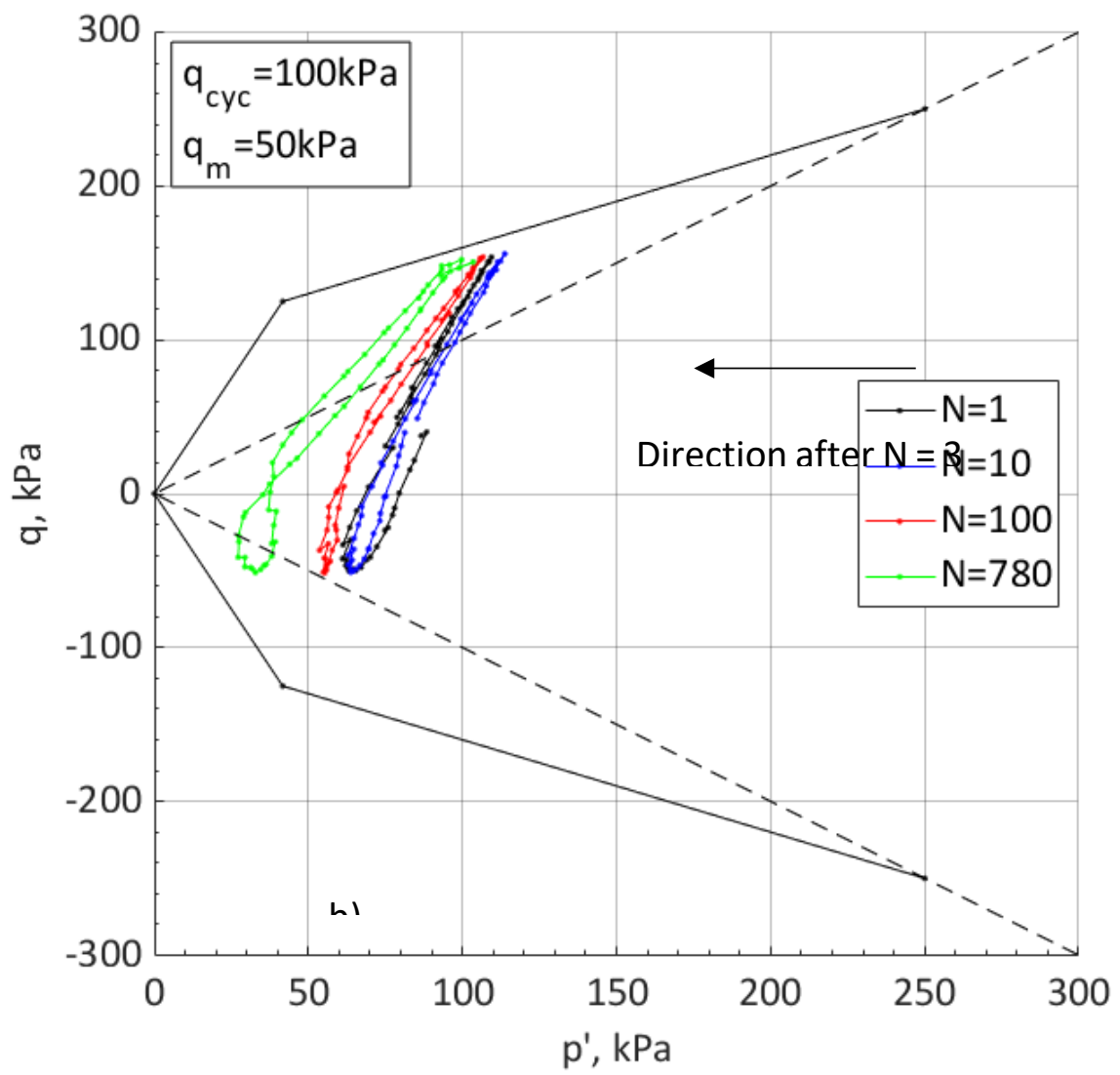

Figure 11 Effective stress paths during cycling with $q_{c y c}=100 \mathrm{kPa}$. Part a) $q_{m}=-25 \mathrm{kPa}$ and b) $q_{m}=$ $50 \mathrm{kPa}$

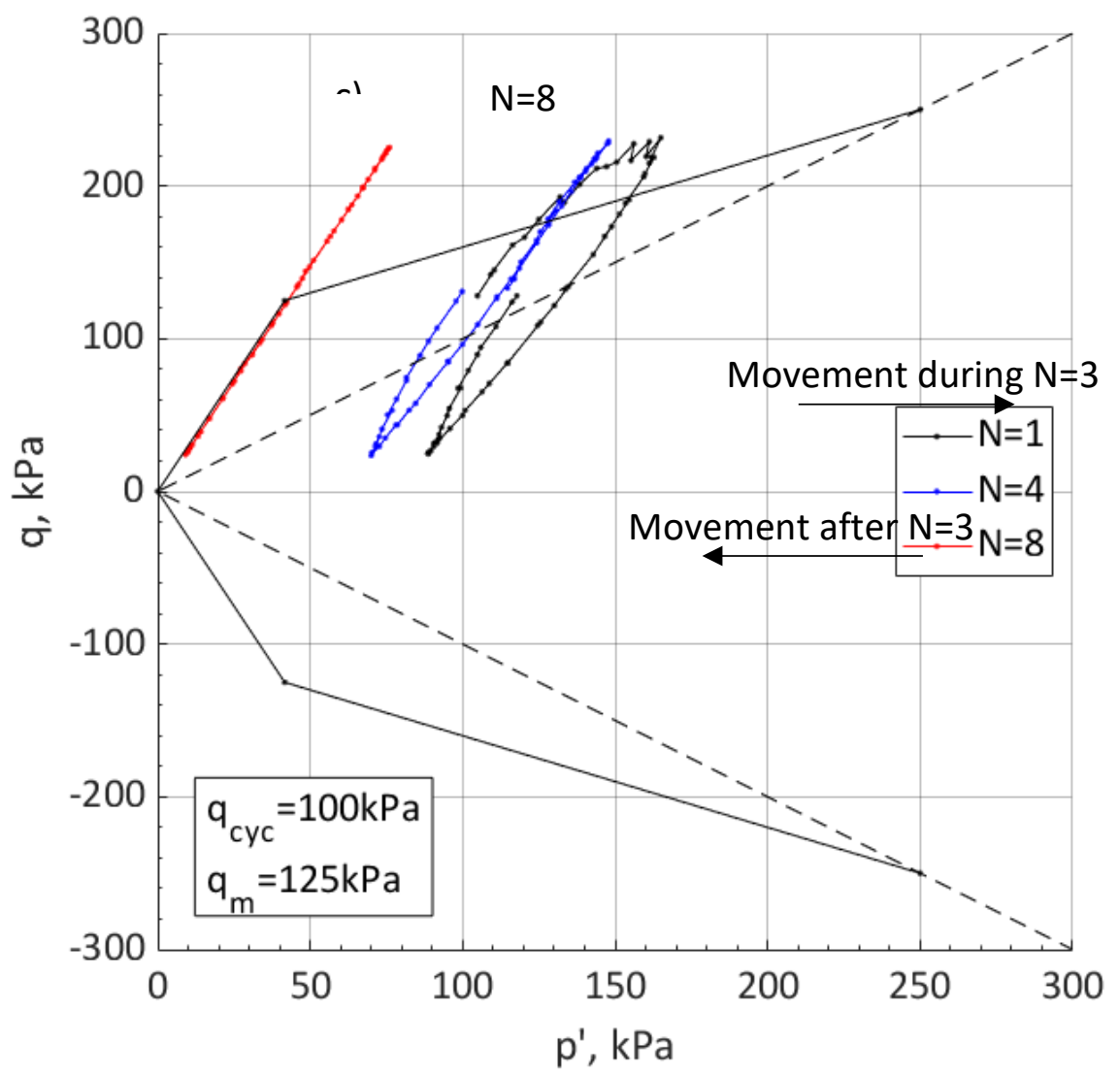

Figure 11 Effective stress paths during cycling with $q_{c y c}=100 \mathrm{kPa}$. Part c) $q_{m}=125 \mathrm{kPa}$ 

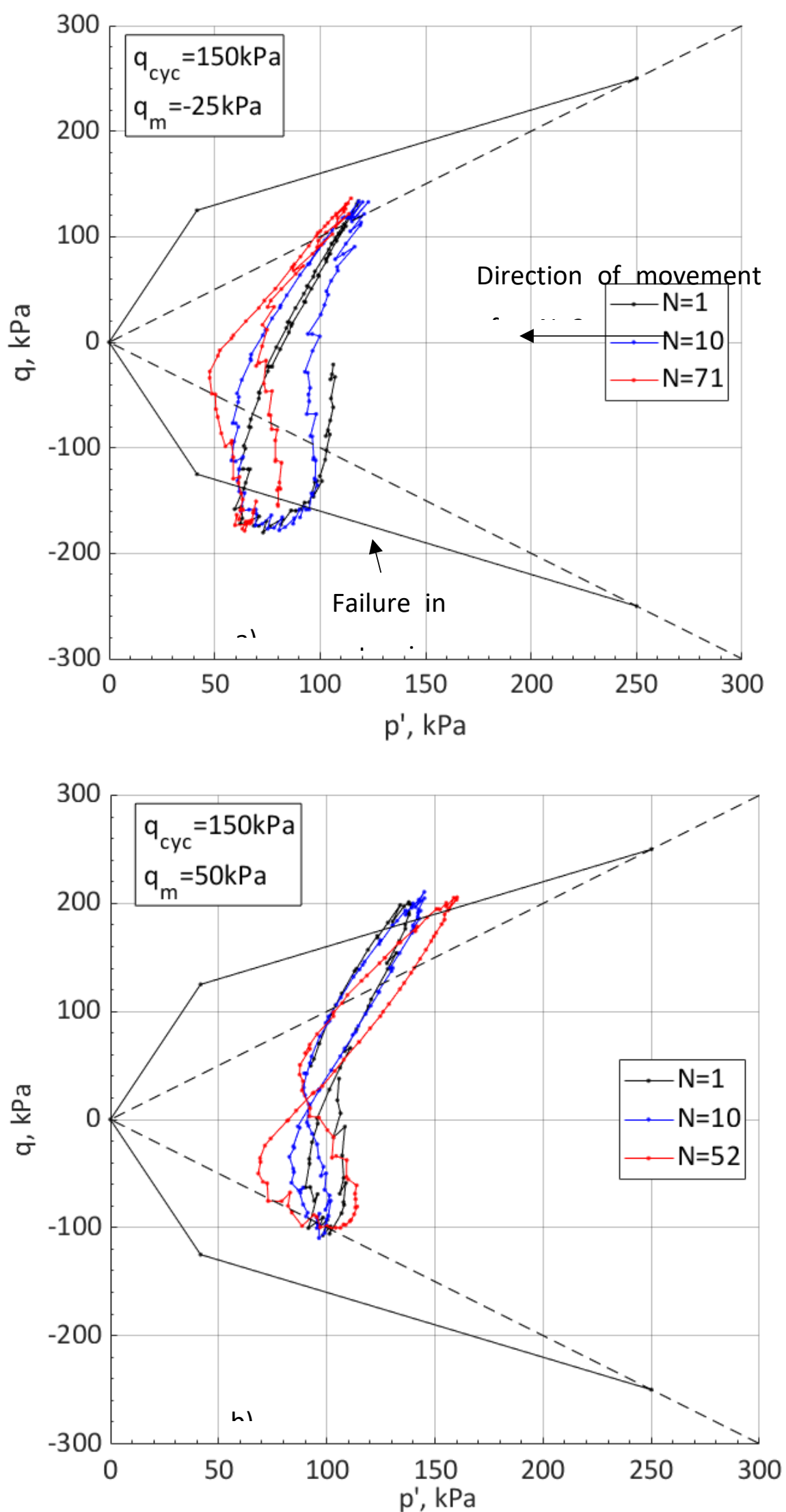

Figure 12 Effective stress paths during cycling with $q_{c y c}=150 \mathrm{kPa}$. Part a) $q_{m}=-25 \mathrm{kPa}$ and b) $q_{m}=$ $50 k P a$ 


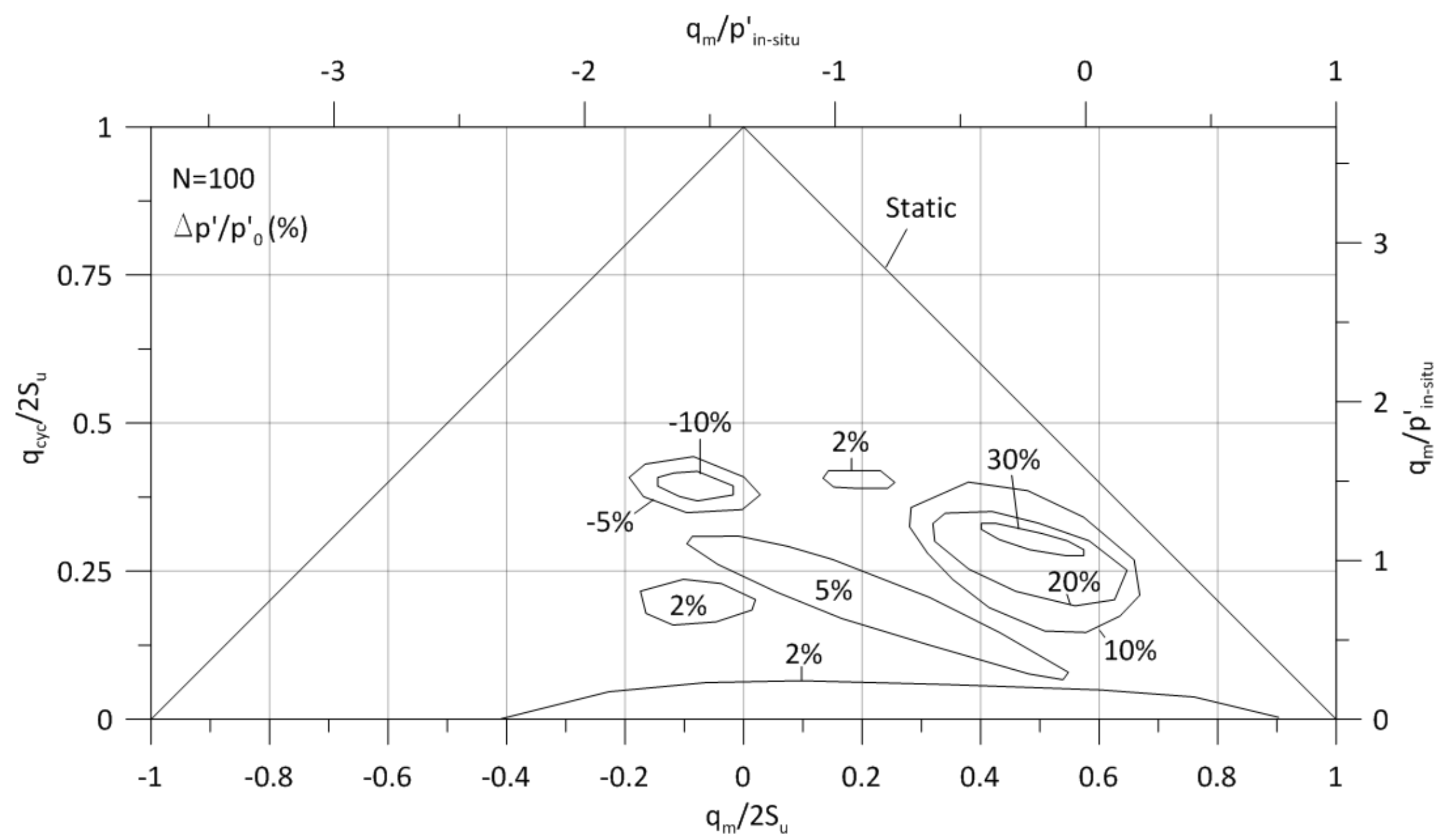

Figure 13 Contours of change in mean effective stress as a function of $q_{c y d} / 2 S_{u}$ and $q_{m} / 2 S_{u}$ as well as $q_{c y c} / p_{\text {in-situ }}^{\prime} v s q_{m} / p_{\text {in-situ; }}^{\prime}$ for $N=100$ 


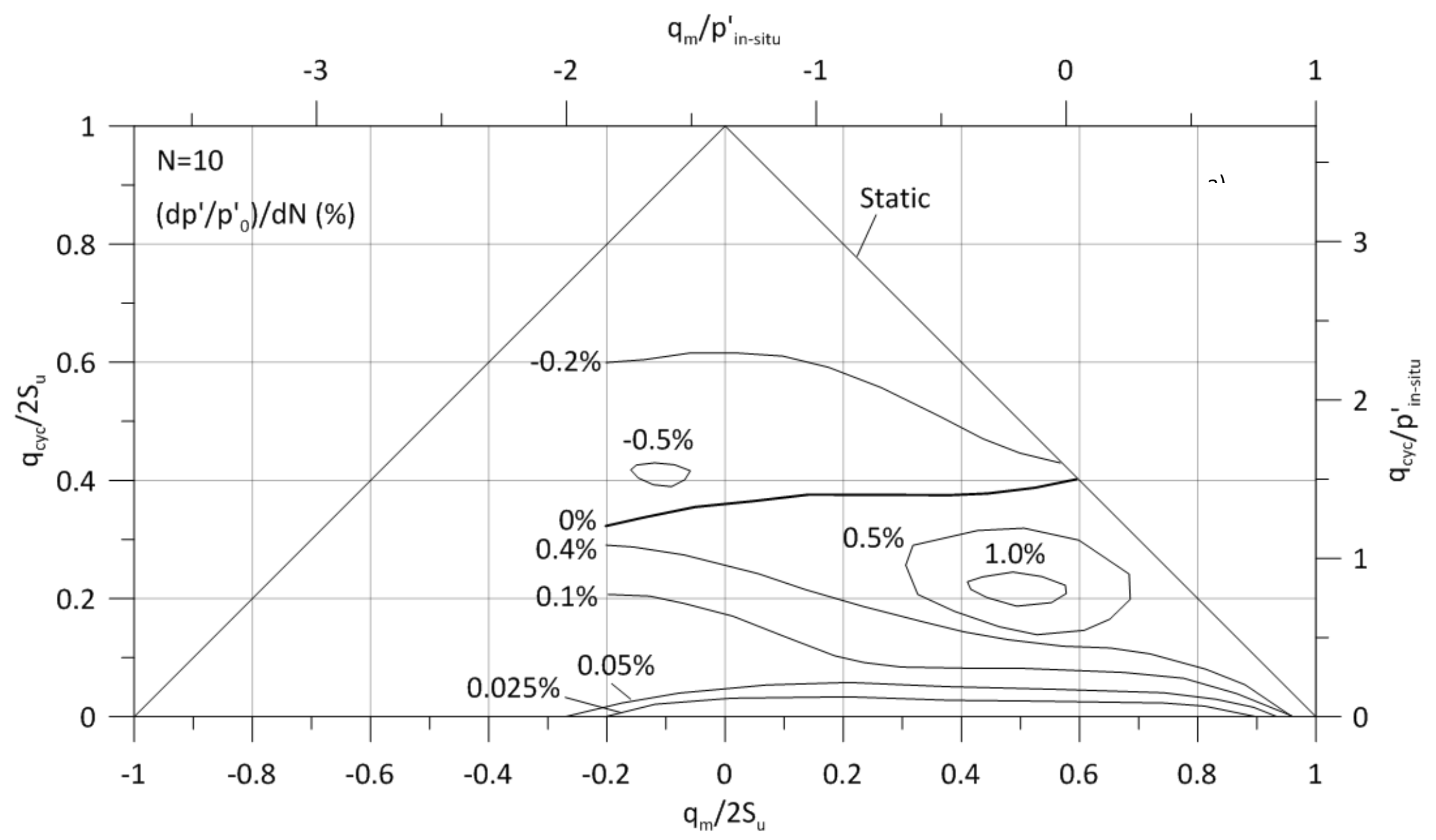

Figure 14 Contours of $\left[\left(d p^{\prime} / d p^{\prime}{ }_{0}\right) / d N\right]$ mean effective stress changes per cycle. Part a) at $N=10$ 


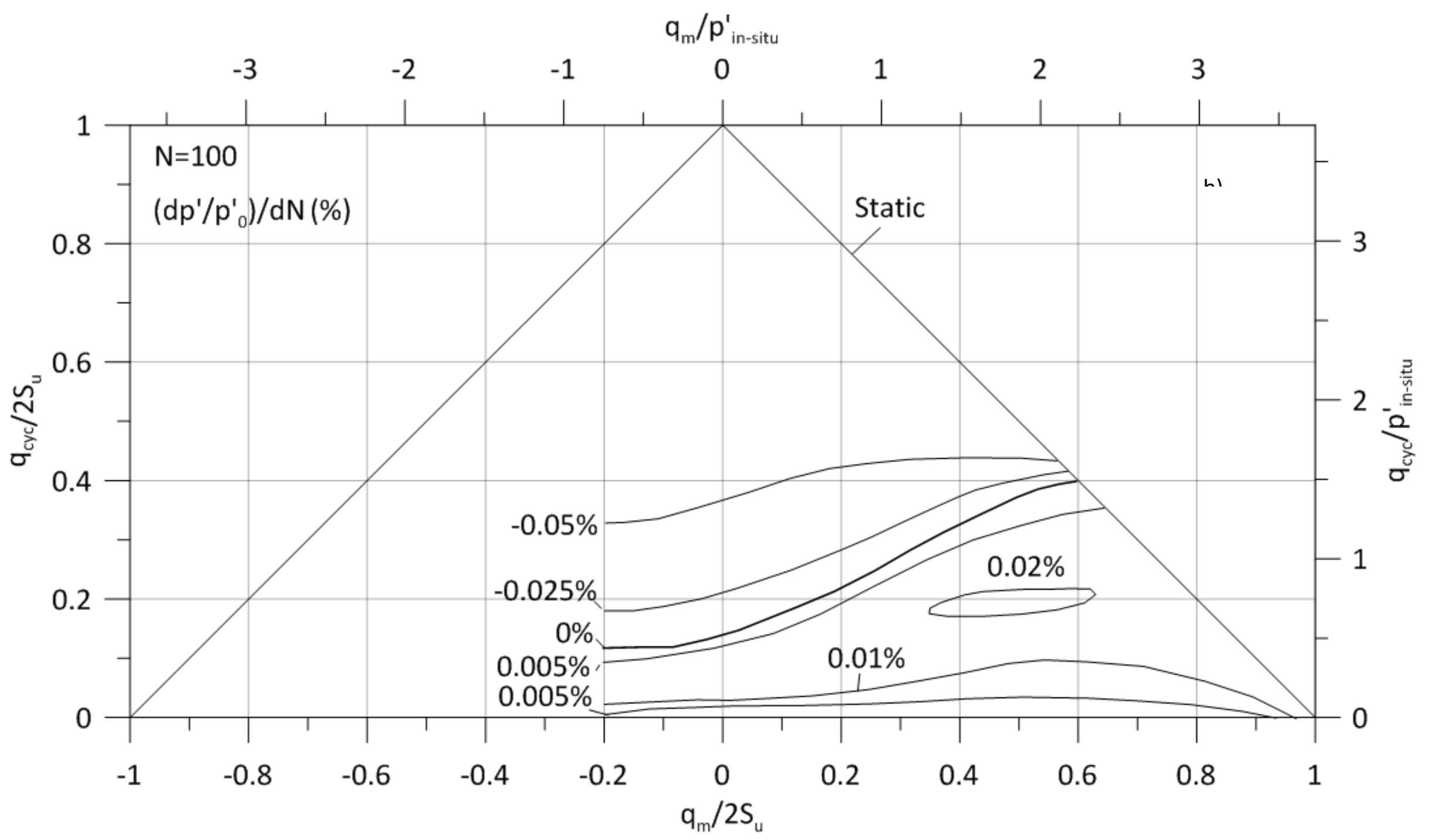

Figure 14 Contours of $\left[\left(d p^{\prime} / d p^{\prime} 0\right) / d N\right]$ mean effective stress changes per cycle. Part b) at $N=100$ 


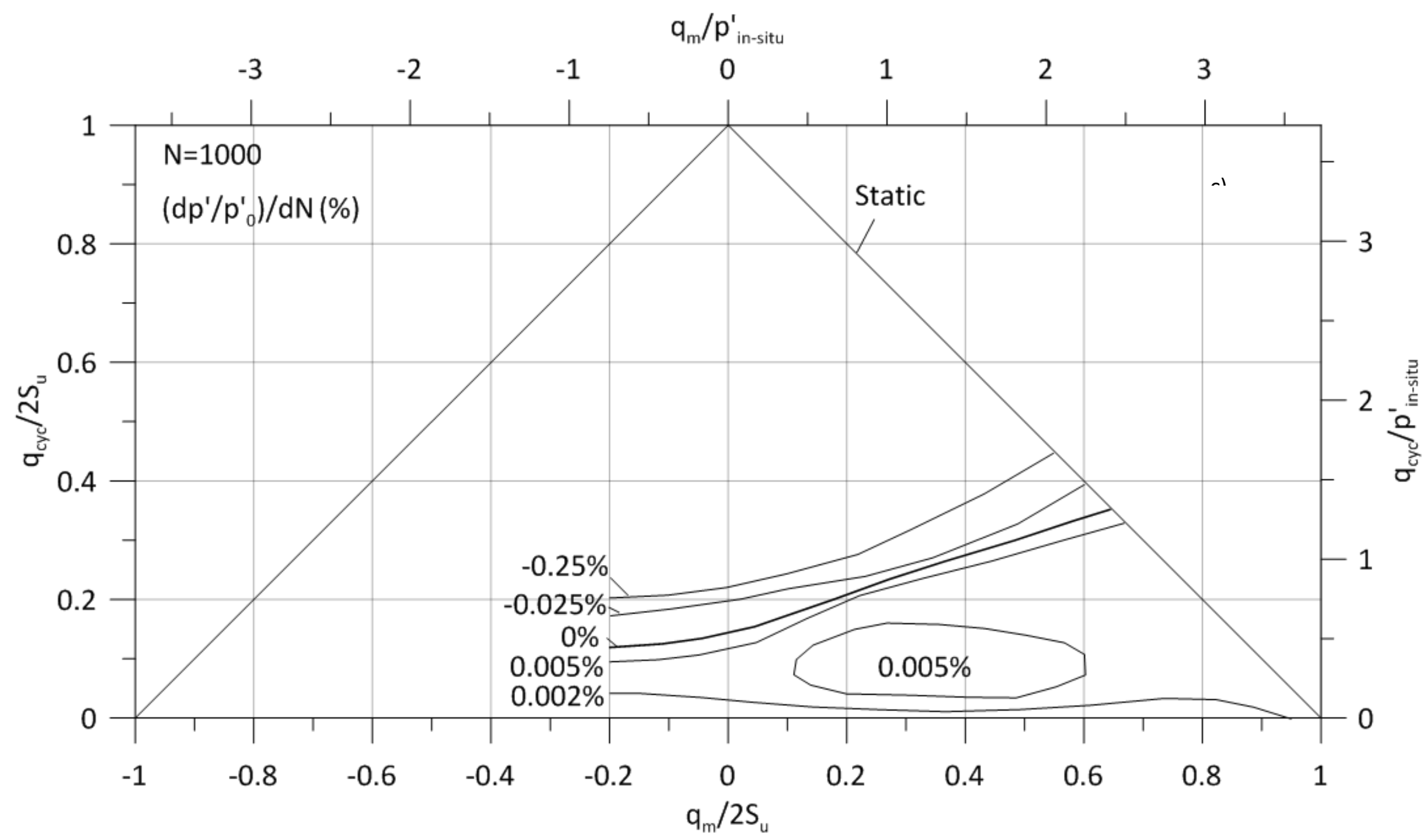

Figure 14 Contours of $\left[\left(d p^{\prime} / d p^{\prime}\right) / d N\right]$ mean effective stress changes per cycle. Part c) at $N=1000$ 


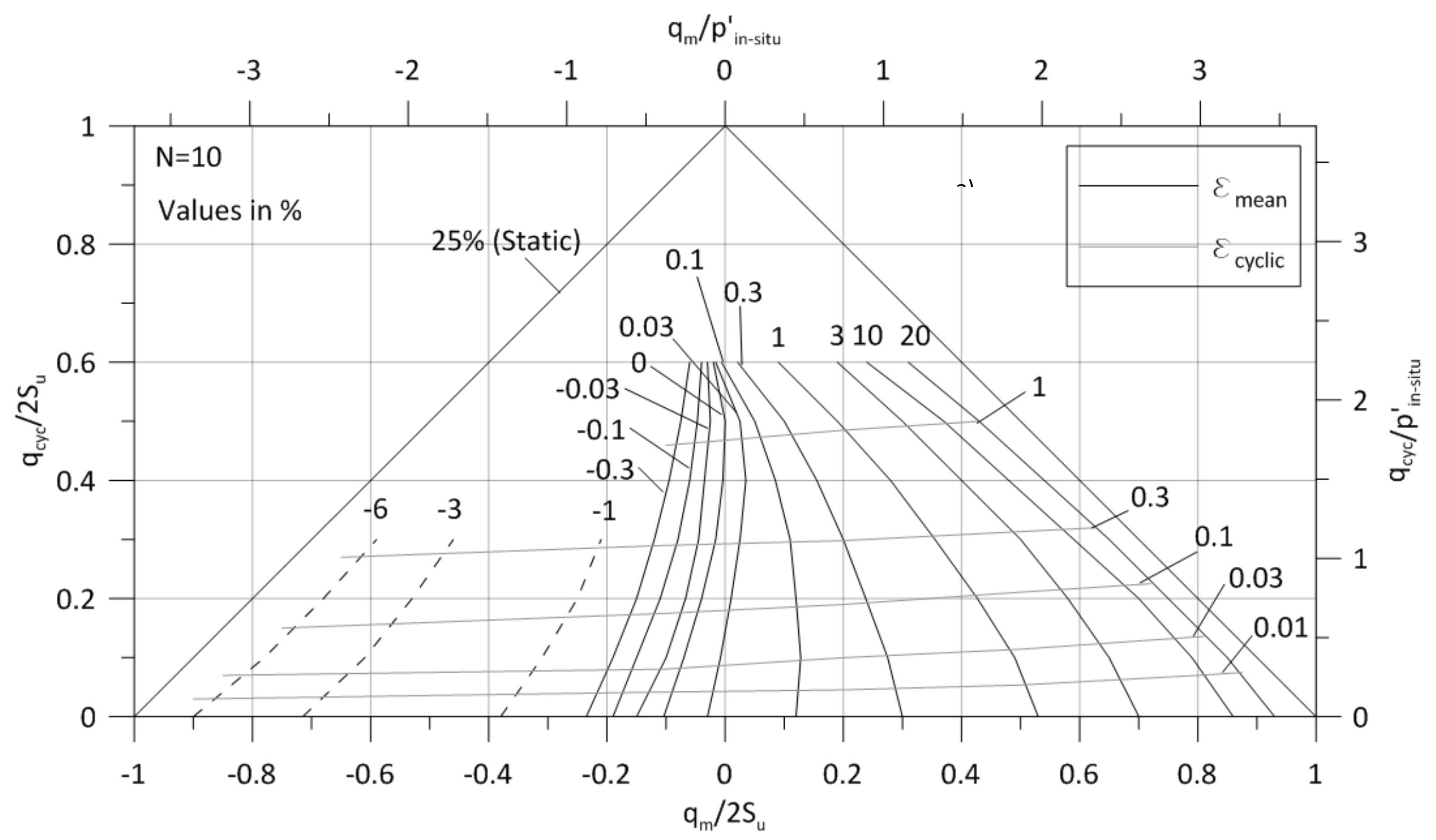

Figure 15 Contours of mean and cyclic strains. Part a) at N = 10 


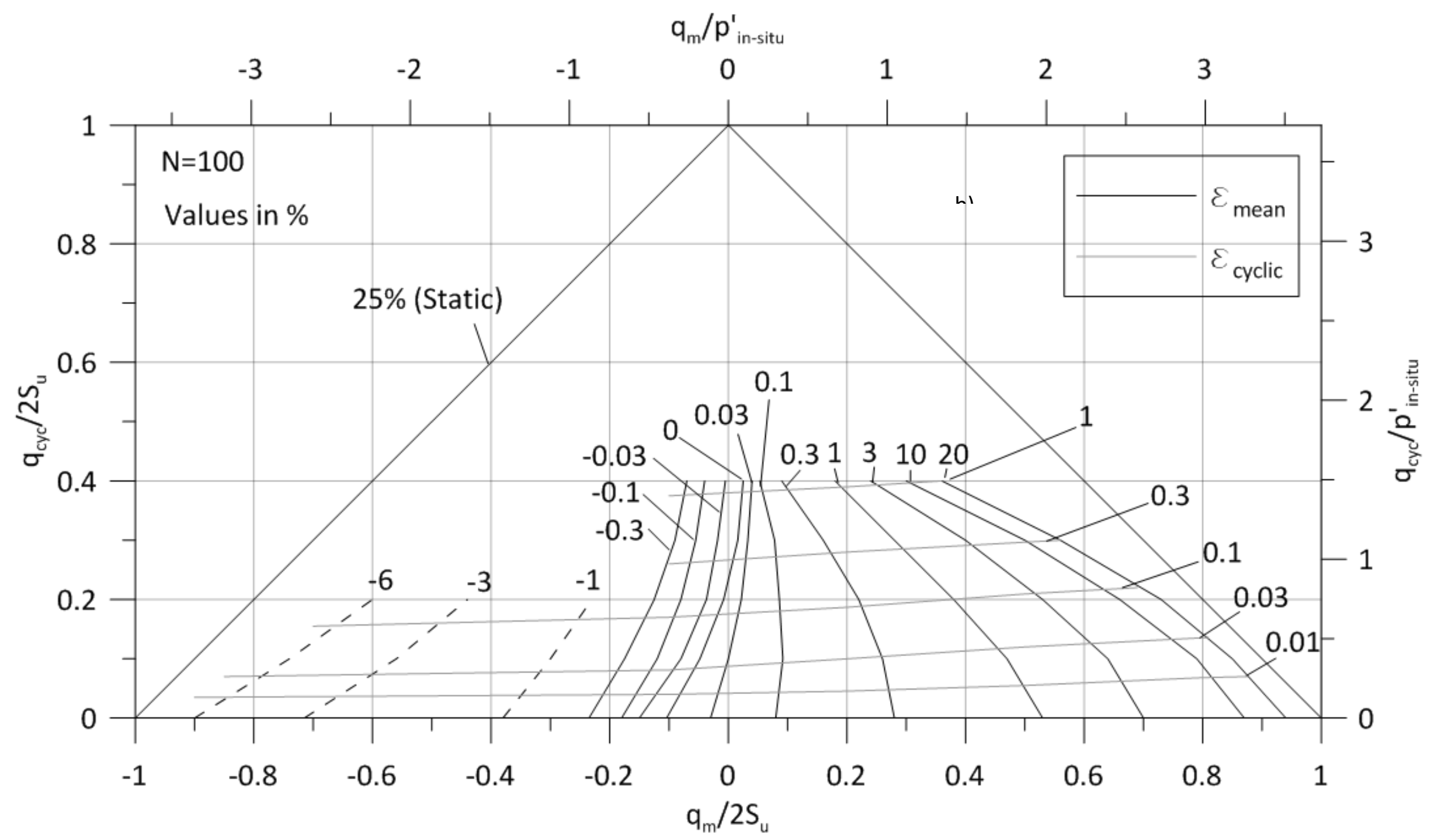

Figure 15 Contours of mean and cyclic strains. Part b) at $N=100$ 


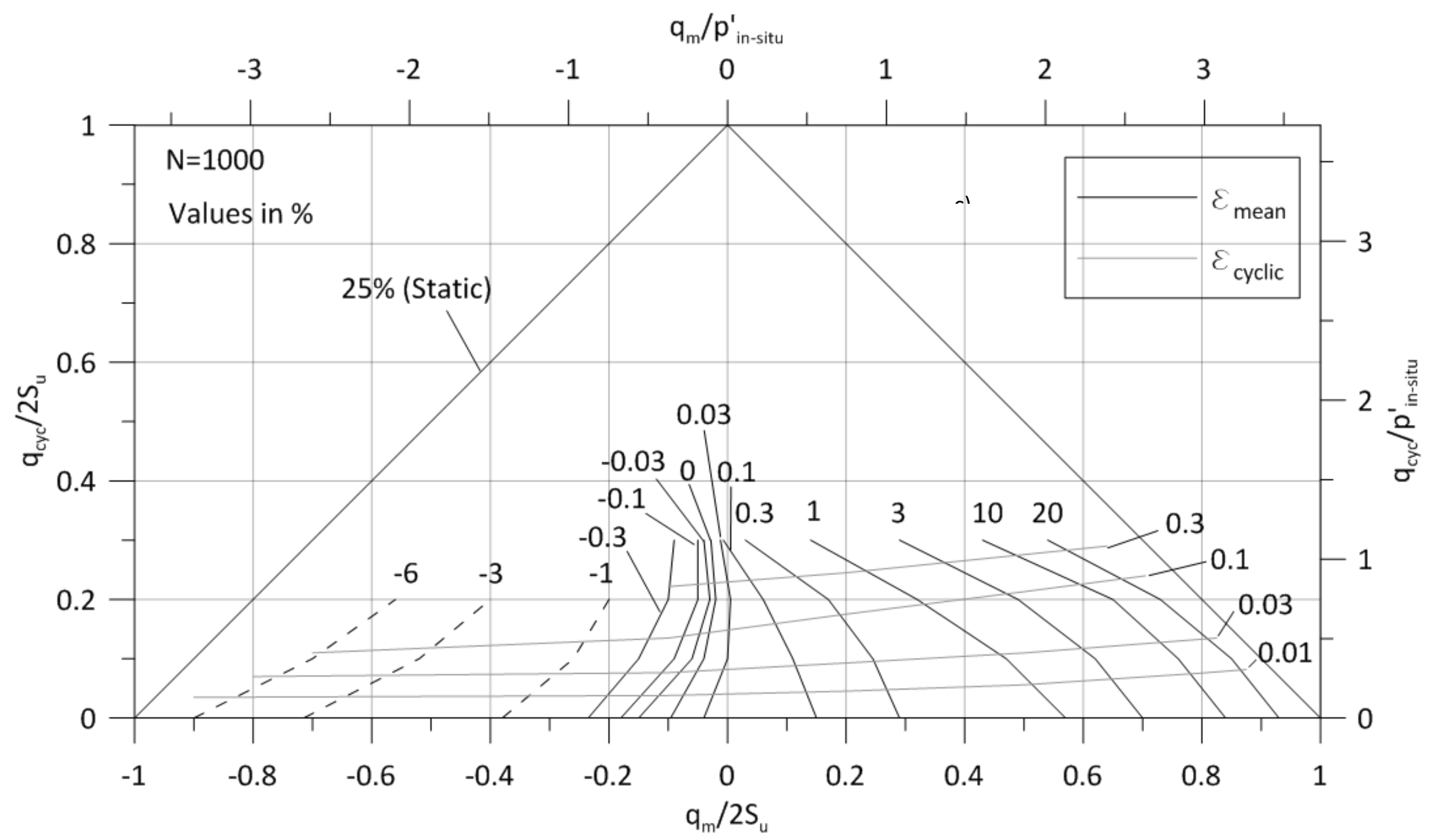

Figure 15 Contours of mean and cyclic strains. Part c) at $N=1000$ 


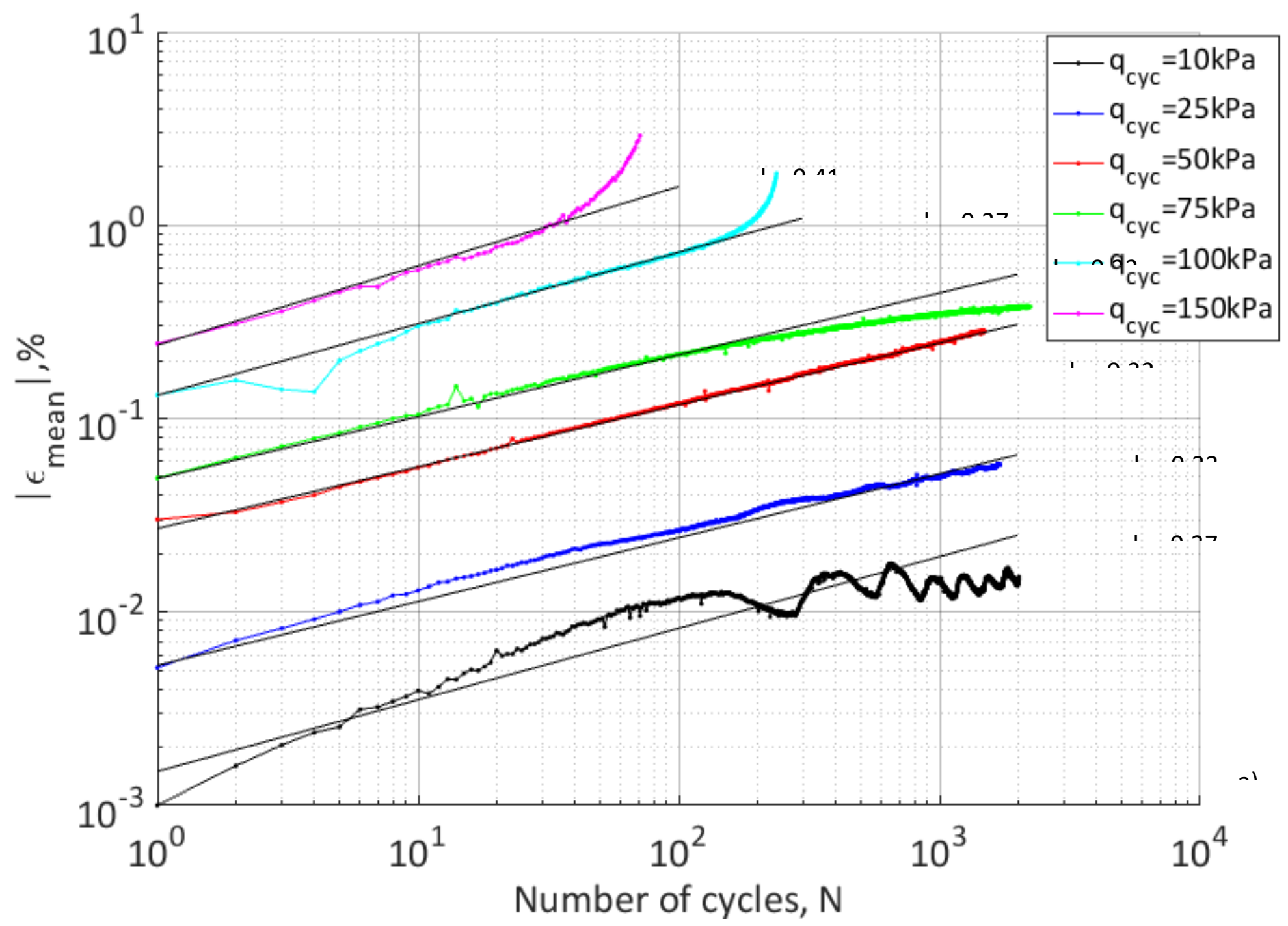

Figure 16 Variation of mean strain with number of cycles; a) $q_{m}=-25 \mathrm{kPa}$ in log-log scale 


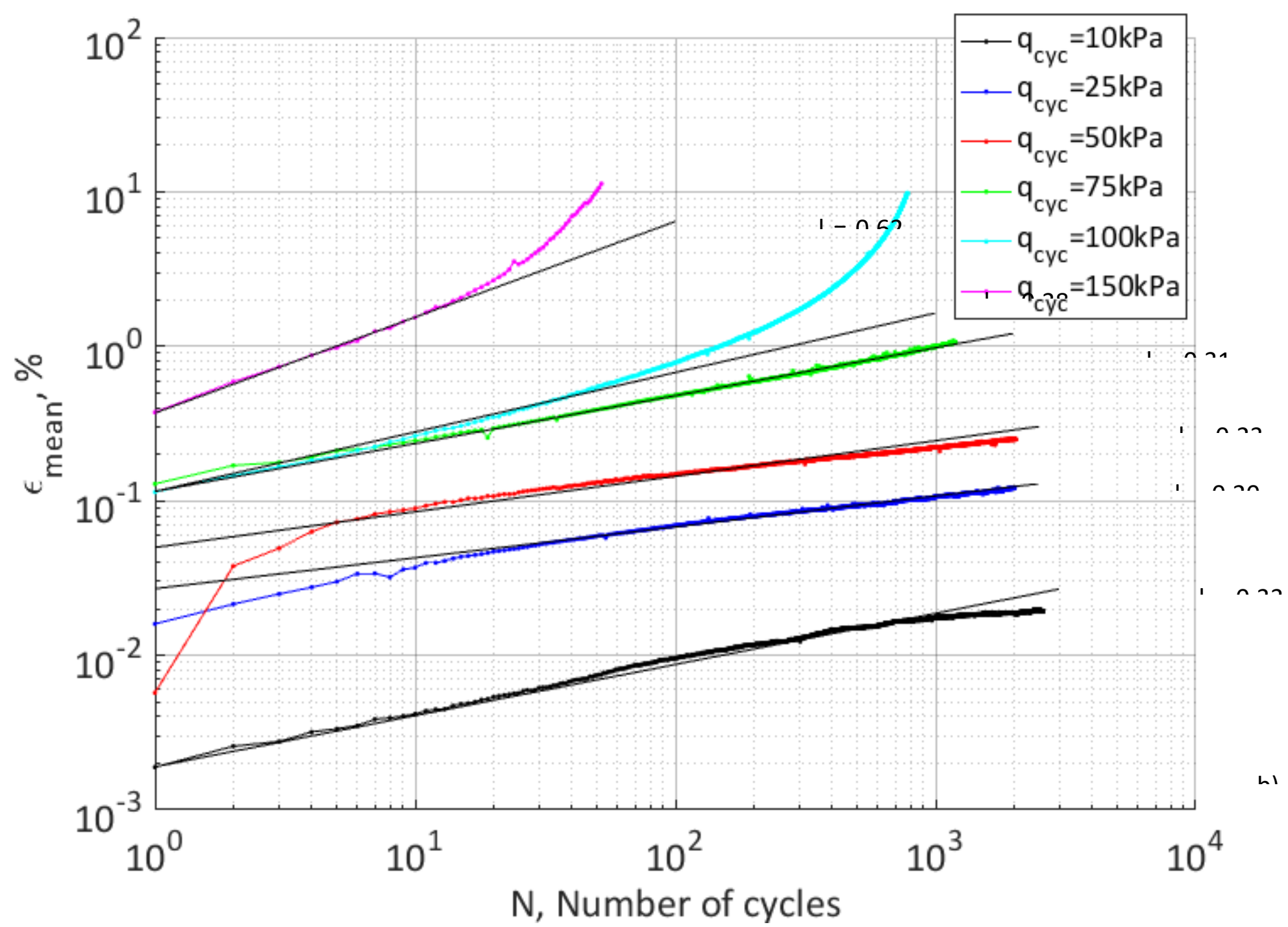

Figure 16 Variation of mean strain with number of cycles; $b) q_{m}=50 \mathrm{kPa}$ in log-log scale 


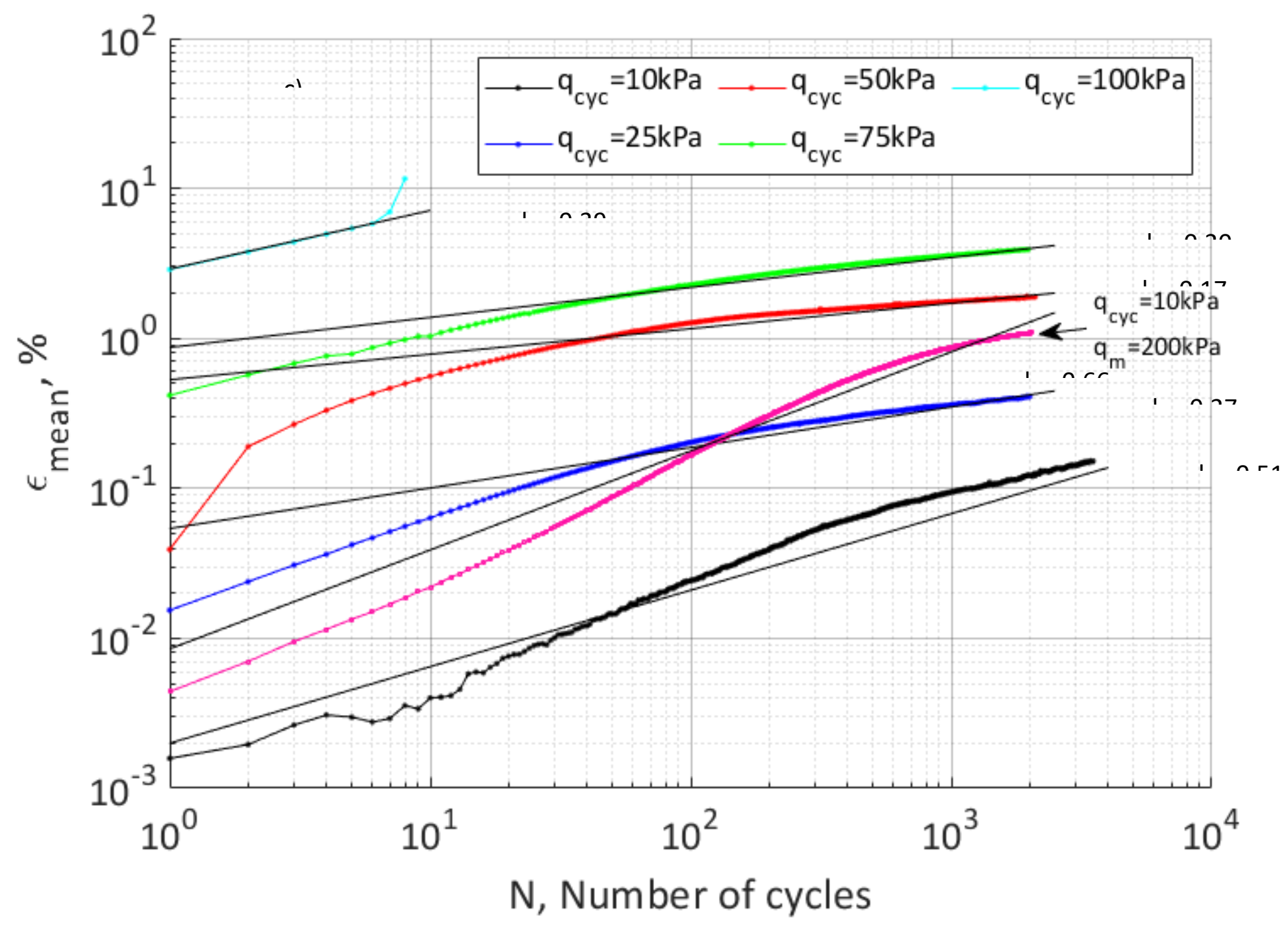


Figure 16 Variation of mean strain with number of cycles; c) $q_{m}=125 \mathrm{kPa}$ in log-log scale 


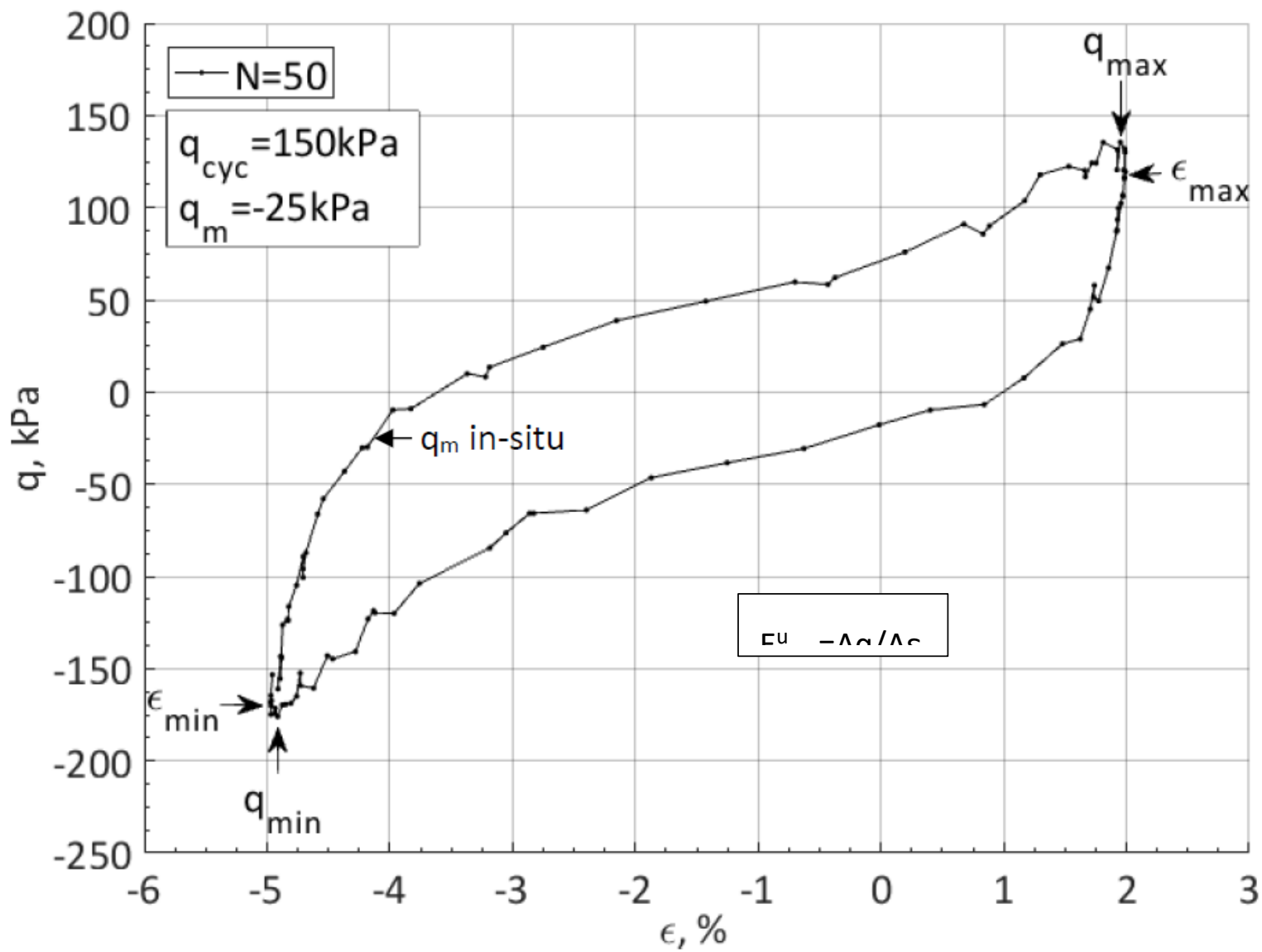

Figure 17 Stress-strain loop showing range of possible of maximum and minimum values of $q$ and $\varepsilon$ from which $E_{u}$ can be calculated for any given cyclic loop 

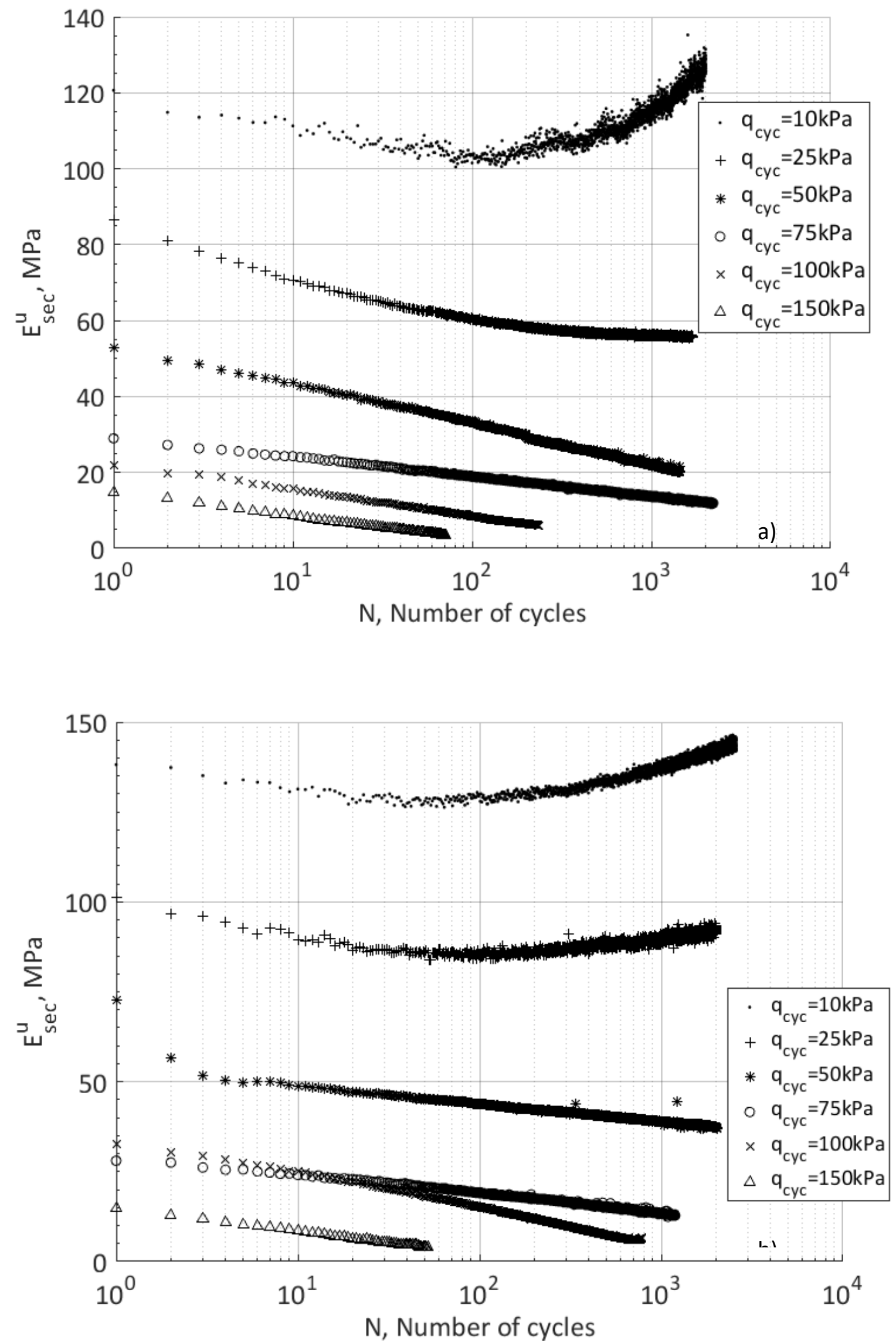

Figure 18 Cyclic secant stiffness against number of cycles at $\left.q_{m}=a\right)-25$ and b) $50 \mathrm{kPa}$ 


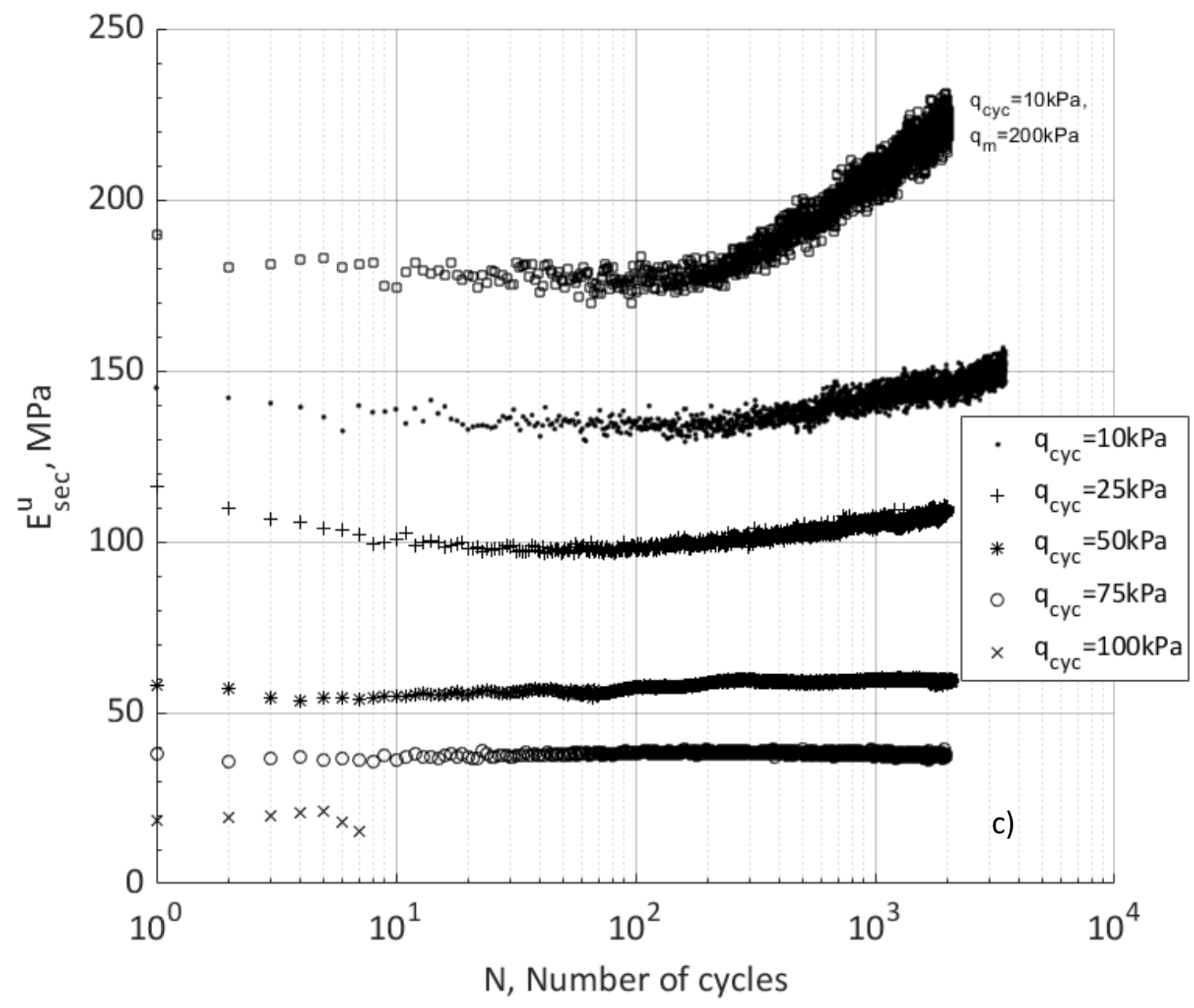

Figure 18 Cyclic secant stiffness against number of cycles at $\left.q_{m}=c\right) 125$ and $200 \mathrm{kPa}$ 

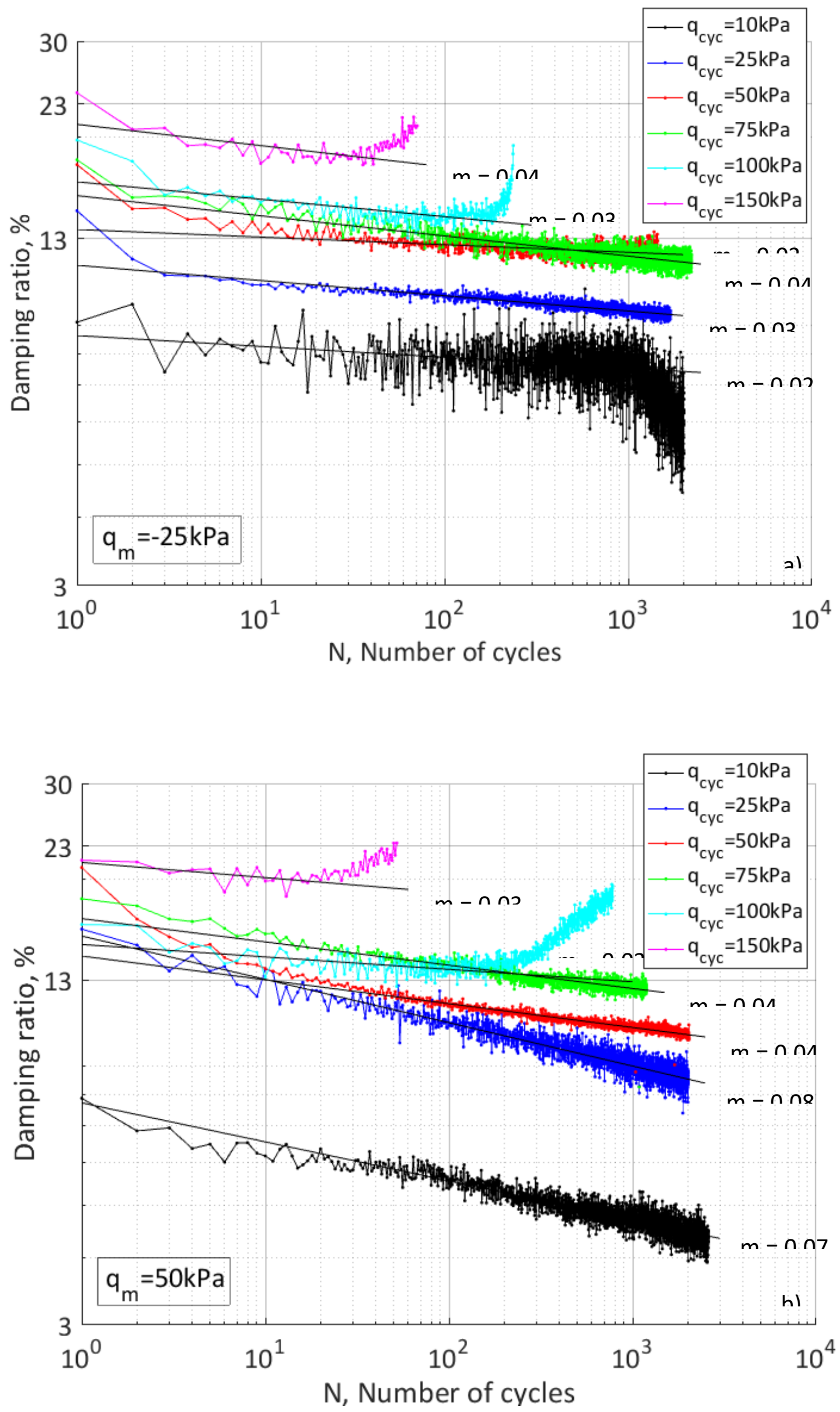
Figure 19 Damping ratios against number of cycles at $\left.q_{m}=a\right)-25$ and b) 50kPa

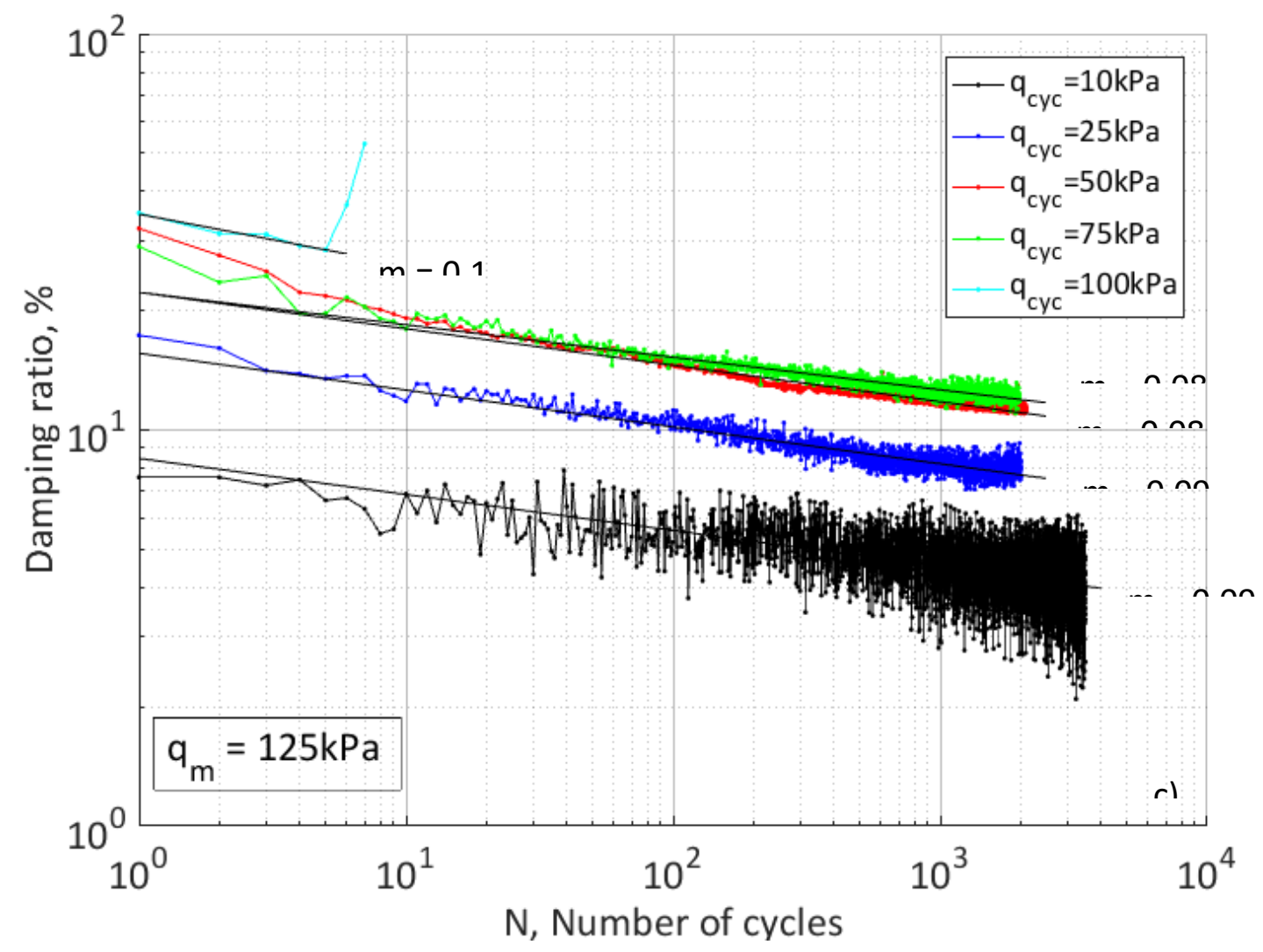

Figure 19 Damping ratios against number of cycles at $\left.q_{m}=c\right) 125$ 


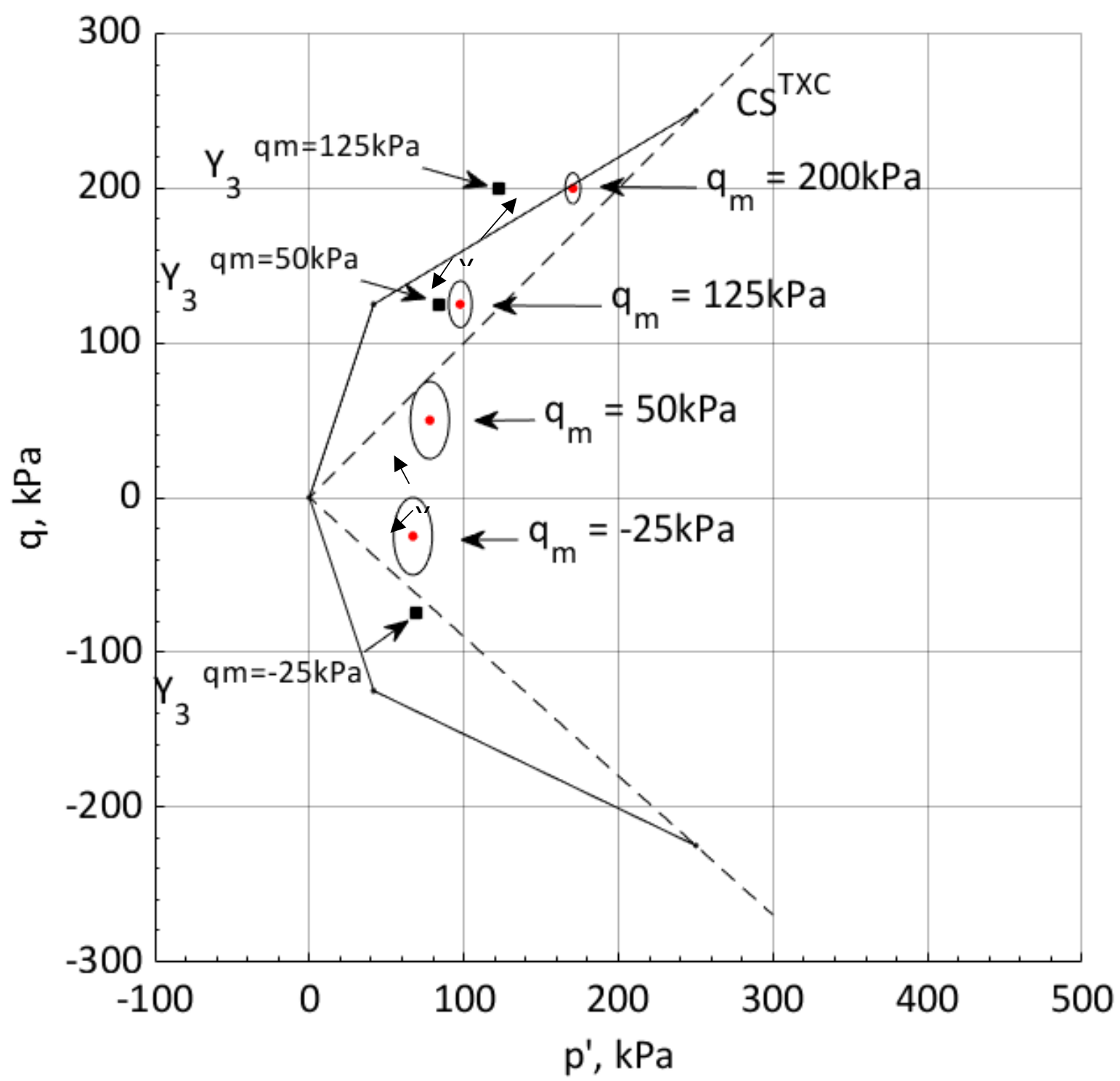

Figure $20 Y_{2}$ Kinematic Yield Surfaces and $Y_{3}$ cyclic yield points interpreted from cyclic undrained tests 